\title{
Incorporating rapid prototyping technology into the IE and MAE undergraduate curriculum at WVU
}

\author{
Abhishek Prasad \\ West Virginia University
}

Follow this and additional works at: https://researchrepository.wvu.edu/etd

\section{Recommended Citation}

Prasad, Abhishek, "Incorporating rapid prototyping technology into the IE and MAE undergraduate curriculum at WVU" (2009). Graduate Theses, Dissertations, and Problem Reports. 4515.

https://researchrepository.wvu.edu/etd/4515

This Thesis is protected by copyright and/or related rights. It has been brought to you by the The Research Repository @ WVU with permission from the rights-holder(s). You are free to use this Thesis in any way that is permitted by the copyright and related rights legislation that applies to your use. For other uses you must obtain permission from the rights-holder(s) directly, unless additional rights are indicated by a Creative Commons license in the record and/ or on the work itself. This Thesis has been accepted for inclusion in WVU Graduate Theses, Dissertations, and Problem Reports collection by an authorized administrator of The Research Repository @ WVU. For more information, please contact researchrepository@mail.wvu.edu. 


\title{
Incorporating rapid prototyping technology into the IE and MAE undergraduate curriculum at WVU.
}

\author{
Abhishek Prasad \\ Thesis submitted to the \\ College of Engineering and Mineral Resources \\ at \\ West Virginia University \\ in partial fulfillment of the requirements \\ for the degree of \\ Master of Science
in
Industrial Engineering
}

Rashpal S. Ahluwalia, Ph.D., Chair

Robert C. Creese, Ph.D.

Ali A. Afshari, Ph.D.

Department of Industrial and Management Systems Engineering

\author{
Morgantown, West Virginia \\ 2009
}

Keywords: Rapid Prototyping; RX-1 Machine; Manufacturing Processes Lab. 


\section{ABSTRACT}

Incorporating rapid prototyping technology into the IE and MAE undergraduate curriculum at WVU.

by

Abhishek Prasad.

It is mandatory for every Industrial Engineering (IE) / Mechanical and Aerospace Engineering (MAE) undergraduate student at WVU to complete the IENG 303 course, introduction to manufacturing processes. At present this course covers Welding, Machining, Casting, AutoCAD (2D), and CNC (Computer Numerical Controlled) programming.

The focus of this thesis was to develop laboratory material so as to introduce solid modeling and rapid prototyping. A “T” shaped bracket was designed in AutoCAD 2008 and manufactured on the RX-1 rapid prototyping machine. The effect of change in saturation level from $46.24 \%$ to $45.00 \%$, change in curing temperature from $350^{\circ} \mathrm{F}$ to $400^{\circ} \mathrm{F}$ and change in curing time from 2 hrs to 2.5 hrs on the dimensions of the manufactured part was examined.

It was found that a higher saturation level of $46.24 \%$ and lower curing time of $2 \mathrm{hrs}$ resulted in lower expansion of the part in $\mathrm{X}$ and $\mathrm{Z}$ direction, however the expansion in $\mathrm{Y}$ direction was higher under the same conditions. At $46.24 \%$ saturation level and higher curing time of 2.5 hrs expansion in the $\mathrm{Z}$ direction was found to be higher compared to that of $\mathrm{X}$ and $\mathrm{Y}$ direction. Experiments run at lower saturation level of $45.00 \%$ at higher temperature of $400^{\circ} \mathrm{F}$ resulted in higher shrinkage in the part. The layering error of 0.002” layer thickness was also considered and the layering error was subtracted from the resultant dimensions to determine the percentage change in dimensions. 


\section{ACKNOWLEDGEMENT}

I would like to thank my committee chair Dr. Rashpal S. Ahluwalia for the constant support and encouragement all through my research. I am thankful to Dr. Ali A. Afshari for agreeing to be on my advisory committee and for his constant advice all through my work. I am grateful to Dr. Robert C. Creese for giving me this topic and for all the help he has extended to me by being my academic advisor through my entire master’s program.

. I am thankful to Mr. James E. Dalton who was a wonderful supervisor and for never ending help he provided me all through my master's program and with all the help with the machines in the lab.

I always believe that it is good to have an end to a journey but it is the journey that matters in the end. I would like to thank my mom, my uncle and my brother for their never ending love and support all throughout my life which has been a blessing with all of them around. I know that my dad has always been around as a guiding star in our lives and he always will. Thanks Dad!!! I would like to dedicate this thesis to my mom, to her hard work, perseverance, sacrifices and for being a pillar of strength in our family.

A journey is well travelled if you have a companion to share it with. Without Reema this journey would have been incomplete. She has brought love, joy and happiness in my life. Having seen me through all the ups and downs in my life for the past 5 years she has been a constant source of encouragement and support. I would like to thank her for being by my side whenever I needed her the most.

Finally, my friends who have always been around with a helping hand whenever I needed them. Thank you to all my Oakland, Gilmore and Inglewood buddies. 


\section{TABLE OF CONTENTS}

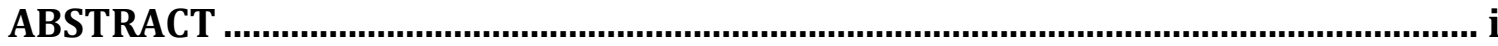

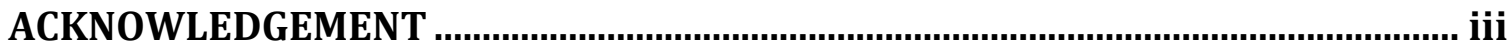

TABLE OF CONTENTS ..................................................................................... iv

LIST OF FIGURES .............................................................................................. vi

LIST OF TABLES

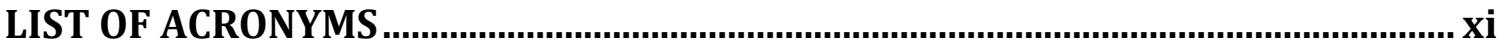

CHAPTER 1: INTRODUCTION .............................................................................. 1

1.1. Brief History of Rapid Prototyping:...........................................................................

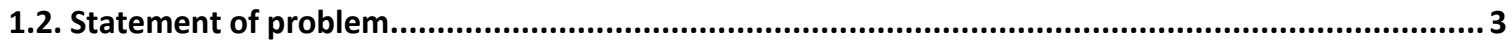

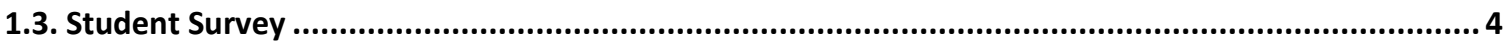

CHAPTER 2: HARDWARE/SOFTWARE DESCRIPTION ........................................... 8

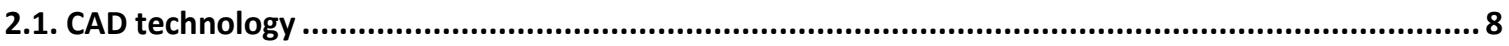

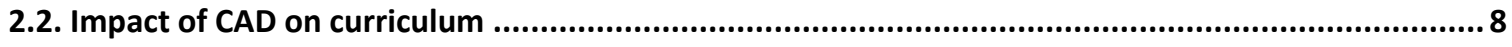

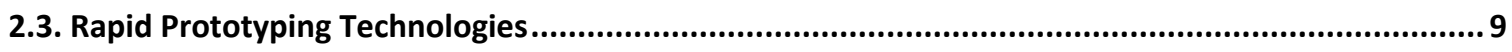

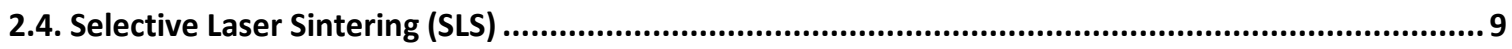

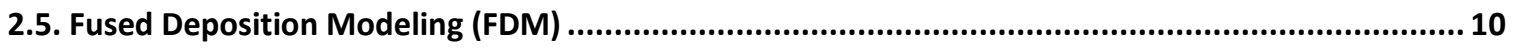

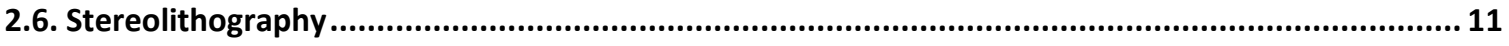

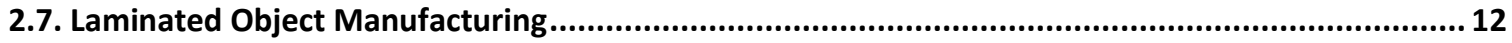

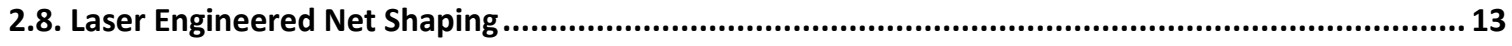

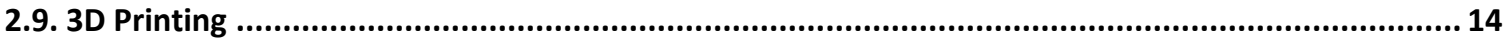

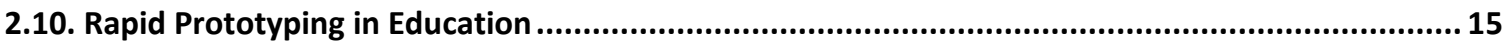


3.1. Hardware and Software Specifications: .......................................................................................17

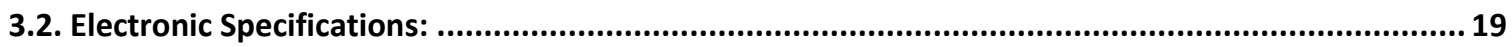

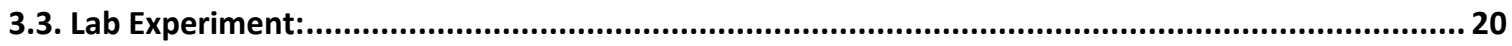

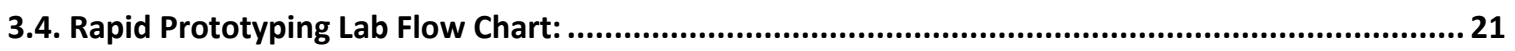

3.5. Lab Procedure:

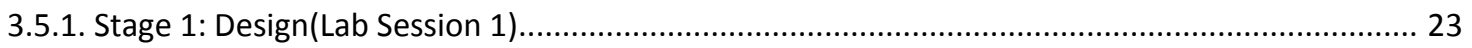

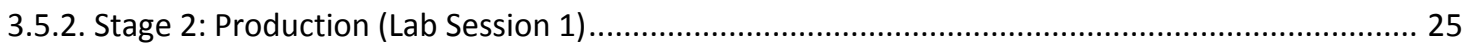

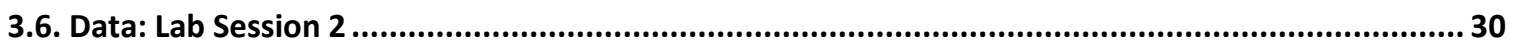

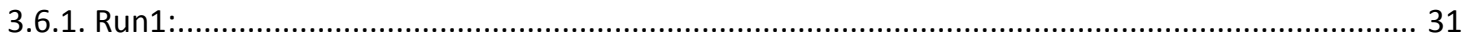

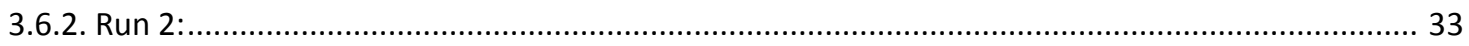

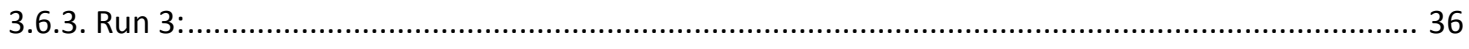

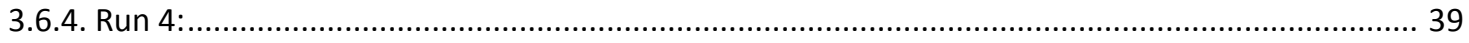

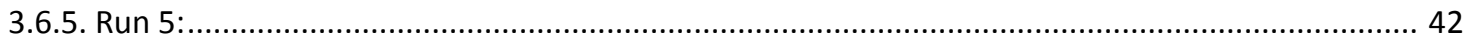

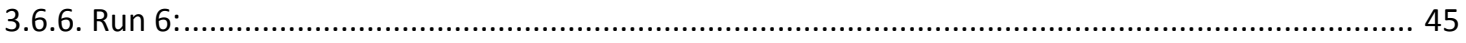

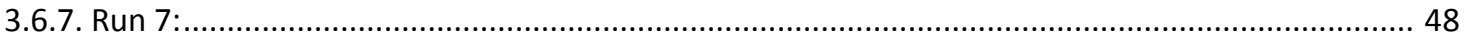

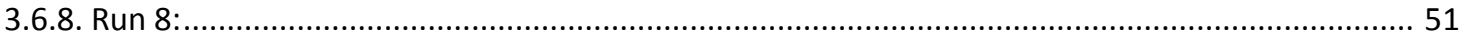

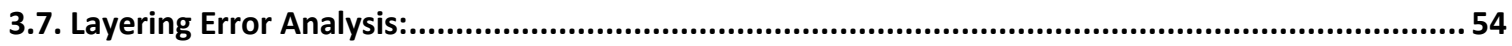

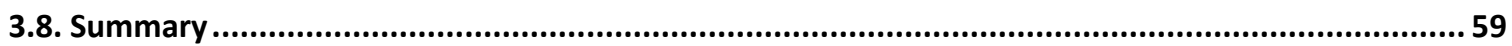

CHAPTER 4: CONCLUSIONS AND FUTURE WORK ……............................................60

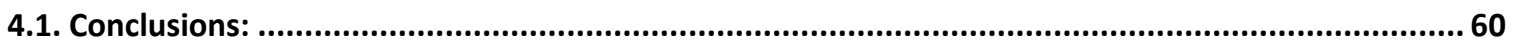

4.2. Future Work:

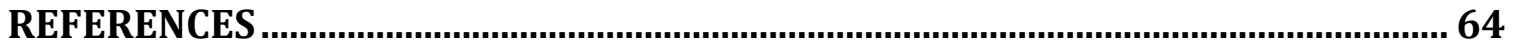

APPENDIX A: AUTOCAD INSTRUCTIONS................................................................ 66

APPENDIX B: PRO METAL SOFTWARE INSTRUCTIONS ........................................... 73

APPENDIX C : MATERIAL SAFETY DATA SHEET FOR BINDER.............................. 83

APPENDIX D: MATERIAL SAFETY DATA SHEET FOR CLEANER............................... 85 


\section{LIST OF FIGURES}

Figure 1.1 Rapid Prototyping in Industries ................................................................. 2

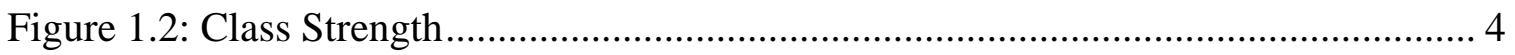

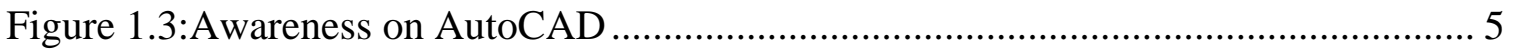

Figure 1.4:Awareness on Rapid Prototyping ............................................................... 5

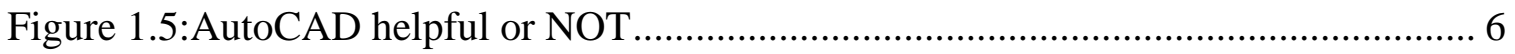

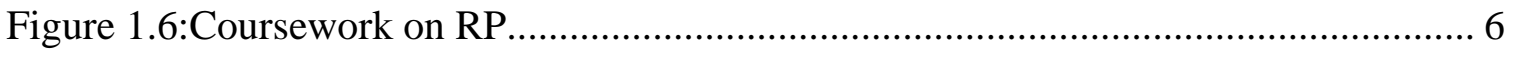

Figure 2.1: Selective Laser Sintering Process............................................................ 10

Figure 2.2 Fused Deposition Modeling. ...................................................................... 11

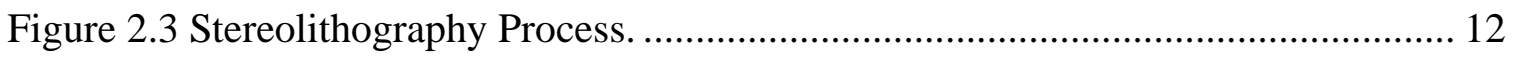

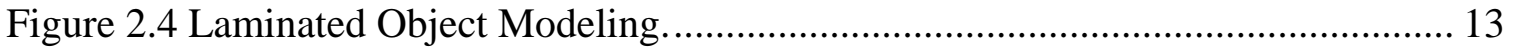

Figure 2.5 Laser Engineered Net Shaping (LENS). .................................................. 14

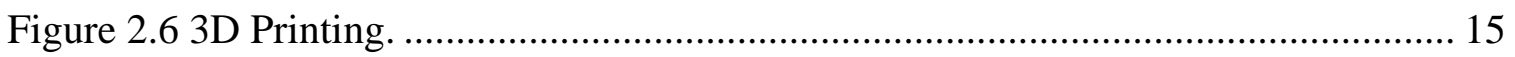

Figure 3.1: Top view of Print Bed: (All Dimensions are in Inches) ................................ 18

Figure 3.2: Front View of the Print Bed: (All Dimensions are in Inches)....................... 18

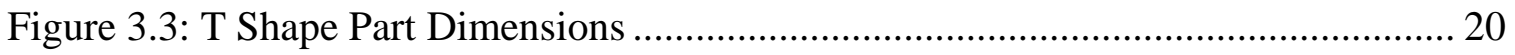

Figure 3.4: Rapid Prototyping Lab Format................................................................. 21

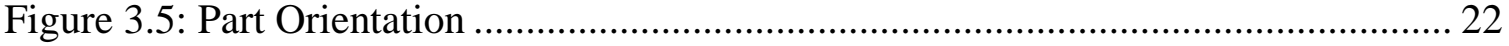

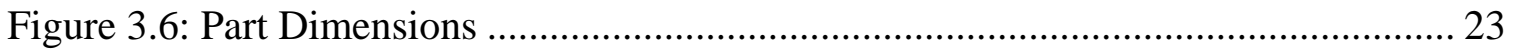

Figure 3.7: Top View (Position 2) Desk Artes View Expert .......................................... 24

Figure 3.8: Triangular Facets on T shape part .......................................................... 24

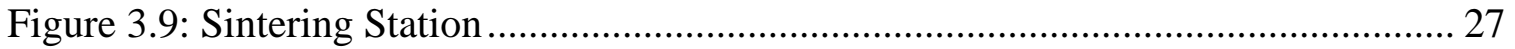

Figure 3.10 Run 1: Change in Dimension vs Part Orientation. ..................................... 33

Figure 3.11:Run 2: Change in Dimensions vs Part Orientation...................................... 36

Figure 3.12:Run 3:Change in Dimensions vs Part Orientation....................................... 39

Figure 3.13:Run 4: Change in Dimensions vs Part Orientation..................................... 42

Figure 3.14:Run 5: Change in Dimensions vs Part Orientation...................................... 45

Figure 3.15:Run 6: Change in Dimensions vs Part Orientation...................................... 48

Figure 3.16:Run 7: Change in Dimensions vs Part Orientation..................................... 51

Figure 3.17:Run 8:Change in Dimensions vs Part Orientation....................................... 54 


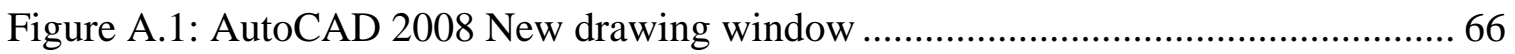

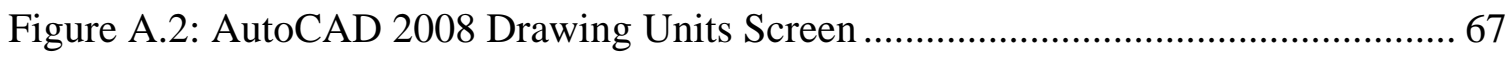

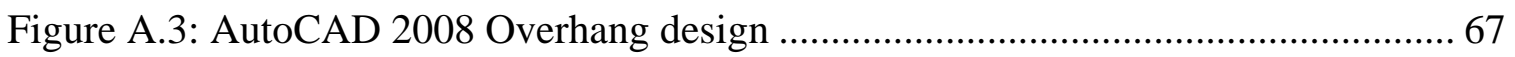

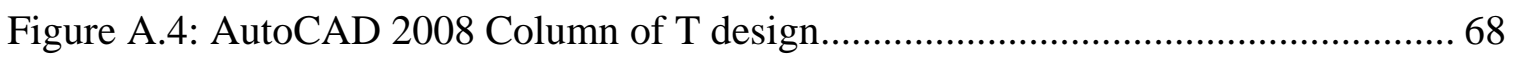

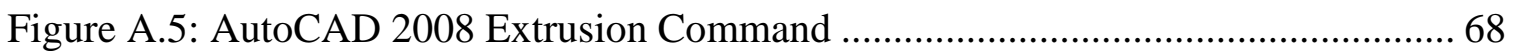

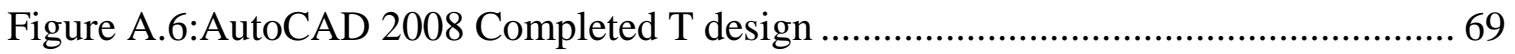

Figure A.7: AutoCAD 2008 3DORBIT view of the solid T bracket............................. 70

Figure A.8: AutoCAD 2008 T bracket dimensions in 2D view. ................................... 71

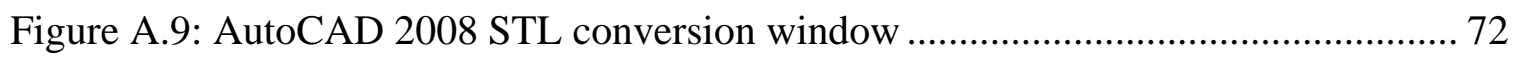

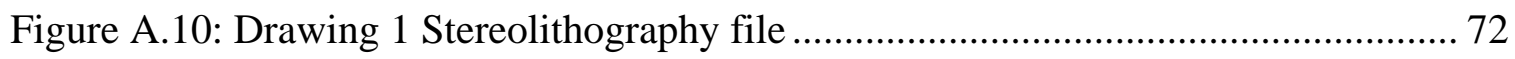

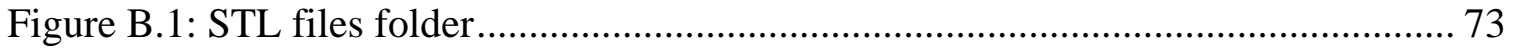

Figure B.2: ProMetal System Startup \& Initialization Screen...................................... 74

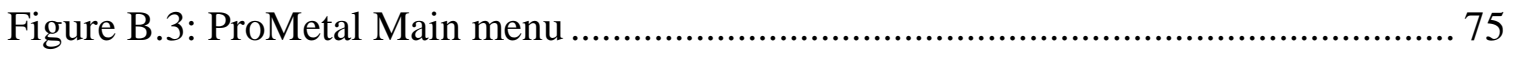

Figure B.4: Pro Metal Printhead Setup and Test Screen ............................................ 76

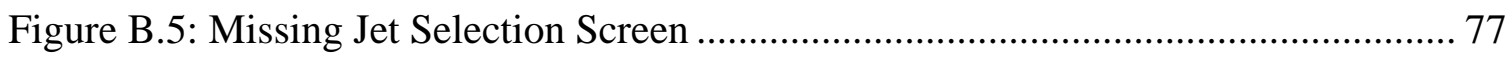

Figure B.6:Print Head Test Pattern Format ................................................................ 77

Figure B.7: Pro Metal Powder Set up Screen ................................................................ 78

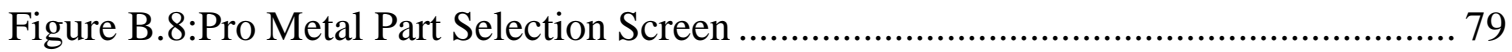

Figure B.9: Pro Metal Print Job Checklist Screen ................................................... 80

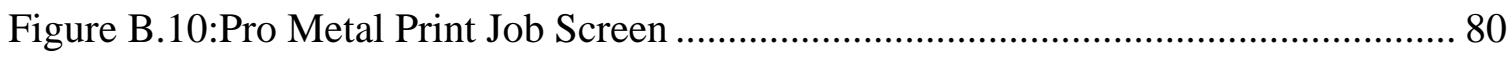

Figure B.11: Pro Metal Maintenance Functions Screen. .............................................. 82

Figure B.12: Pro Metal Advanced Maintenance Functions Screen................................ 82 


\section{LIST OF TABLES}

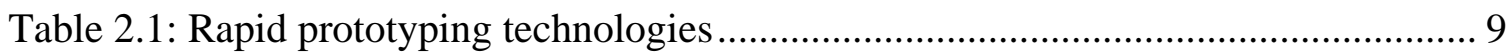

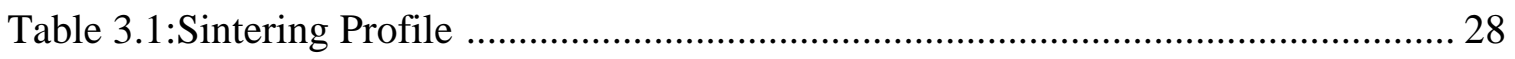

Table 3.2:Infiltration Settings ................................................................................... 29

Table 3.3:One Step Settings........................................................................................... 30

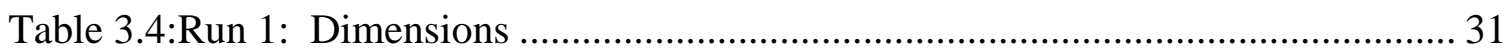

Table 3.5:Run 1: Print Conditions ............................................................................ 31

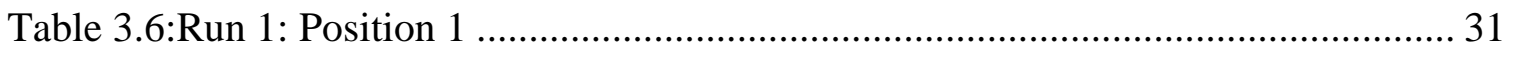

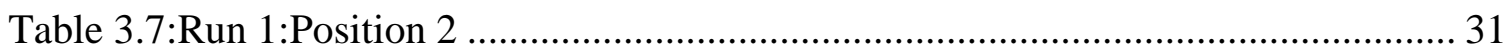

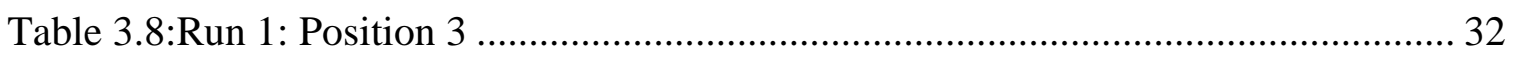

Table 3.9:Run 1: Final Average Dimensions.................................................................. 32

Table 3.10:Run 1: Change in Dimensions .................................................................. 32

Table 3.11:Run 2: Dimensions .................................................................................. 34

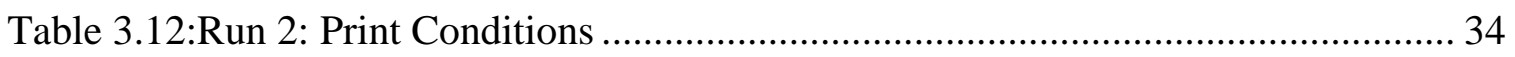

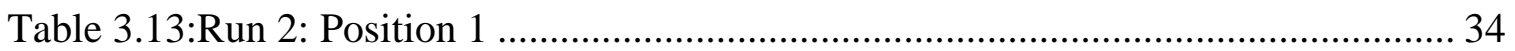

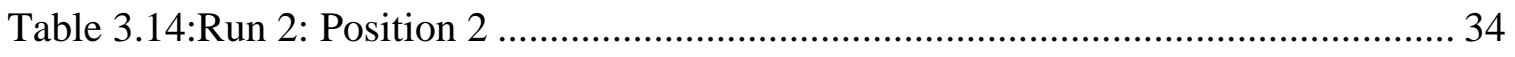

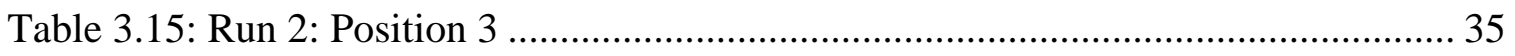

Table 3.16:Run 2: Final Average Dimensions............................................................... 35

Table 3.17:Run 2: Change in Dimensions .................................................................... 35

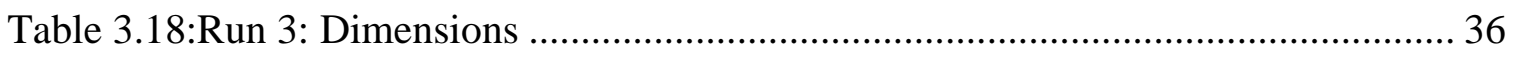

Table 3.19:Run 3: Print Conditions ............................................................................... 37

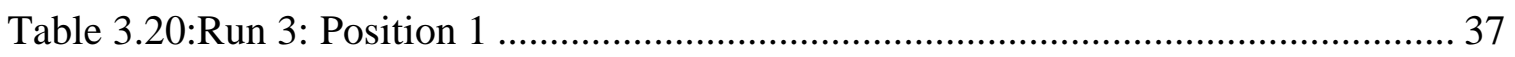

Table 3.21:Run 3: Position 2 ................................................................................. 37

Table 3.22:Run 3: Position 3 ……………………….......................................... 37

Table 3.23:Run 3: Final Average Dimensions................................................................ 38

Table 3.24:Run 3: Change in Dimensions .................................................................... 38

Table 3.25:Run 4: Dimensions .................................................................................... 39

Table 3.26:Run 4: Print Conditions .............................................................................. 40

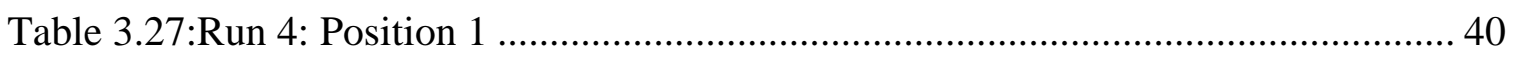

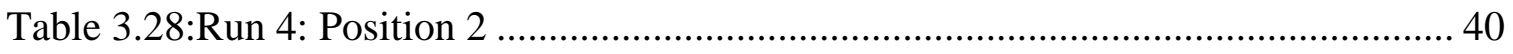




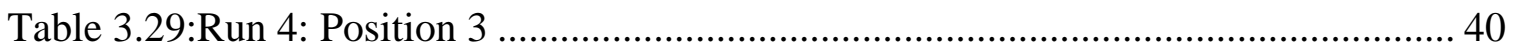

Table 3.30:Run 4: Final Average Dimensions.............................................................. 41

Table 3.31:Run 4: Change in Dimensions ................................................................... 41

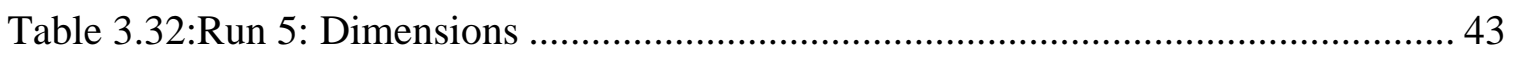

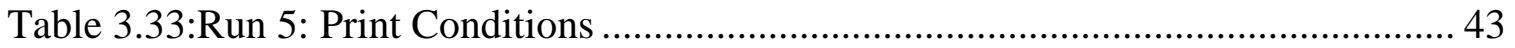

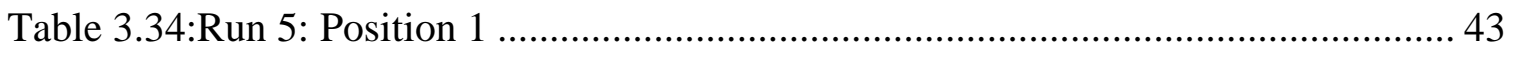

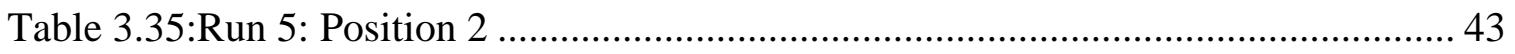

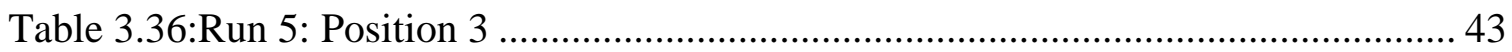

Table 3.37:Run 5: Final Average Dimensions................................................................ 44

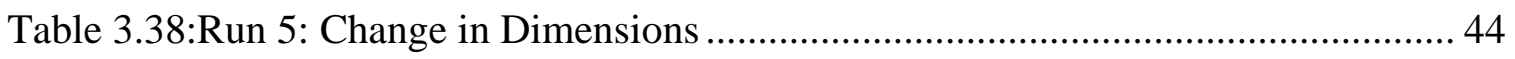

Table 3.39:Run 6: Dimensions .................................................................................. 45

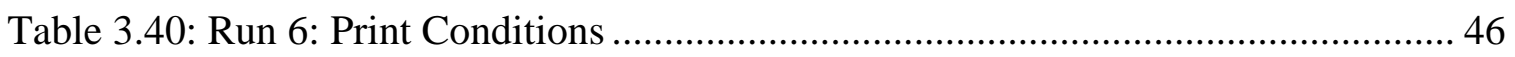

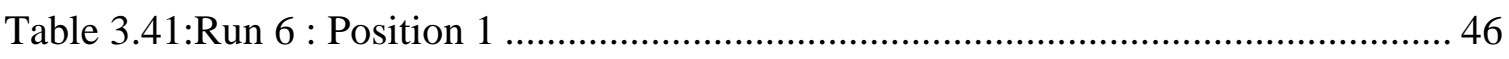

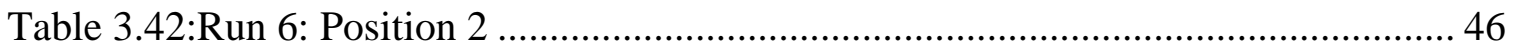

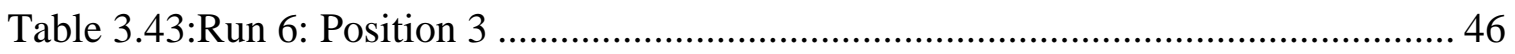

Table 3.44:Run 6: Final Average Dimensions............................................................. 47

Table 3.45:Run 6: Change in Dimensions ................................................................... 47

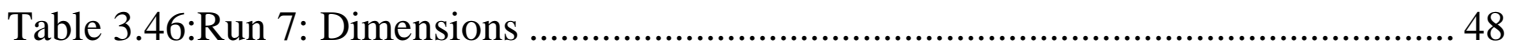

Table 3.47:Run 7: Print Conditions ............................................................................. 49

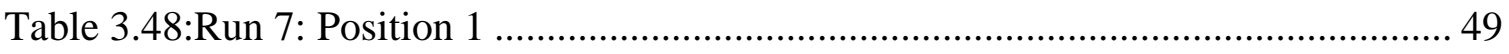

Table 3.49:Run 7: Position 2 ..................................................................................... 49

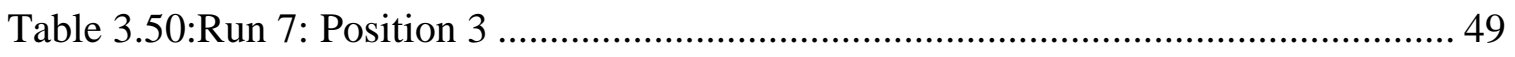

Table 3.51:Run 7: Final Average Dimensions..................................................................... 50

Table 3.52:Run 7: Change in Dimensions ..................................................................... 50

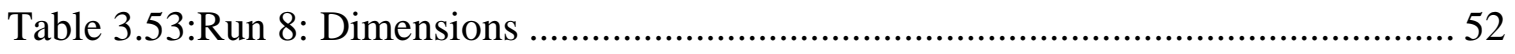

Table 3.54:Run 8:Print Conditions ............................................................................. 52

Table 3.55:Run 8: Position 1 ................................................................................... 52

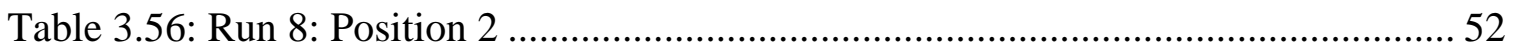

Table 3.57:Run 8: Position 3 ……………………………................................. 52

Table 3.58:Run 8: Final Average Dimensions.................................................................... 53

Table 3.59:Run 8: Change in Dimensions ......................................................................... 53 
Table 3.60:Change in dimensions after layering error at $350^{\circ} \mathrm{F}$ and 2 hrs. .................... 55

Table 3.61: Change in dimensions after layering error at $400^{\circ} \mathrm{F}$ and $2 \mathrm{hrs}$................... 56

Table 3.62: Change in dimensions after layering error at temp $350^{\circ} \mathrm{F}$ and $2.5 \mathrm{hrs}$........ 57

Table 3.63: Change in dimensions after layering error at $400^{\circ} \mathrm{F}$ and $2.5 \mathrm{hrs} \mathrm{.................} 58$

Table 3.64:Percentage change in dimension along XYZ direction at all levels............... 59 


\section{LIST OF ACRONYMS}

ACRONYMN

1. 3D

2. CAD

3. $\mathrm{CNC}$

4. DMD

5. FDM

6. FEF

7. IE

8. LAM

9. LENS

10. LOM

11. MAE

12. MSOE

13. NC

14. $\mathrm{PH}$

15. RP

16. SLA

17. SLS

18. STL

19. WVU

\section{DEFINITION}

Three Dimensional.

Computer Aided Design.

Computer Numerical Controlled.

Direct Metal Deposition.

Fused Deposition Modeling.

Form Extrusion Fabrication.

Industrial Engineering.

Laser Additive Manufacturing.

Laser Engineered Net Shaping.

Laminated Object Manufacturing.

Mechanical and Aerospace Engineering.

Milwaukee School of Engineering.

Numerical Controlled.

Print Head.

Rapid Prototyping.

Stereolithography Apparatus.

Selective Laser Sintering.

Standard Tessellation Language.

West Virginia University. 


\section{CHAPTER 1:INTRODUCTION}

Rapid Prototyping (RP) refers to a class of machines designed to rapidly print physical objects from three dimensional (3D) computer aided design (CAD) data with little or no human intervention during the production process [1]. The first techniques of RP were used in the 1980's to produce models and prototype parts.

Rapid Manufacturing refers to both additive and subtractive manufacturing processes. However this thesis focuses on additive manufacturing technology. Additive manufacturing systems join together liquid, powder or sheet materials to form parts that may be impossible to fabricate by any other method. Based on the CAD data, the system produces plastic, metal, ceramic or composite parts layer upon layer.

The additive fabrication process expedites the product development process. Any manufacturing firm would be focused towards reducing the time it takes to launch its product into the market. In such a situation, it would be ideal to rely on a prototype model which would help in visualizing the actual product before it goes into the market. This would save time and reduce the likelihood of delivering the wrong product or a product which does not meet any specific requirement.

\subsection{Brief History of Rapid Prototyping:}

According to Terry Wohlers, Wohlers Report 2005 [2], the first of the RP machines were made available by 3D systems in 1987. The technology was Stereolithography which solidified thin layers of ultraviolet (UV) light-sensitive liquid polymer using a laser. 3D Systems launched the commercial version of the machine SLA 250 (StereoLithography Apparatus).

In 1991 three additive technologies commercialized were Fused Deposition Modeling (FDM) from Stratasys, Solid Ground Curing (SGC) from Cubital and Laminated Object Manufacturing (LOM) from Helisys. In 1992, Selective Laser Sintering (SLS) was made available by DTM which is now a part of 3D systems. In 1995, 
DTM, a subsidiary of BFGoodrich Company, announced the commercial availability of its Rapid Tool тM technology. IBM's Watson Research Centre developed an additive process similar to the extrusion process of FDM known as Genisys for Stratasys in 1996. In the same year 3D systems launched its first 3D printer known as Actua 2100. In 1997, AeroMet was founded as a subsidiary of MTS Systems Corp. It developed a process using high power laser and powdered titanium alloys known as Laser Additive Manufacturing (LAM).

According to Terry Wohlers [2], the new generation RP machines are:

1. Quadra.

2. Pattern Master.

3. Direct Metal Deposition (DMD).

4. Prodigy.

5. Pro Metal RX-1

The Figure 1.1 indicates the various sectors of manufacturing which have accepted RP or the additive fabrication technology [3].

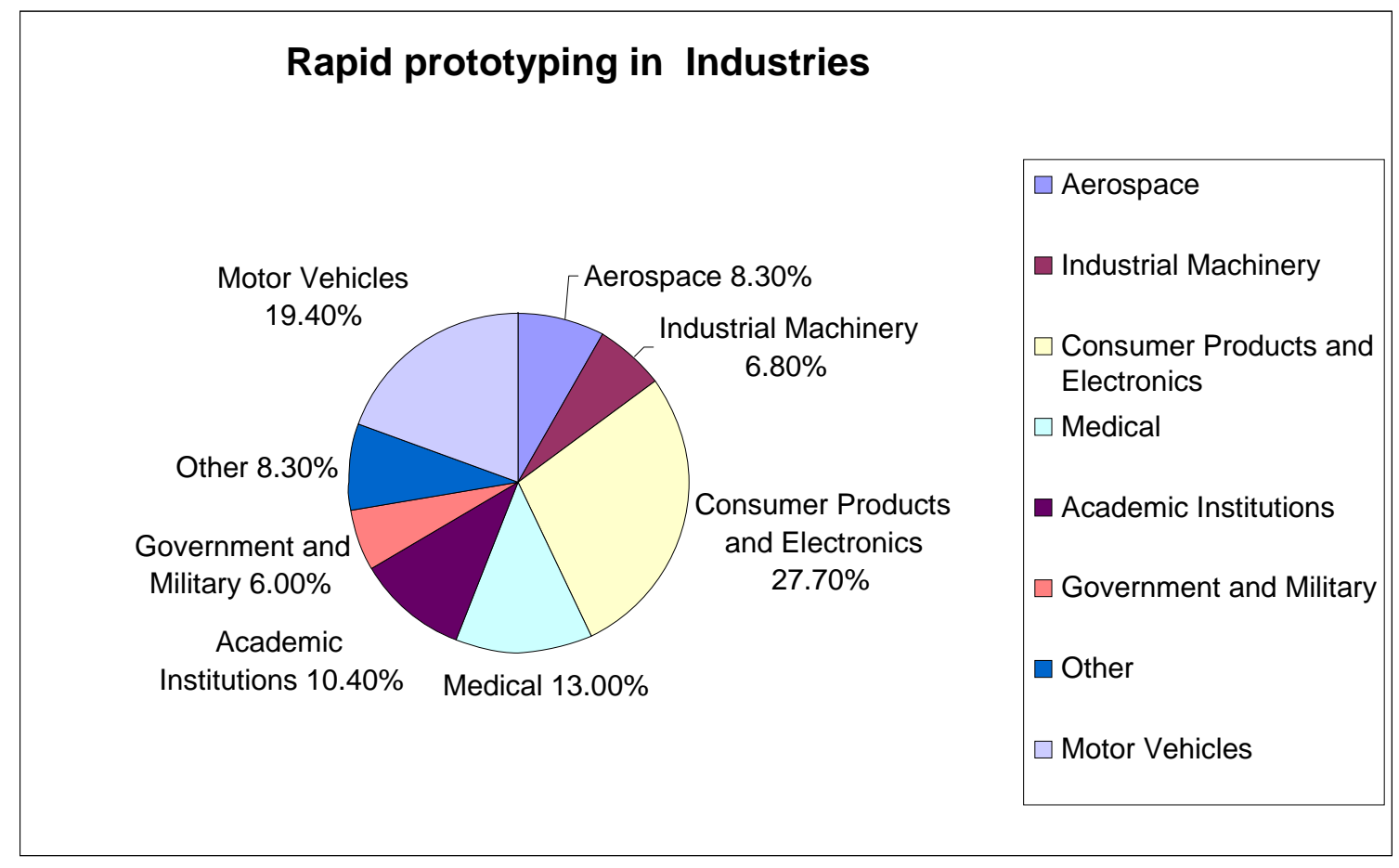

Figure 1.1 Rapid Prototyping in Industries taken from Source: Wohlers Associates, Inc., Wohlers Report 2005. 
The percentage of academic institutions embracing the Rapid Prototyping technology was $10.4 \%$ which indicates that the use of this technology as a part of the engineering curriculum is in its early stages. It would be beneficial for the students if academic institutions incorporate the latest technology at an early stage into their curriculum so that the students may have an opportunity to use the RP machines.

\subsection{Statement of problem}

It is very important to recognize emerging technology and to be able to adopt it into the system at an early stage. It is at this early stage that one would have to be careful about the research and impact it would have on the students. The focus of this thesis is mainly to introduce students to the emerging technology of Rapid Prototyping (RP) as part of the IE and MAE undergraduate curriculum at West Virginia University (WVU).

Conventional mechanical engineering or product design practices use orthogonal multi-view drawings to convey the design parameters for manufacture. The latest versions of AutoCAD software have made it possible for the designer to simulate the product in 3D space. By using RP technology the students would be able to fabricate the three dimensional model that they visualize which would give them a better understanding of the product design. The lab experiments have been designed to lay a foundation to improve their knowledge and also to better understand the entire Rapid Prototyping concept.

In order to achieve this goal of including RP into the curriculum it is very important to learn about awareness of RP among students. To serve this purpose, a student survey was conducted and the results analyzed which gave an insight into the student's knowledge about RP and lay a foundation to proceed towards achieving the goal. Experiments were conducted and lab exercises developed for the students to enable them to use the RX-1 rapid prototyping machine in a more efficient manner. Video demonstrations were also created to demonstrate the basic operations of the machine to the students and also an instructor version of the video to help the TA assist the students in a more efficient manner and maintain the machine in proper working condition. 


\subsection{Student Survey}

While introduction of new technology as a part of the curriculum is important, it is also important to know the awareness of the new technology among students. The best form of knowing that is to survey the students on a few basic questions and analyze their responses.

The following questions were asked and the results obtained after surveying a group of 41 students of which 32 were from Mechanical and Aerospace Engineering and 9 were from Industrial engineering.

\section{Q1. What is your major?}
a. IE
b. MAE

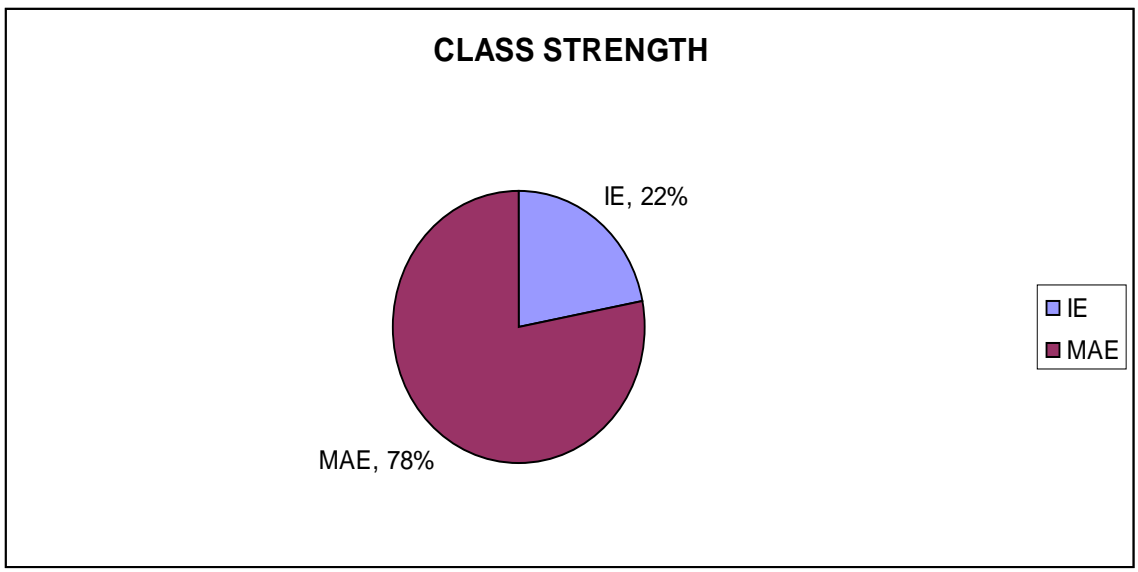

Figure 1.2: Class Strength 
Q2. Are you familiar with any CAD software? If yes, please specify which one.
a. Yes
b. No

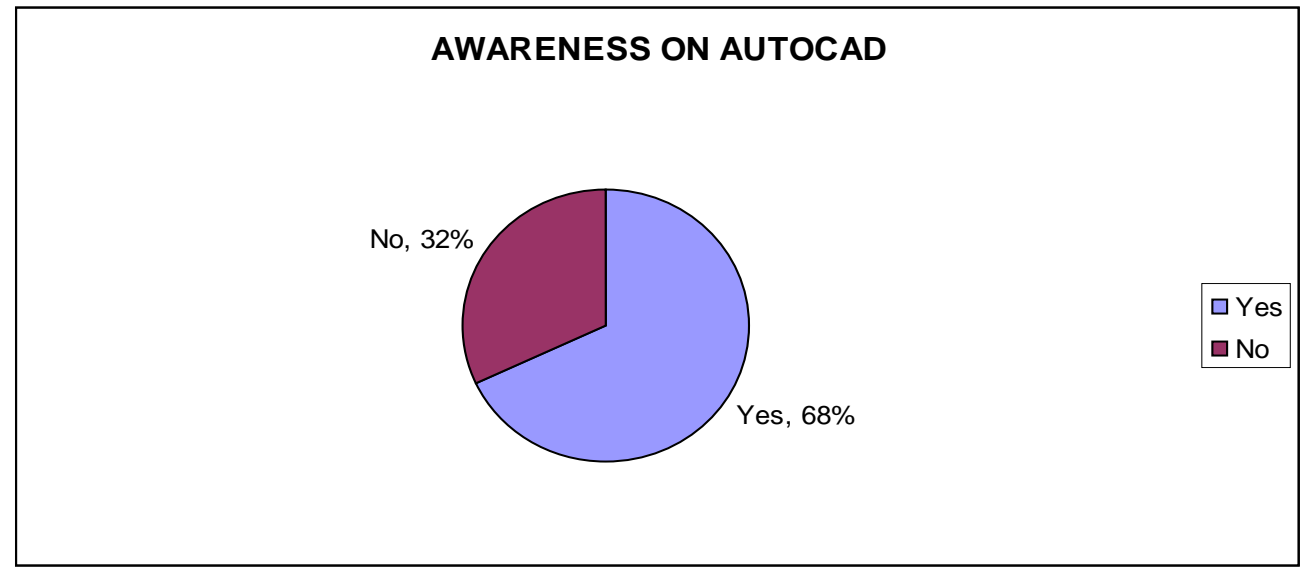

Figure 1.3:Awareness on AutoCAD

Q3. Are you aware of the latest manufacturing technology known as "Rapid Prototyping"?
a. Yes
b. No.

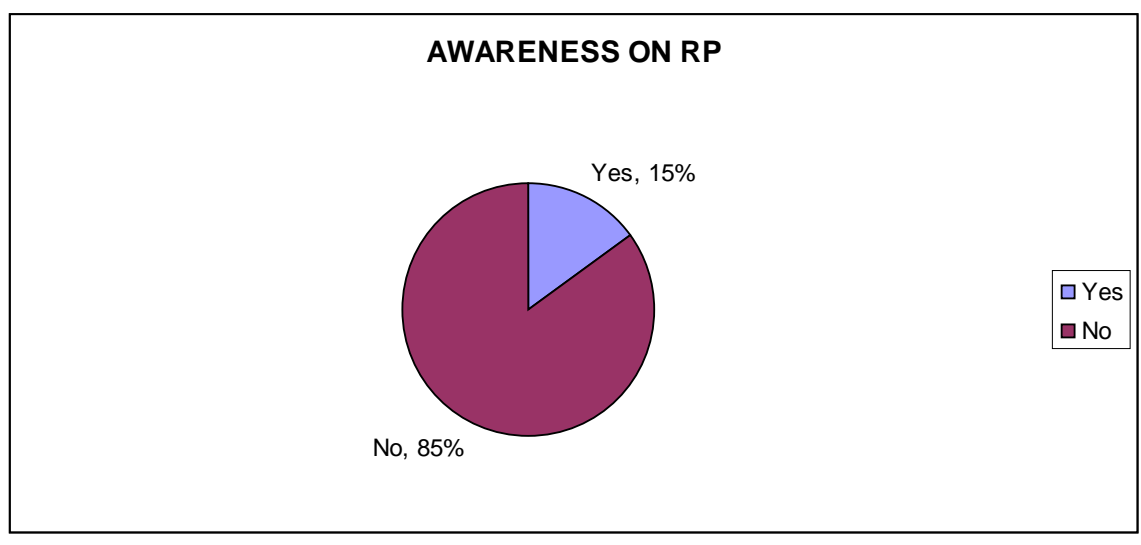

Figure 1.4:Awareness on Rapid Prototyping 
Q4. Do you want think AutoCAD would be helpful for you in the future and would you like it to be covered in more depth and if so please suggest a course in which you think that could be done?
a. Yes
b. No

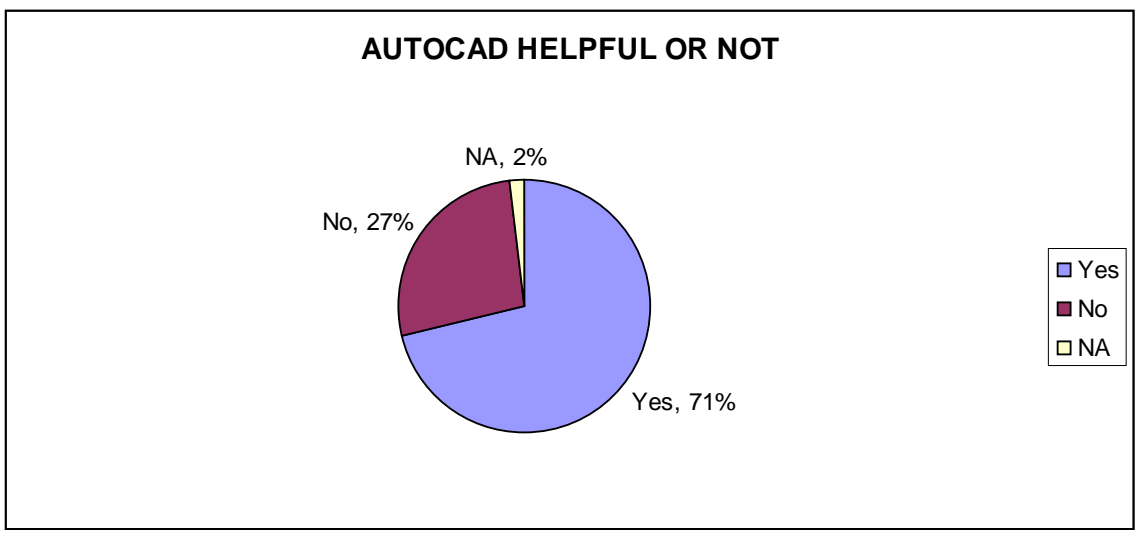

Figure 1.5:AutoCAD helpful or NOT

COURSES SUGGESTED: IENG 304, MAE 241, MAE 456, IENG 302, IENG 303. Q5. Would you like Rapid Prototyping to be a part of your coursework and if so which course would you recommend that it be included with?
a. Yes
b. No.

\section{COURSEWORK ON RP}

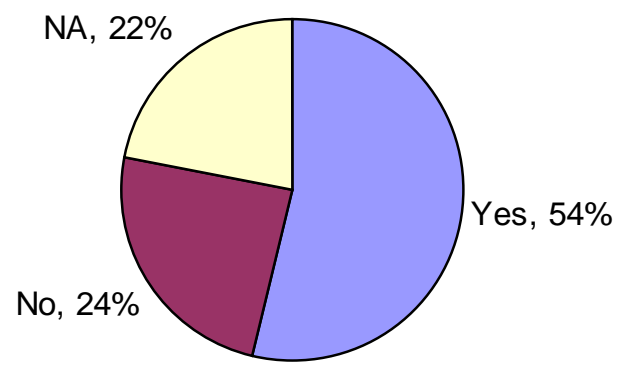

Figure 1.6:Coursework on RP 
Based on the results obtained in the student survey, from Figure 1.4 it is evident that $85 \%$ of the students surveyed were unaware of any technology such as Rapid Prototyping. Therefore this thesis is based on the results to help introduce the new technology and to improve the awareness of Rapid Prototyping among the IE and MAE undergraduate students at WVU. 


\section{CHAPTER 2:HARDWARE/SOFTWARE DESCRIPTION}

\subsection{CAD technology}

For years sophisticated 3D CAD systems have been trying to replace the 2D CAD systems [4]. It is very important to assess whether 3D modeling is required or not for a particular model. Many projects do not require 3D modeling such as simple plans, diagrams and flow charts. On the other hand much of what is designed and built in three dimensions and 3D modeling can be the most natural way to create and document the design. But 3D modeling sometimes adds time and complexity to the design process. It is very important to understand the advantages of 3D modeling and decide when it is worth the added time and effort.

While using the 3D modeling the extruded entities such as surfaces etc., could very well be applied to architectural models, piping and machinery design, topographical models and package designs to name a few. For precision in mechanical parts design, one would need the solid modeling. Surfaces are only considered approximation but solids are mathematically precise enough to far exceed the abilities of NC machines.

In $3 \mathrm{D}$ modeling what is shown on the screen is just one of many possible views of the 3D models created and stored in AutoCAD. The distinction between the model and a view of the model is important. AutoCAD 2008 and 2009 have certain built in tools for viewing them.

\subsection{Impact of CAD on curriculum}

During the early years CAD was primarily viewed by students as a useful method of improving the 2D renderings or of combining text with graphics. Since then, the continuing development of affordable, powerful and rapid processors has created an opportunity for the students and has given an increased access to the CAD technology. As a result, CAD has moved from a peripheral component of design, education to a 
central tool in the design process. In particular, the introduction of middle range CAD software in 1998 changed the role of computer technology in the curriculum. Students were equipped with a tool to explore the $3 \mathrm{D}$ properties of their designs.

\subsection{Rapid Prototyping Technologies}

There are a large number of competing RP technologies available in the market. As all are based on additive fabrication technology, their main differences are found in the way layers are built to create parts. Some are based on softening or melting the material to produce the layers where as others rely on laying liquid material thermosets that are cured with different technologies. Table 2.1 lists a few of the most important technologies and the base materials used by them: [5]

Table 2.1: Rapid prototyping technologies, taken from the web, Source: http://en.wikipedia.org/wiki/Rapid_prototyping\#Technologies

\begin{tabular}{|c|c|}
\hline Rapid Prototyping Technologies & Base Materials \\
\hline Selective laser sintering (SLS) & Thermoplastics, metals powders \\
\hline Fused Deposition Modeling (FDM) & Thermoplastics, Eutectic metals. \\
\hline Stereolithography (SLA) & Photopolymer \\
\hline Laser Engineered Net Shaping (LENS) & Various materials \\
\hline Laminated Object Manufacturing (LOM) & Various materials \\
\hline 3D Printing (3DP) & Paper \\
\hline
\end{tabular}

\subsection{Selective Laser Sintering (SLS)}

Selective Laser Sintering process [6] as shown in Figure 2.1 is an additive rapid manufacturing technique that uses a high power laser (for example, a carbon dioxide laser) to fuse small particles of plastic, metal or ceramic powders into a mass representing a desired 3-dimensional object. The laser selectively fuses powdered material by scanning the cross sections generated from a 3D digital description of the part on the surface of a powder bed. After each cross section is scanned the powder bed is lowered by one layer thickness and a new layer of material is applied on the top and the process is repeated until the part is completed. 
The materials which may be used during this process are nylon, polystyrene, steel, titanium, alloy mixtures, composites and green sand. Depending on the material upto $100 \%$ density can be with material properties comparable to those from conventional manufacturing methods.

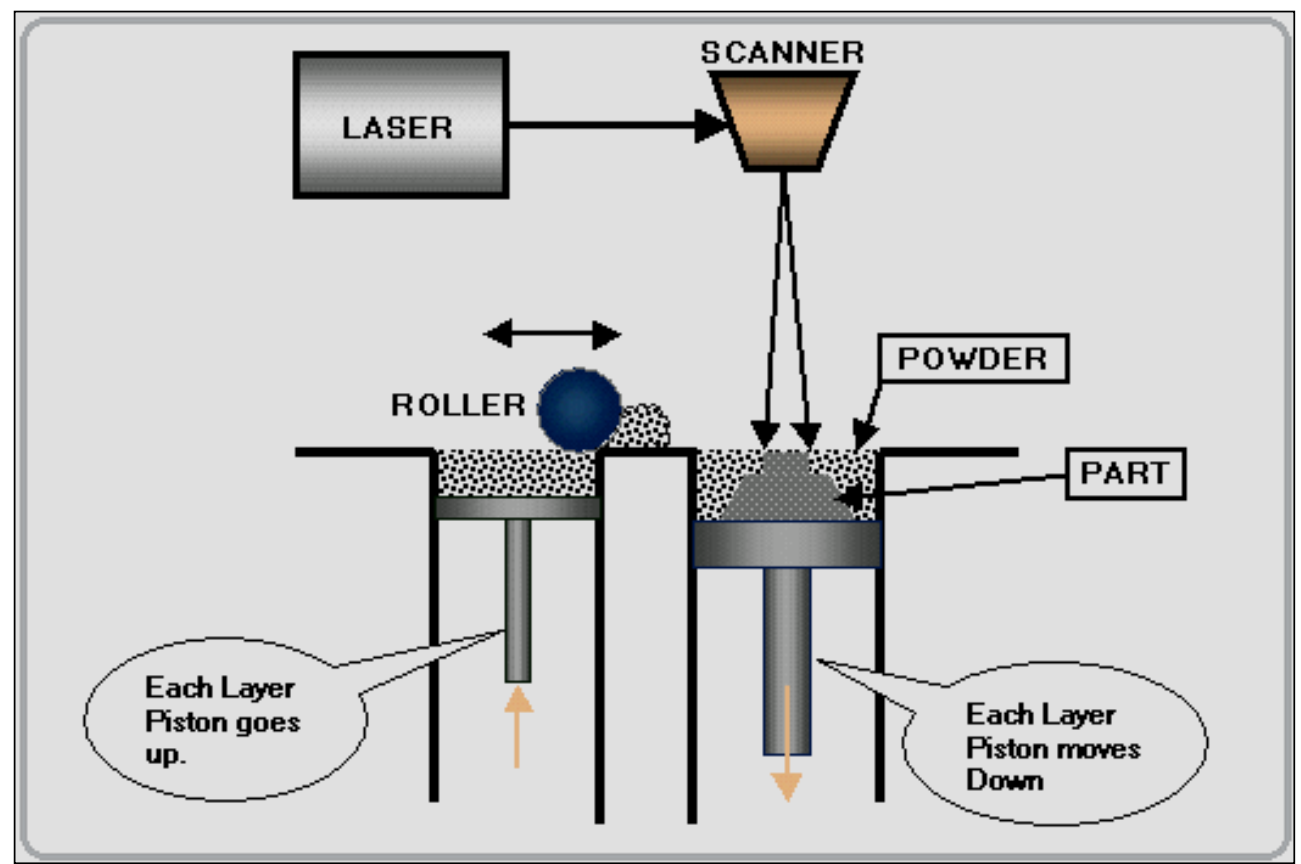

Figure 2.1: Selective Laser Sintering Process, taken from the web, Source: http://blog.mindtribe.com/usercontent/2009/06/SLS_blg11.gif

\subsection{Fused Deposition Modeling (FDM)}

Fused Deposition Modeling (FDM) [7] was developed by S.Scott Crump in the late 1980's and was commercialized in the 1990. The FDM technology is marketed commercially by Stratasys Inc.

Like most other additive fabrication processes FDM as shown in Figure 2.2 works on additive principle by laying down material in layers. A plastic filament or a metal wire is made to pass through a set of rollers and through the liquefier into the extrusion nozzle which can turn the supply on or off. The nozzle heats up the plastic and directed by the program it deposits the liquid plastic layer by layer and hence the model is built up. 


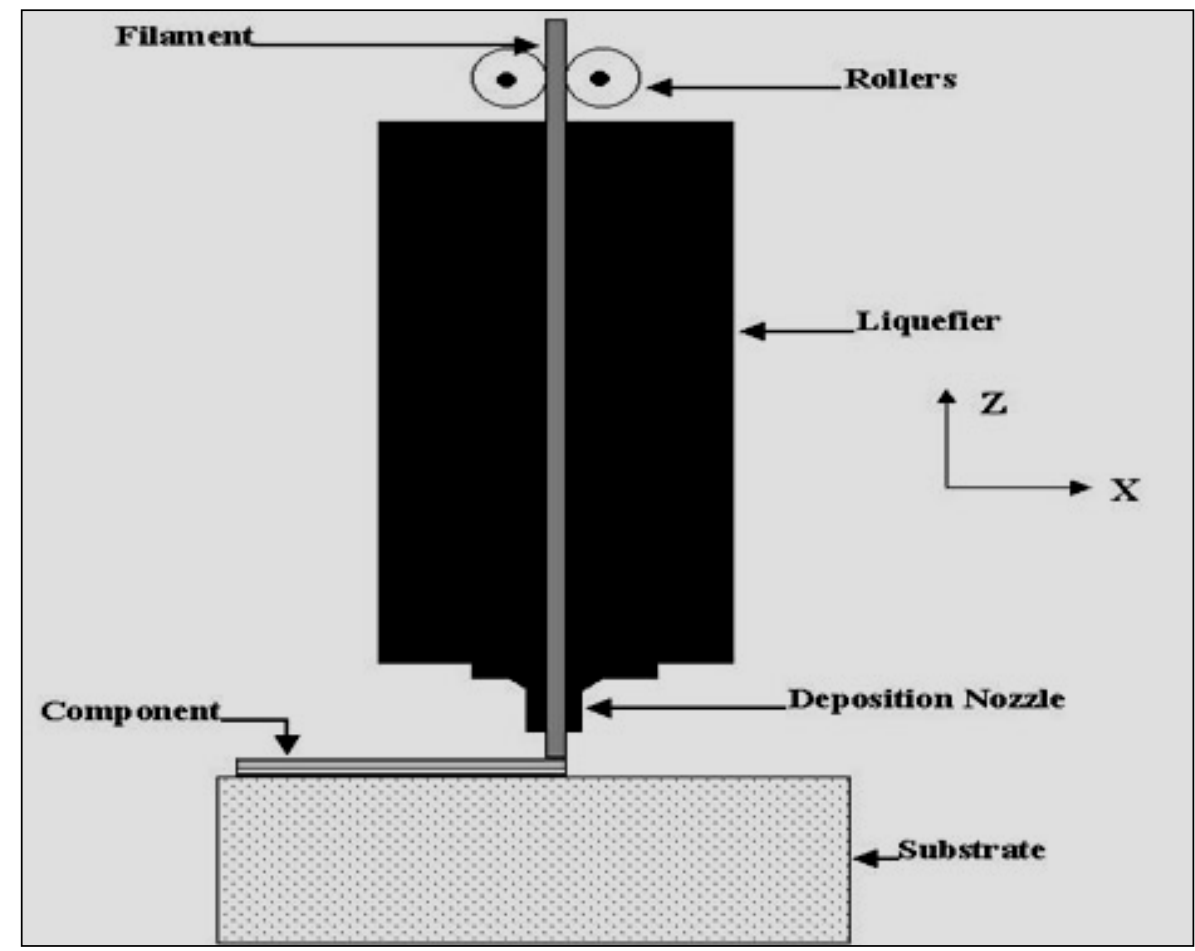

Figure 2.2 Fused Deposition Modeling, taken from the web, Source: http://www.emeraldinsight.com/fig/1560080405001.png

\subsection{Stereolithography}

Stereolithography [8] is an additive fabrication process which was patented in 1986. It was the first fully commercial rapid prototyping technology and till date remains the most widely used one. When a designer needs to obtain a good surface finish or a very precise modeling procedure then Stereolithography process is used. In this process the part is built on a support positioned just below the surface in a vat of liquid photocurable polymer. Usually an epoxy or acrylate resin is used. The CAD data of the sliced model is fed into the system and a low powered UV light beam traces out the first layer. As shown in Figure 2.3 the first layer is scanned and cured by the light beam. This procedure takes place within the boundaries of the cross section of the model. The support is then lowered and a fresh layer of liquid polymer about the thickness of the slice covers the first layer. This process is repeated until the model is complete. Depending upon the design of the model different support systems are built to support the model in the entire process. 
According to Michael Legault , "typical tolerances for an SLA part with an edge ranging in length to $200 \mathrm{~mm}$ (8inches) is $\pm 0.1 \mathrm{~mm}$ ( \pm 0.004inches) and about $\pm 0.4 \mathrm{~mm}$ ( \pm 0.016inches) for a part with an edge up to 500mm(19inches)long

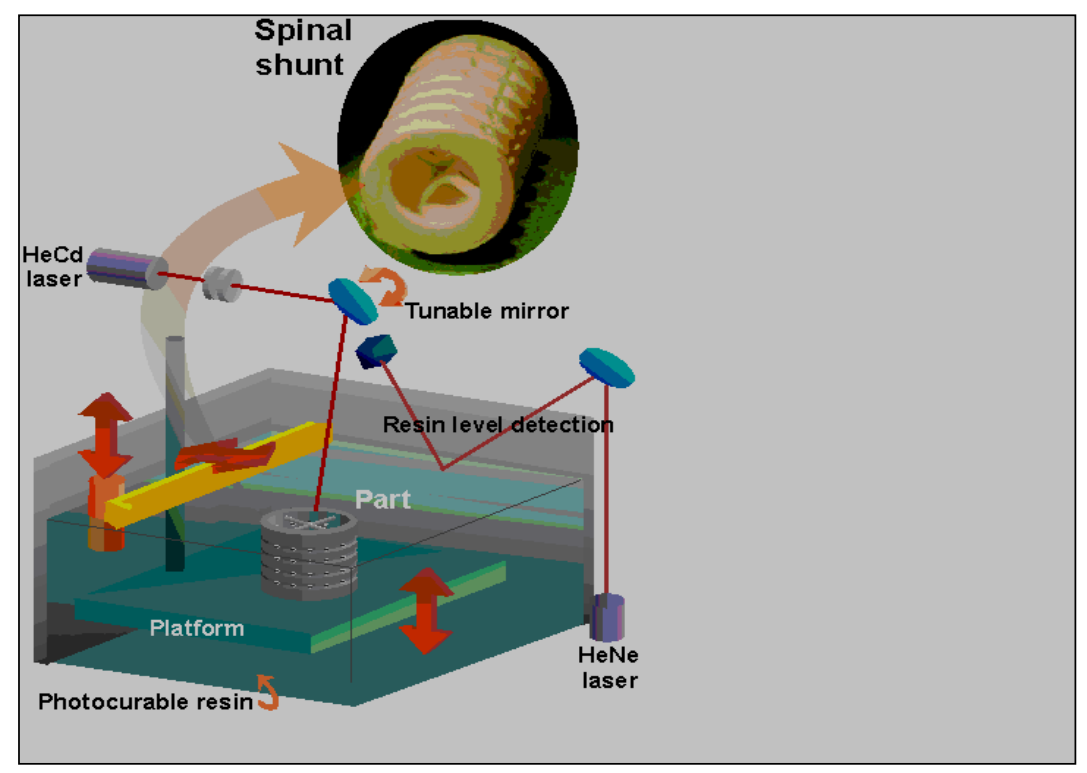

Figure 2.3 Stereolithography Process, taken from the web, Source: http://www.princeton.edu/ cml/assets/images/stereo02.gif

\subsection{Laminated Object Manufacturing}

The LOM [9] manufacturing process uses a carbon dioxide laser to cut cross sections of three dimensional object from layers of paper with a coating of polyethylene on the other side of it. As shown in Figure 2.4 the first step is to create a base which the paper can attach itself to. A special tape on the platform adheres to the paper supply. Large sheet of paper is mounted on rollers to feed into the system. The paper passes on the platform and the heated roller melts the coating on the paper so that each layer will adhere to the previous layer.

The carbon dioxide laser cuts the cross sectional pattern on top of the paper. After this is done the outline is defined and the same procedure is repeated until the entire product is built. Once the pattern is outlined the laser creates hatch marks or cubes around the pattern which act as a support to the platform. After the model is built the entire frame 
is lifted and the supports are dismantled from the platform. The unfinished part is sanded and a layer of lacquer is used to seal the part. Since paper is the raw material used in this process, different factors such as temperature and humidity and pressure effect the composure of the model. This process is very useful in manufacturing large parts effectively and in a short period of time.

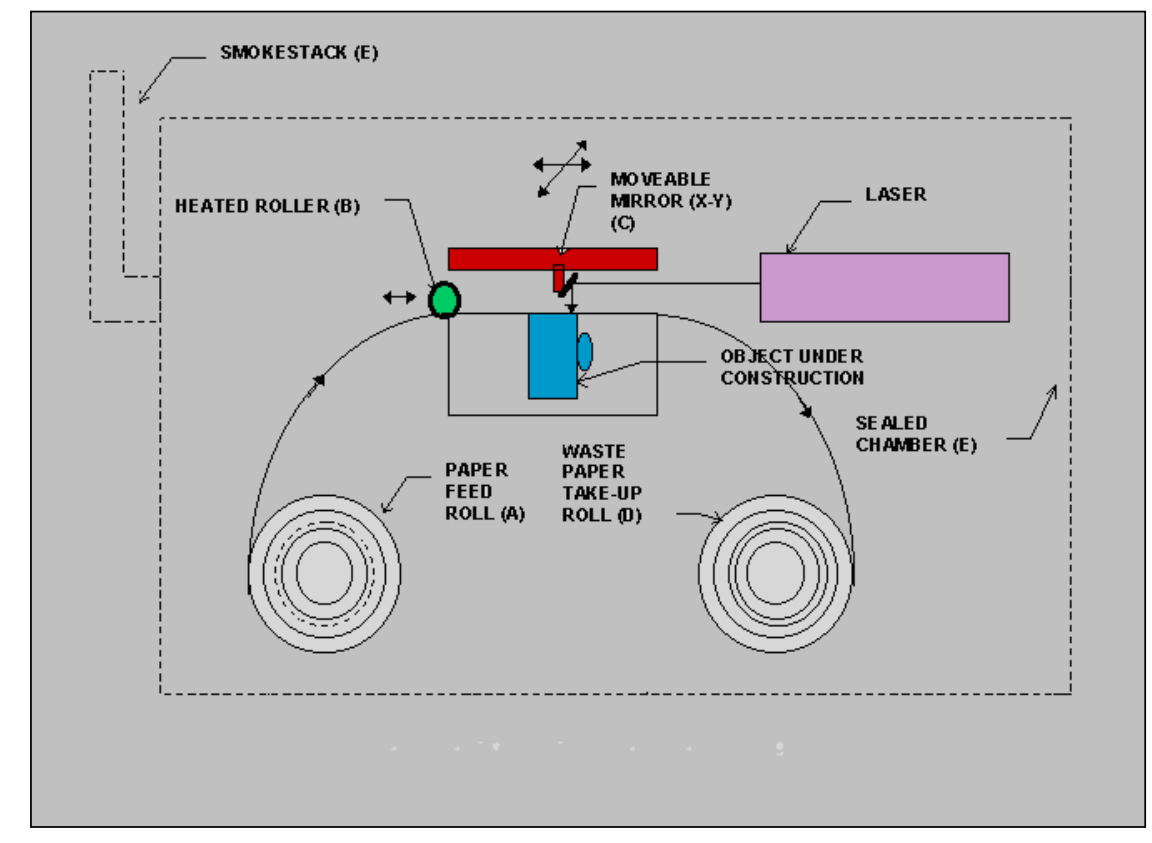

Figure 2.4 Laminated Object Modeling, taken from the web, Source: http://home.att.net/ castleisland/lom.gif

\subsection{Laser Engineered Net Shaping}

If a process requires a production of dense, functional powder metal components directly from CAD model then Laser Engineered Net Shaping (LENS) [10] is used. This process was developed by Optomec Inc., in partnership with Sandia National Laboratory. The materials used in this process are eutectic metals, superalloys etc. This process directs powder material based on high lowered laser that focuses on to a supporting platform. As shown in Figure 2.5 the subsequent scanning of the laser on the support surface deposits thin layer of the metal. Since the CAD data fed into the system is in the form of a sliced pattern the layers are also built in the same manner. This results in a dense metal part with dimensional accuracy. This process is also able to produce tools which conform to the molding surface in the injection molding process. 


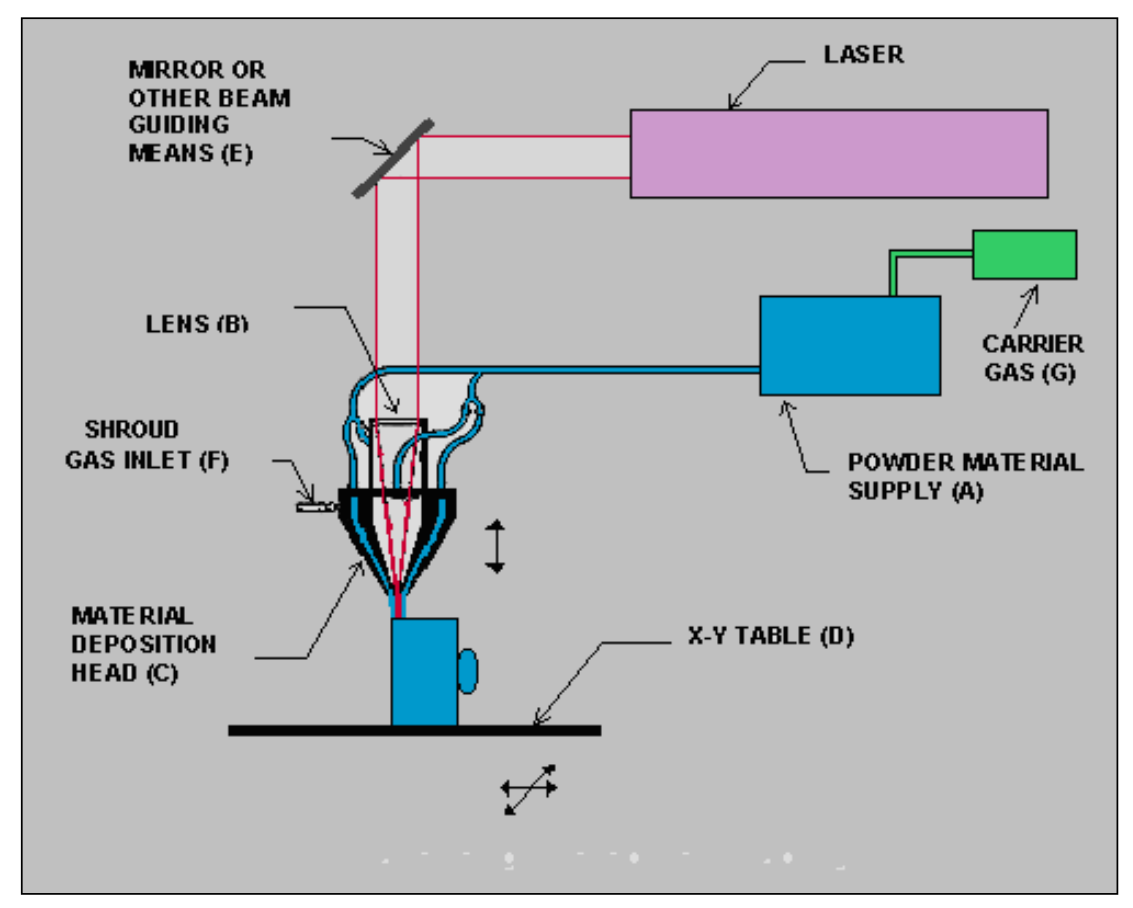

Figure 2.5 Laser Engineered Net Shaping (LENS), taken from the web, Source: http://home.att.net/ castleisland/lens.gif

\subsection{D Printing}

This is the most affordable and the fastest method available compared to the other additive fabrication technologies. The same procedure also follows here in which successive layers are built one on top of the other as shown in Figure 2.6. The materials used in this process are powdered plaster and resins. The material is selectively bonded by printing the adhesive on to the supporting platform by the printing head which usually is an inkjet print head. The cross section of the model is determined by the CAD file input into the system. 3D printing allows printing of color prototypes. Different 3D printing machines are also available. This is a low cost and the most easy to use type of RP technology.[11]

The RX-1 Rapid Prototyping machine by Ex-One is a 3D printing machine. The metal used in this process is powdered Stainless Steel (S4). As the part builds up the binder is deposited on every layer by the print head. This process produces a green part 
which is then heat treated through processes such as curing and sintering to improve its strength.

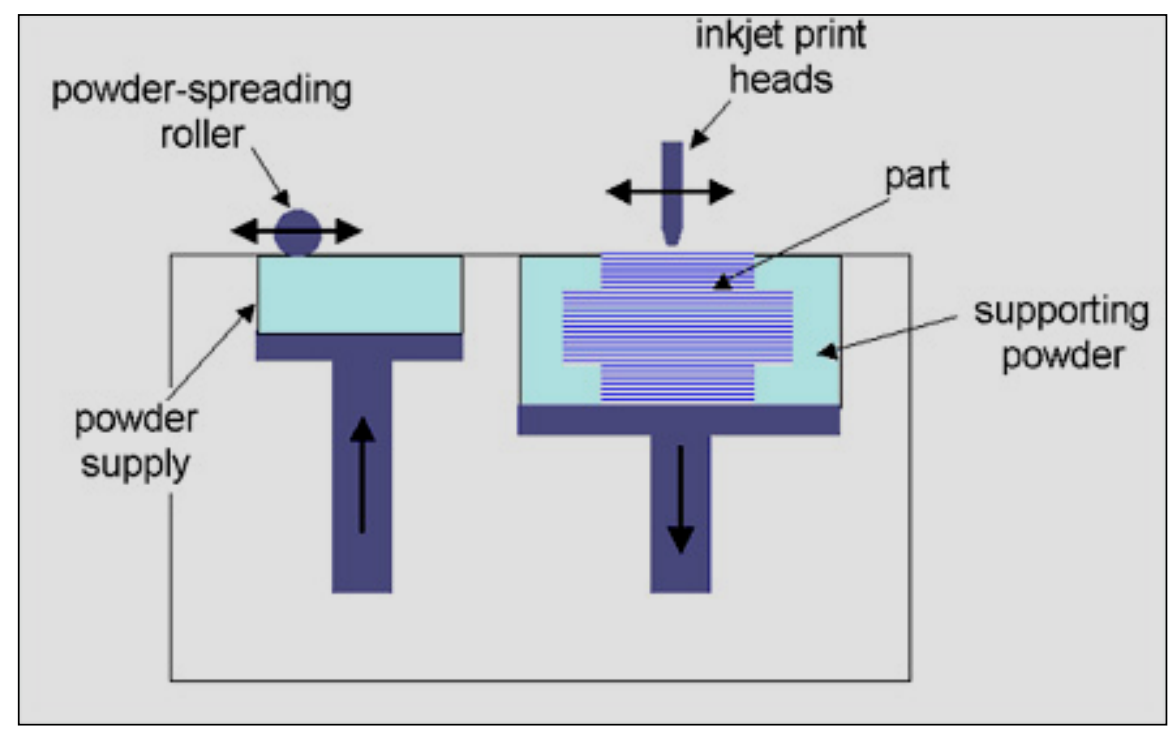

Figure 2.6 3D Printing, taken from the web, Source: http://www.rpc.msoe.edu/images/3dp_process.jpg

\subsection{Rapid Prototyping in Education}

Over the years education has played an important role in exploring new concepts while understanding the theory to support emerging systems for additive fabrication. Colleges and universities worldwide have assisted in the startup, education and process development of new applications. Many universities such MIT and University of Texas at Austin have welcomed the additive fabrication technology and thus have helped it grow via research and development of multiple applications of the process more than the concept modeling for which it was originally designed.

Education in Rapid Prototyping is instrumental in the use and the advancement of the technology. Colleges and Universities have already developed laboratories dedicated to additive processes to support the infusion of new technology into its curriculum. Following are a few examples of the same: 


\section{Rapid Product Design - University of Missouri - Rolla.}

The Virtual Reality and Rapid Prototyping Laboratory at University of Missouri at Rolla houses Rapid Freeze Prototyping experimental system. The research involves Freeze Form Extrusion Fabrication (FEF) of Ceramic Components [18].

\section{Rapid Prototyping in Engineering - Georgia Institute of Technology.}

Georgia Institute of Technology has a Rapid Prototyping and Manufacturing Institute dedicated to Rapid Tooling, Rapid Inspection and Computer Aided Verification (CAV), RPM within Product Realization and Alternative applications of SLA [18].

\section{Non- Traditional Manufacturing Processes - Southern Methodist University.} The Rapid Manufacturing Lab at Southern Methodist University has a wide range of rapid manufacturing research projects which involve Rapid Prototyping based on Variable Polarity Gas Tungsten Arc Welding, Solid Freeform Fabrication based on Micro-Plasma Powder Deposition [18].

\section{The Rapid Prototyping Center - Milwaukee School of Engineering.}

The Rapid Prototyping Center at MSOE owns and operates 5 machines. Stereolithography Apparatus, Selective Laser Sintering, Laminated Object Manufacturing and 3D printing machines [18].

In the end, since the IMSE (Industrial and Management Systems Engineering) department at WVU currently owns a rapid prototyping machine of its own, by it being a part of the curriculum would help spread interest and awareness among the students. Therefore this thesis aims to make a beginning and explains about the RX-1 machine and its processes in the later chapters. 


\section{CHAPTER 3:RX-1 RAPID PROTOTYPING MACHINE}

The RX-1 rapid prototyping machine housed in the Manufacturing Processes Laboratory at West Virginia University is designed by Ex-One Company based in Irwin PA. The RX-1 machine is designed for research and experimental purposes. The hardware, software specifications and electronic specifications are mentioned below:

\subsection{Hardware and Software Specifications:}

1. Model Number: 0500121

2. Print Head Serial Number: 12570155

3. Pro Metal R-1 software version: 2.3.1.1

4. Binder: Stainless PM-B-SR1-01

5. Powder: S4-30micron

6. Print Bed Specifications (X*Y*Z): 1.6"*2.4"*1.0" 


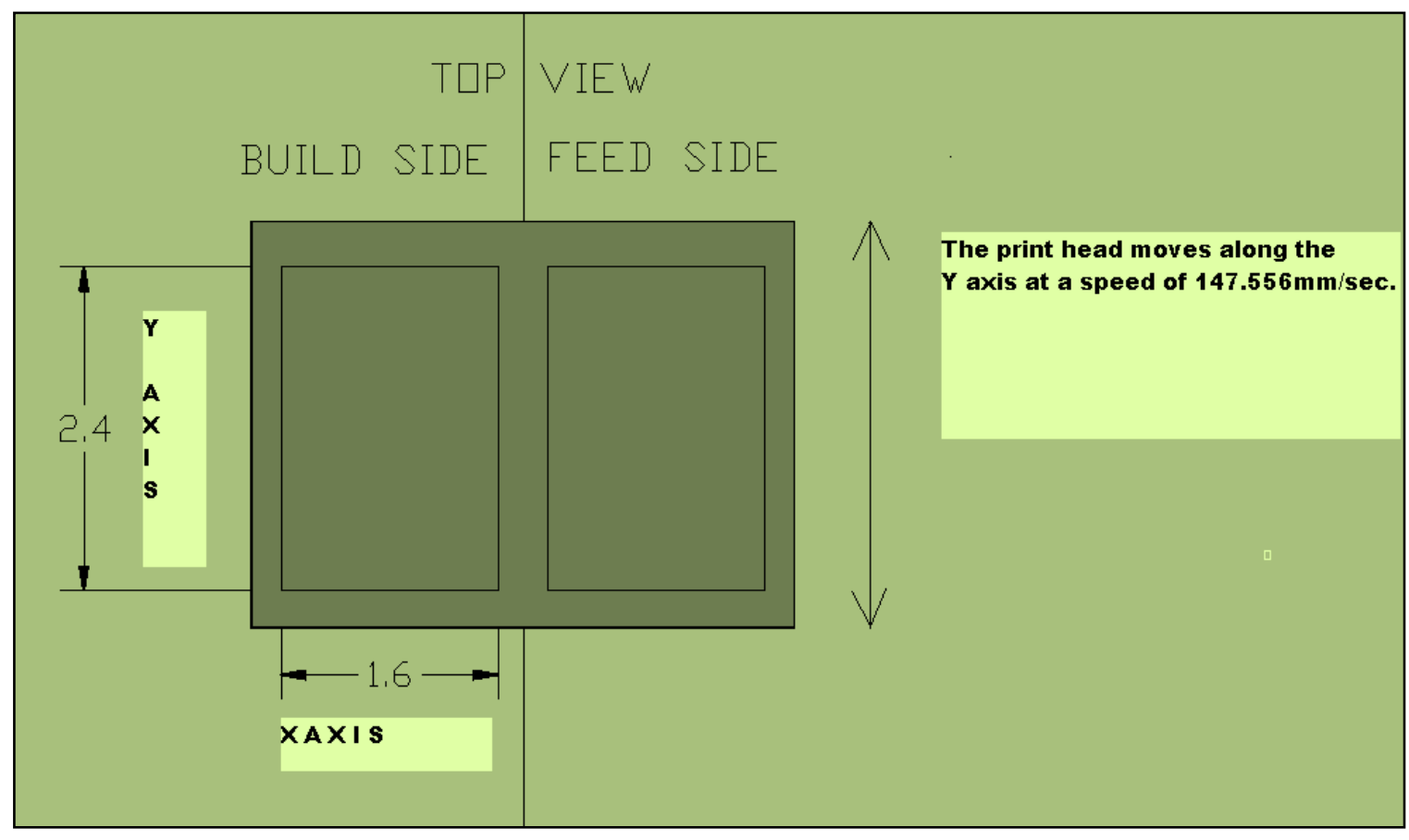

Figure 3.1: Top view of Print Bed: (All Dimensions are in Inches)

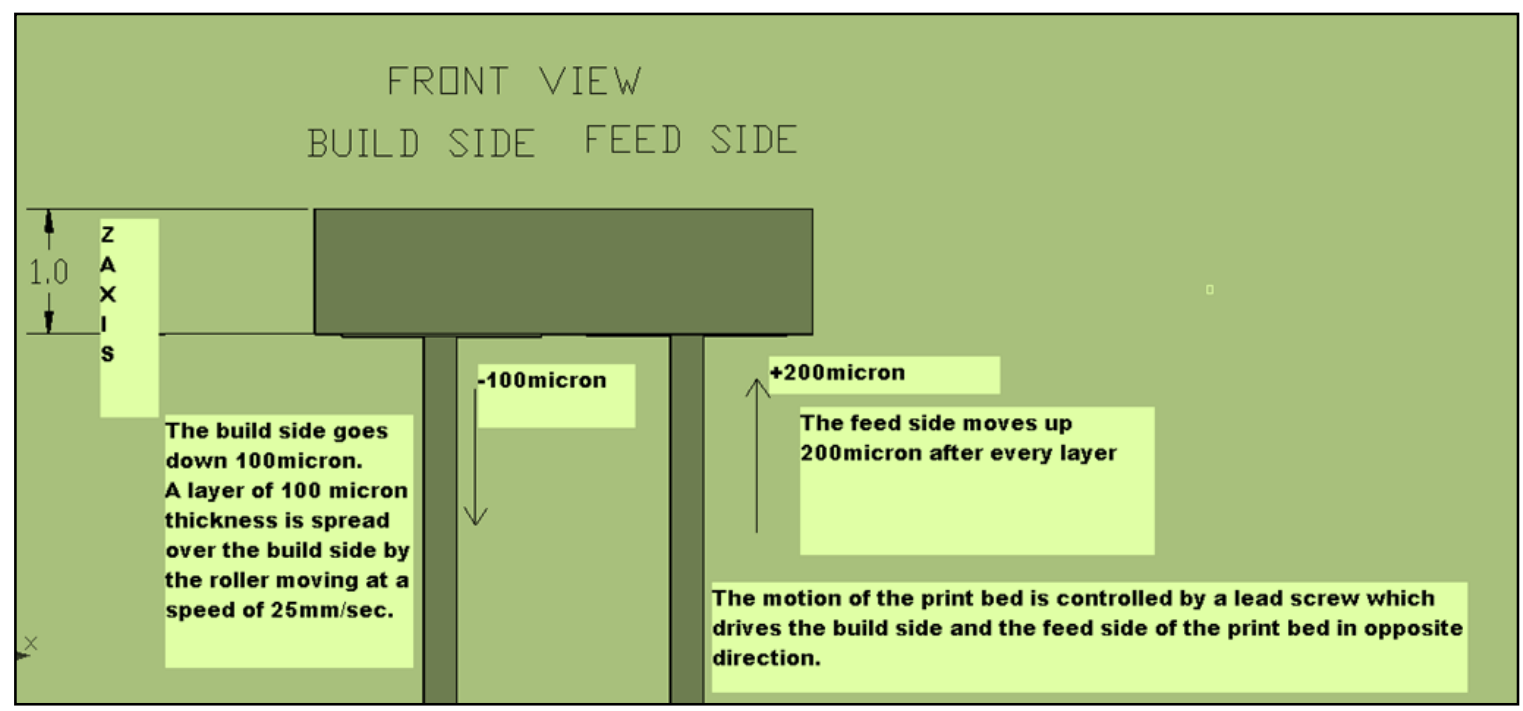

Figure 3.2: Front View of the Print Bed: (All Dimensions are in Inches)

7. Powder Packing Rate (\%): 55.000

8. Binder Density (g/ml): 1.02

9. Spreader Rapid Traverse speed (mm/sec): 25.0

10. Left spreader rapid traverse border(mm): 5.0

11. Right spreader rapid traverse border(mm): 5.0 
12. Spreader part traverse speed(mm/sec): 1.0

13. Feed powder to layer thickness ration: 2.00

14. Build/Feed retract distance(mm): 0.500

15. Drying Time: 20secs

16. Drying Power Control Setting (\%): 65

17. Heater Warm up time(sec): 60

18. Minimum Powder preheat time(sec): 240

19. Wiper Clean count: 2

20. Cap Clean Count: 1

21. Print Head Prime and Fire count: 1

22. Print Head Prime and Fire time(sec): 10

23. Cap Cleaning Frequency(Layers) : 1

24. Max time between cap cleaning (sec): 600

25. Wiper Cleaning Frequency(Layers): 5

26. Max time between wiper cleaning(sec): 600

27. Full Prime Frequency(Layers): 2

28. Max time between Primes(sec): 600

\subsection{Electronic Specifications:}

1. Capping Station Prime Pump, Capping Station Overflow Waste Pump, Wiper Waste Pump, Cleaner Pump:

$>$ PN: SP 200.004E

$>$ Pump: 70rpm, Silic-5

$>$ Voltage: 12VDC; $170 \mathrm{~mA}$

2. Cleaner to Cap Station Solenoid Valve, Cleaner to wiper Solenoid Valve:

$>$ 24VDC; Orifice:055

> Valve Number: GS2014-S46 


\subsection{Lab Experiment:}

Design a T shaped part in AutoCAD 2008 and produce the part using RX-1 Rapid Prototyping machine. Analyze the change in dimension with the change in the saturation level from $46.24 \%$ to $45 \%$, change in curing temperature from $350^{\circ} \mathrm{F}$ to $400^{\circ} \mathrm{F}$ and also change in curing time from 2 hrs to 2.5 hrs.

All dimensions used in the exercise are in Inches.

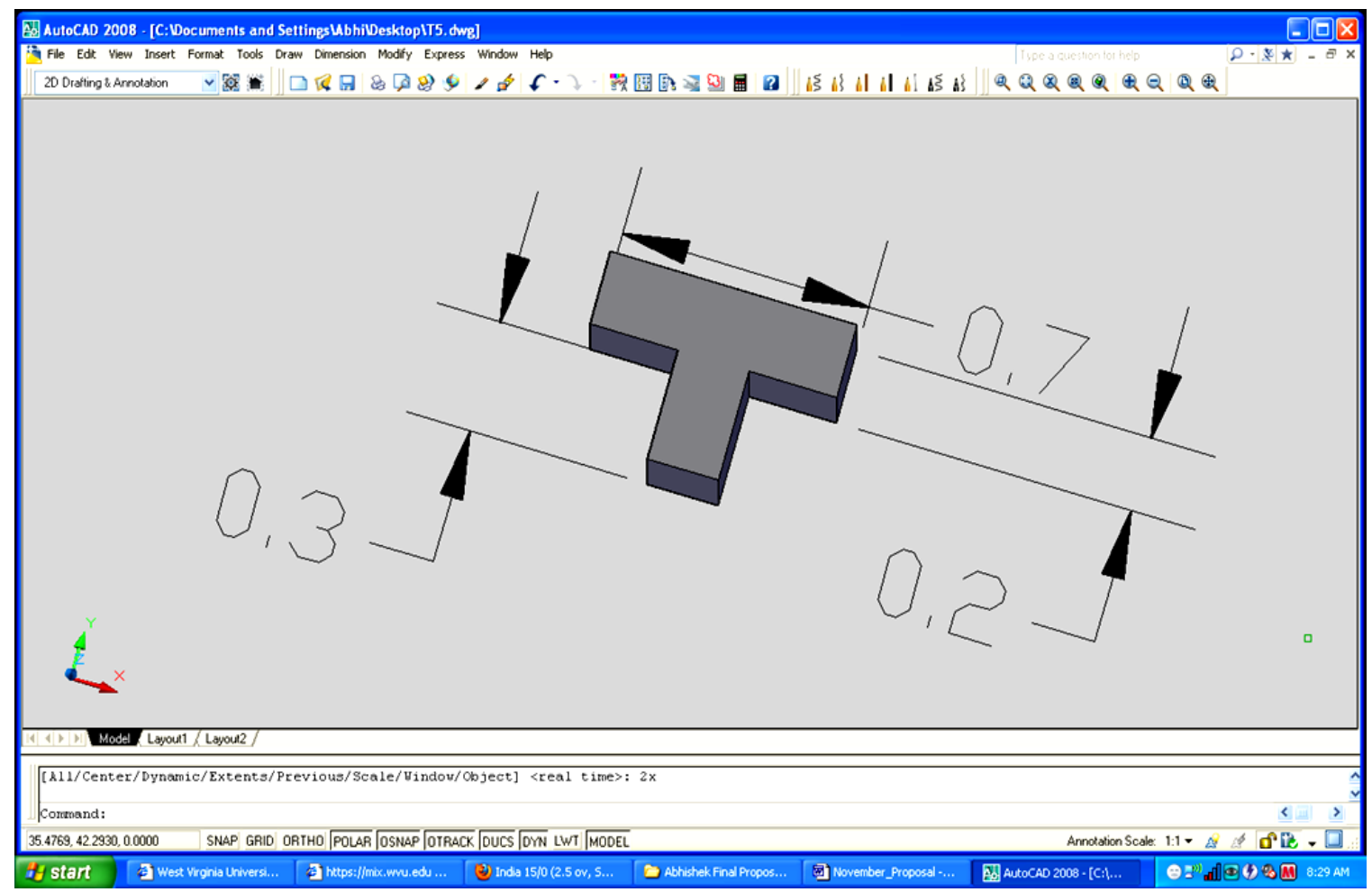

Figure 3.3: T Shape Part Dimensions 


\subsection{Rapid Prototyping Lab Flow Chart:}

The Rapid Prototyping lab follows the following procedure as shown in Figure 3.4:

1. The first and second steps are in which the part was designed and modeled using AutoCAD 2008 as shown in Appendix A.

2. Then the 3D model of the part was converted into an STL file as shown in the Figure A.9.

3. Since the experiment does not involve using any form of support this step was not utilized.

4. When the STL file was input into the system the Pro Metal software sliced the part itself to enable the fabrication process as shown in Figure B.8.

5. The RX-1 machine then generated its print head path and produced the part on the print bed.

6. The post production processes involve curing, sintering and infiltration which are discussed in the later chapters.

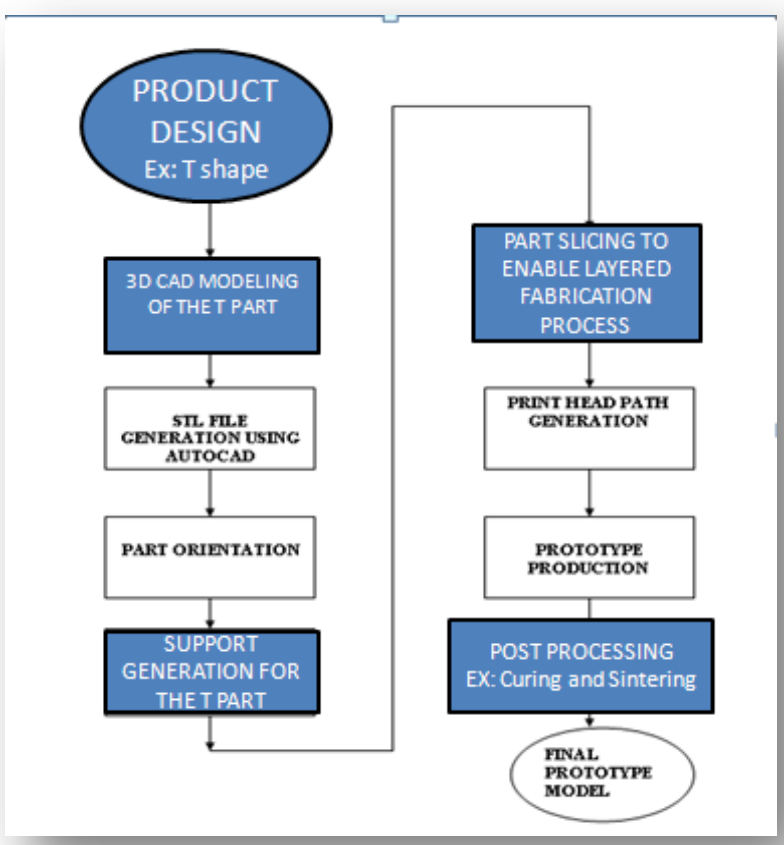

Figure 3.4: Rapid Prototyping Lab Format 


\subsection{Lab Procedure:}

1. Designed the part using AutoCAD 2008 and converted the file into an STL file format compatible with the RX-1 machine.

2. The part was then produced using RX-1 rapid prototyping machine using S4 Stainless steel powder.

3. The dimensions of the $\mathrm{T}$ part was pre defined; however the parts were measured after sintering to determine the effect of saturation level, curing time and curing temperature on the bonding of the Stainless Steel powder under the tool makers microscope. The change in the final dimensions of the part produced due to the part orientation was also analyzed.

4. The three different orientations of the part on the print bed are shown in Figure 3.5.

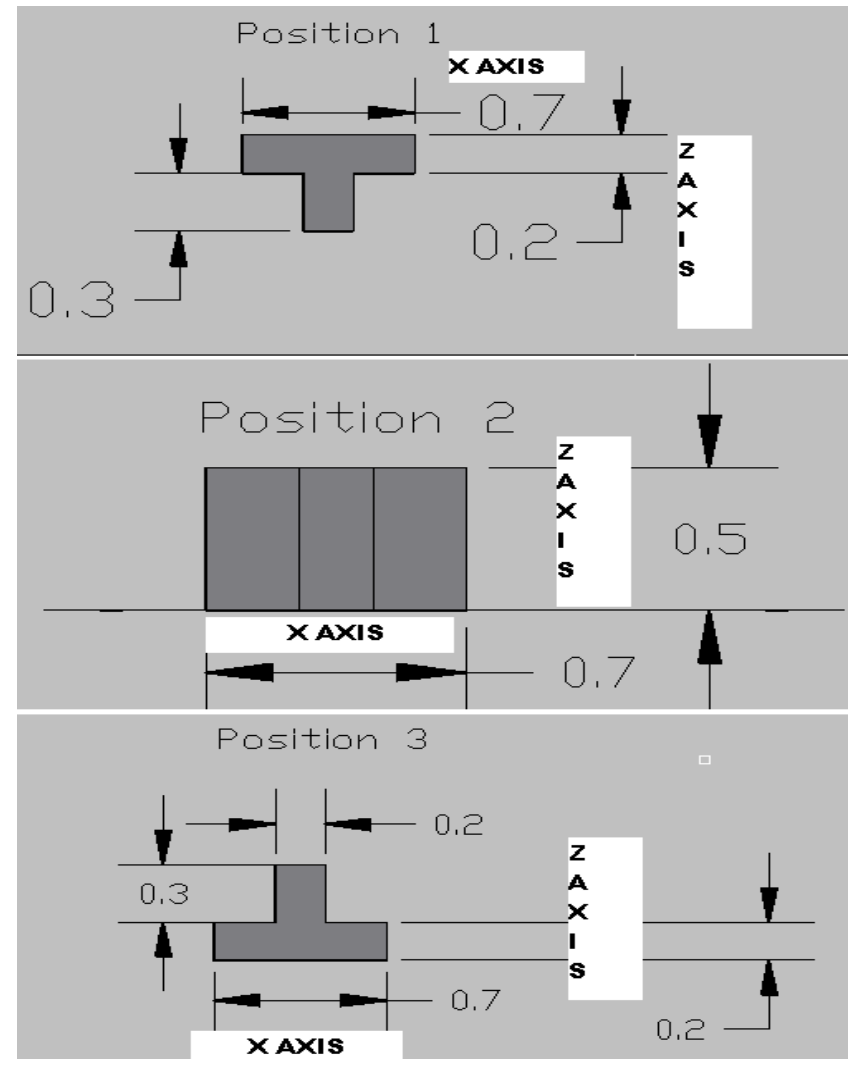

Figure 3.5: Part Orientation

Since printing is a time consuming process, the lab consists of two sessions. Lab session 1 involves designing and part printing. Lab session 2 involves part measurement and analysis. 


\subsubsection{Stage 1: Design(Lab Session 1)}

In this stage the $\mathrm{T}$ bracket is designed using AutoCAD 2008. Dimensions as shown in

Figure 3.6 were used to design the part.

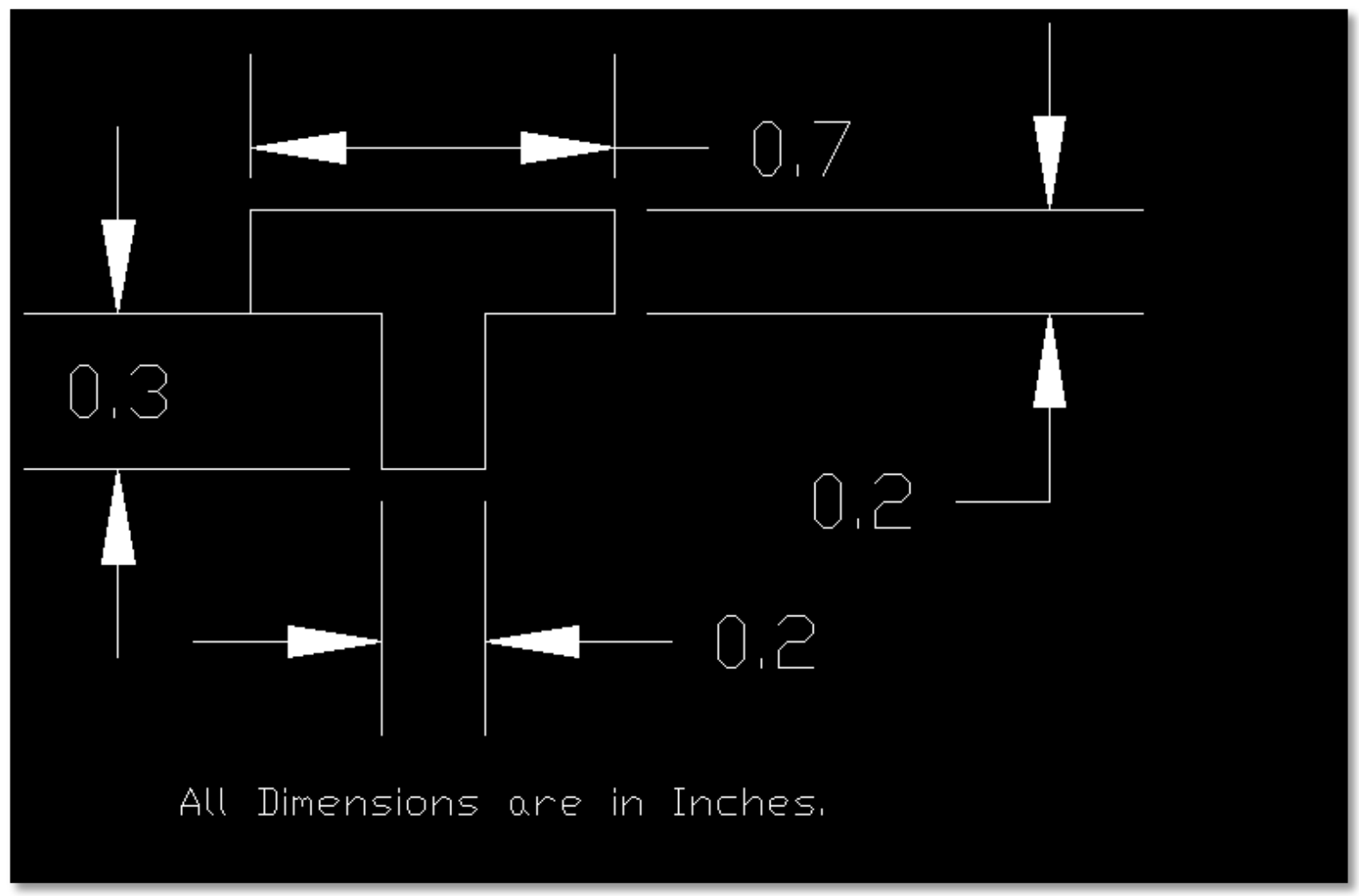

Figure 3.6: Part Dimensions

After the part is designed in AutoCAD 2008, the drawing is converted into an STL file which is the format compatible to the RX-1 Rapid Prototyping Machine.

\subsubsection{Stereolithography (STL) / Standard Tessellation Language}

Standard Tessellation Language (STL) or more commonly known as Stereolithography is a file format mostly used in Rapid Prototyping. The STL model is sliced into different layers each of which is printed by the RP machine in the process of producing the prototype. The layer thickness used to manufacture the part has an effect on the surface finish, layering error and the build time of the part.[17] 
In RX-1 Rapid Prototyping machine the layer thickness is 50micron. Since: 1 micron $=0.00003937$ inches, 50 microns $=0.0019685$ inches $\approx 0.002$ inches .

The sliced layers or planes are represented by straight horizontal lines, which cross the sides of triangular facets creating intersecting points all of which are joined to form slice contours. DeskArtes View Expert is software which enables to view the STL files and also gives a sketch of the triangular facets on the part being produced [19].

For example, as shown in figure 3.4 is the $\mathrm{T}$ shaped part being produced in Position 2 on the print bed a TOP VIEW on Desk Artes View Expert. Figure 3.8 shows the different triangular facets on the part.

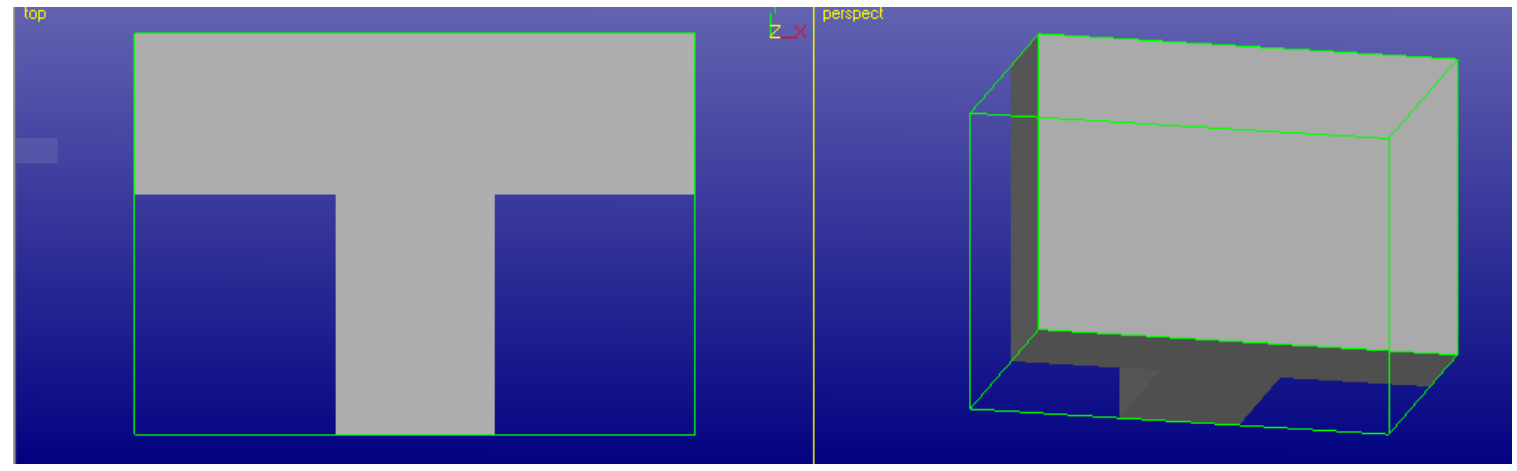

Figure 3.7: Top View (Position 2) Desk Artes View Expert

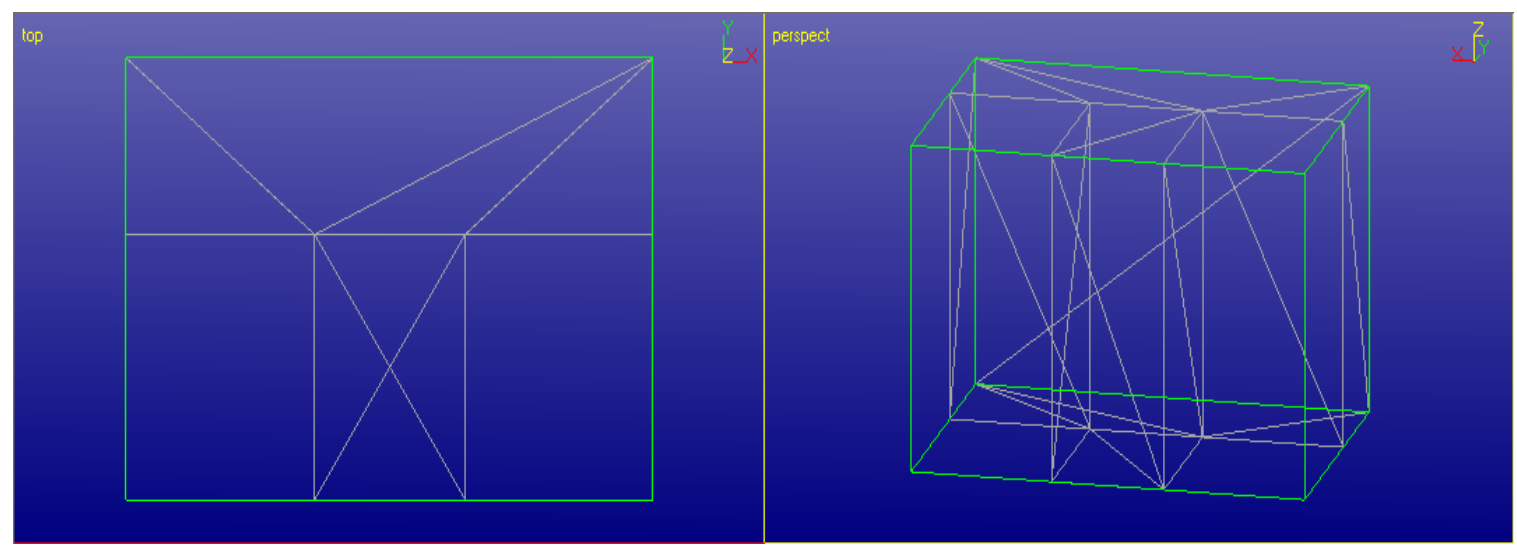

Figure 3.8: Triangular Facets on T shape part

STL file only describes the surface geometry of a 3D object without describing any other common attributes associated with the CAD model. An STL format defines the 
$\mathrm{XYZ}$ coordinates of the vertices for the triangles that describe the 3D object. Since the part produced in this experiment does not have any curves or smooth edges, even fewer triangles formed to define the surface geometry will give accurate data.

\subsubsection{Stage 2: Production (Lab Session 1)}

During the production stage the STL file of the 3D part is input into the RX-1 Rapid Prototyping Machine. The part was oriented in three positions defined earlier. Since the powdered metal used in the process was Stainless Steel S4 powder, the machine had an inbuilt scaling factor of 1.02 for the part in all the three directions (XYZ).

The part had a dimension of 0.7 " in the $\mathrm{X}$ direction, 0.5 ” in the $\mathrm{Y}$ direction and 0.5 " in the $\mathrm{Z}$ direction, the scaling factor of 1.02 would not allow the part to be completed with the amount of powder supply in the feed box. Therefore a new scaling factor of 0.8 was defined for the part only in the $\mathrm{Z}$ axis to enable the part to be completely printed.

The new scaled dimensions were $\mathrm{X}=0.714$ ", $\mathrm{Y}=0.51$ ” and $\mathrm{Z}=0.4$ ”. The reason for the scaling the parts to the new dimensions was to accommodate the expansion or shrinkage of the parts due to heat treatment of the green parts. The saturation level of the print head was set to $46.24 \%$ for the first set of parts produced whereas it was changed to $45 \%$ for the second set of the parts produced. A comparison between the parts with different saturation level is also discussed in the data analysis section.

\subsubsection{Saturation Level}

1. The saturation level of the machine is indicates the percentage of binder being deposited on the print bed.

2. The procedure to measure the saturation level has been explained in the TA version of the video demonstrations.

3. The machine automatically calculates the saturation level after the weight of the binder deposited and the number of missing jets have been entered into the system.

4. For the experiments and analysis there were two levels of saturation levels used $45 \%$ and $46.24 \%$. 
5. Higher saturation level indicates more binder being deposited on the print bed.

\subsubsection{Curing}

1. All parts produced during the printing process are green perform parts.

2. The parts contain approximately $60 \%$ volume stainless steel powder, $10 \%$ volume binder and the remaining $30 \%$ pores.

3. The green perform part were very fragile and were handled with care.

4. The green part underwent thermal processing to achieve desirable mechanical properties.

5. During the curing process the binder was dried which increased the green strength of the part considerably.

6. The first thermal process that the green part undergoes is that of curing in an oven at $350^{\circ} \mathrm{F}$ and for $2 \mathrm{hrs}$ for small parts such as the T shape part produced in the lab to about 4 hours for larger parts.

7. The desired temperature was $350^{\circ} \mathrm{F}$ however to analyze the effect of the curing temperature on the dimensions of the part the temperature was raised to $400^{\circ} \mathrm{F}$ and the analysis of the dimensions obtained from parts cured at that temperature has been discussed in the data analysis section.

8. The curing time was also a factor to be considered in post production. Analysis of dimensions due to change in the curing time from $350^{\circ} \mathrm{F}$ to $400^{\circ} \mathrm{F}$ has also been discussed in later chapters.

\subsubsection{Sintering}

1. Sintering is a key step in transforming the fragile green parts into high strength parts.

2. Even though curing dried up the binder, the sintering cycle burns out the polymer and the stainless steel powder sinters together to form the skeleton that will be infiltrated to full density by Bronze in the infiltration cycle.

3. Sintering involves heating the cured parts to high temperature of $1120^{\circ} \mathrm{C}$ where the particles weld to each other, almost similar to the formation of ice cubes in the refrigerator. 
4. In the sintering station the parts are supported by ceramic powder.

5. The sintering station creates an environment of low vacuum to the level of $7 \mathrm{~mm}$.

6. Then the parts were heat treated at a temperature of $1120^{\circ} \mathrm{C}$.

7. A combination of $96 \%$ Argon and $4 \%$ Hydrogen is used during the sintering process.

8. The first function of the sintering process is to remove the binder used for shaping/bonding the particles together.

9. The process pyrolysis means burning out the polymer binder.

10. In this stage the cured part is heated to a temperature where the polymer binder becomes unstable and evaporates.

11. Most binder used in these kinds of machines contains basic carbon-carbon, carbon-oxygen and carbon-hydrogen bonds.

12. The sintering process takes place in the Sintering Station displayed in the Figure 3.9

13. The sintering setting profile used is shown in Table 3.1

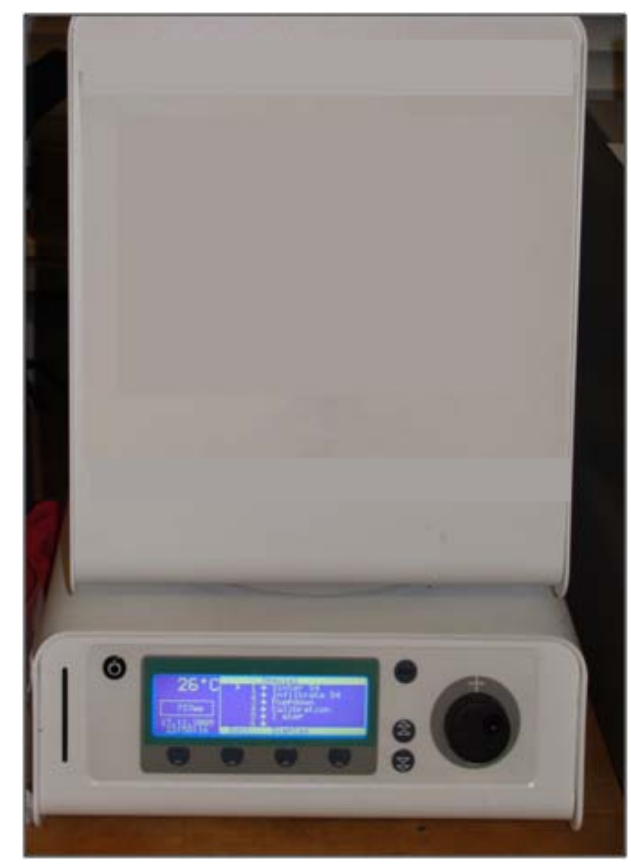

Figure 3.9: Sintering Station 
Table 3.1:Sintering Profile Used

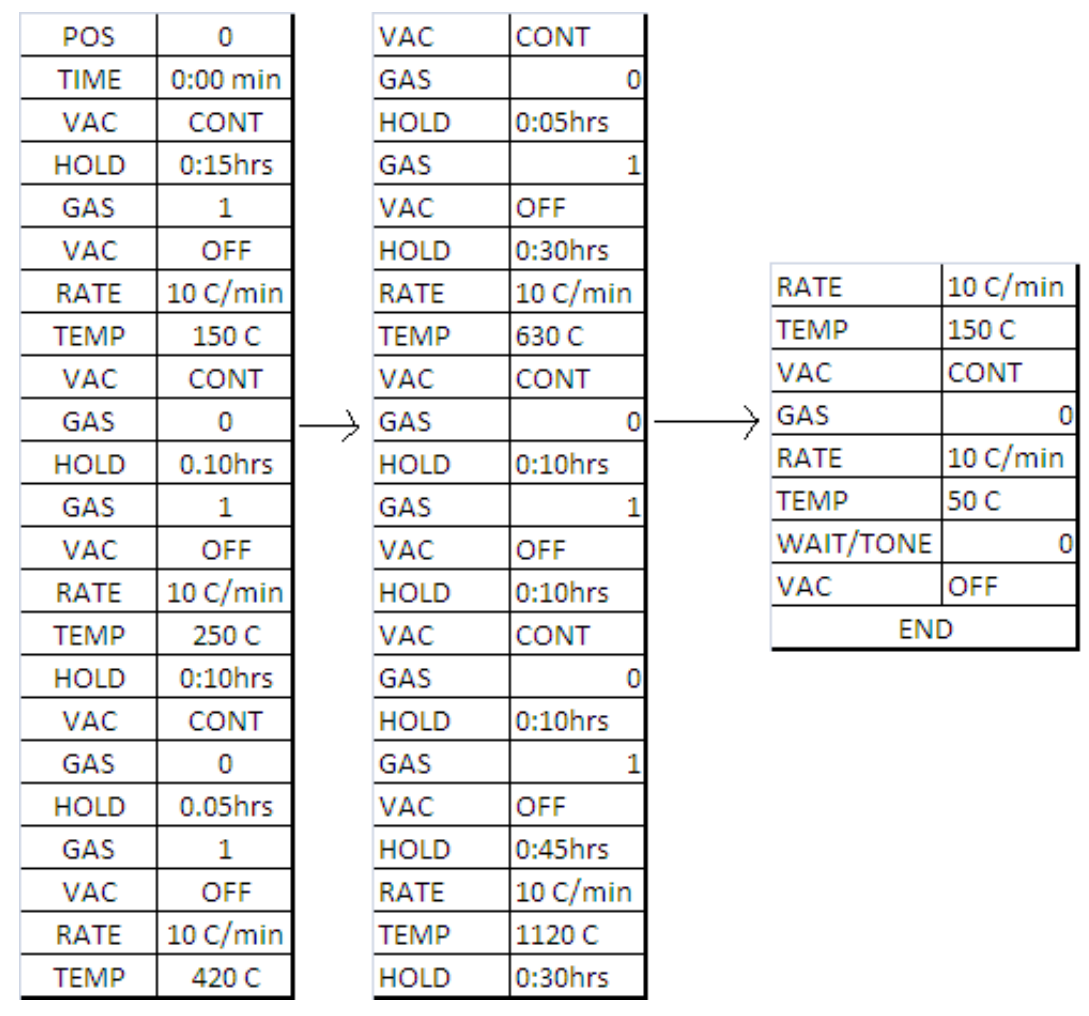

\subsubsection{Infiltration}

Infiltration is the third thermal process the green part undergoes. During the infiltration process the molten bronze flows into the steel structure through the surface pores leading to dense pore free compact part. There is a possibility of swelling during infiltration process. However, as the entire process of rapid prototyping is time consuming and to accommodate the concept into the lab, this section has not been included in this thesis. However the settings used on the sintering station to perform the infiltration process are shown in Table 3.2 and the formula to calculate the amount of infiltrant to be used is shown below:

Amount of infiltrant $=0.86 *$ (Weight of the sintered or green part + Weight of any support material) 


\section{Table 3.2:Infiltration Settings}

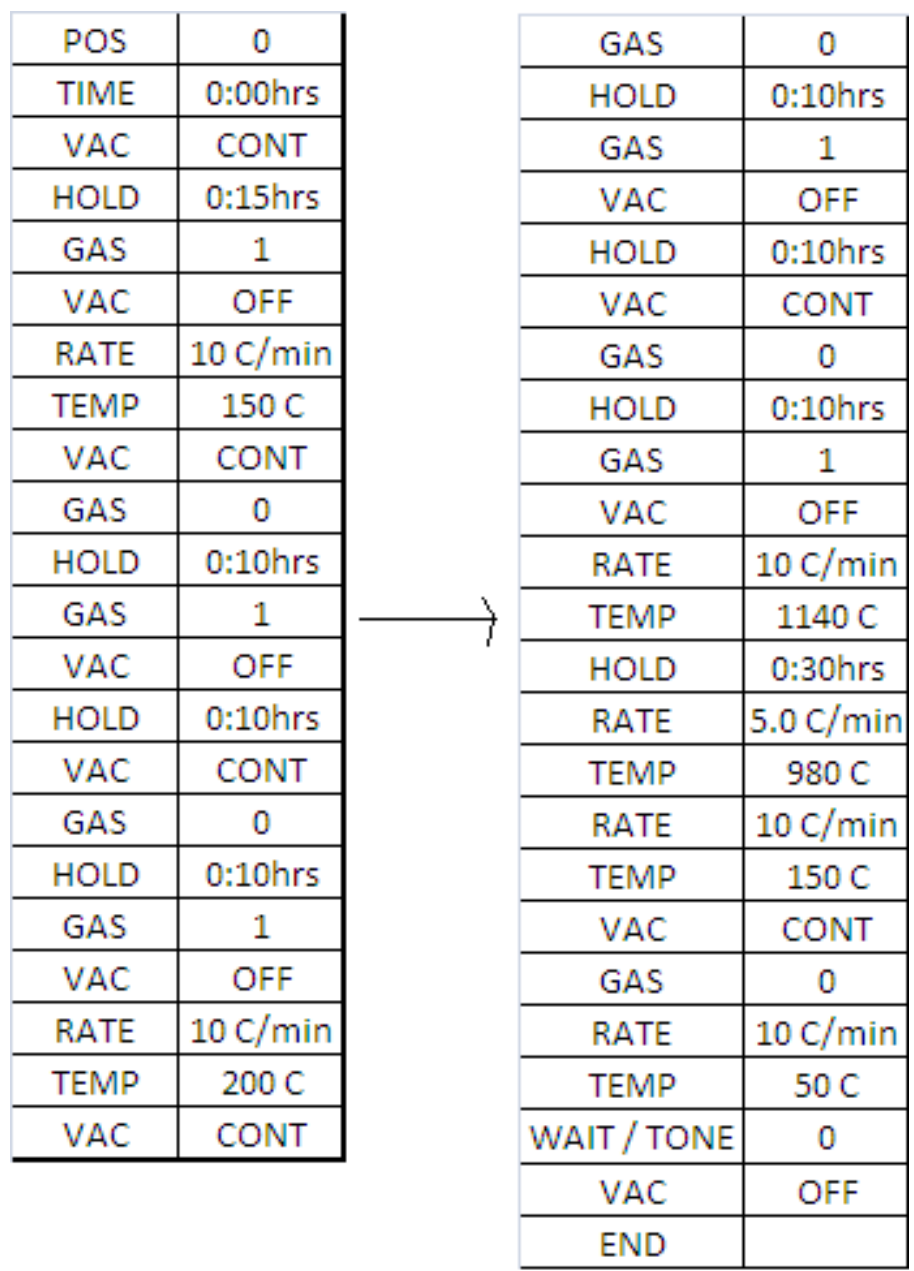

\subsubsection{One Step Process}

In one step process, both the sintering and infiltration are carried out at the same time. The green parts after curing are placed in the crucible with the calculated amount of the infiltrant and this process is selected on the sintering station.

The settings to be used on the sintering station are as shown in the Table 3.3 
Table 3.3:One Step Settings

\begin{tabular}{|c|c|c|c|}
\hline RATE & $10 \mathrm{c} / \mathrm{min}$ & VAC & CONT \\
\hline TEMP & $150 \mathrm{C}$ & GAS & 0 \\
\hline VAC & CONT & HOLD & $0: 10 \mathrm{hrs}$ \\
\hline GAS & 0 & GAS & 1 \\
\hline HOLD & $0: 10 \mathrm{hrs}$ & VAC & OFF \\
\hline GAS & 1 & HOLD & $0: 10 \mathrm{hrs}$ \\
\hline VAC & OFF & VAC & CONT \\
\hline RATE & $10 \mathrm{c} / \mathrm{min}$ & GAS & 0 \\
\hline TEMP & $250 \mathrm{C}$ & HOLD & $0: 10 \mathrm{hrs}$ \\
\hline HOLD & $0: 10 \mathrm{hrs}$ & GAS & 1 \\
\hline VAC & CONT & VAC & OFF \\
\hline GAS & 0 & HOLD & $0: 45 \mathrm{hrs}$ \\
\hline HOLD & 0:05hrs & RATE & $10 \mathrm{c} / \mathrm{min}$ \\
\hline GAS & $\begin{array}{r}1 \\
\end{array}$ & TEMP & $1140 \mathrm{C}$ \\
\hline VAC & OFF & HOLD & $0: 30 \mathrm{hrs}$ \\
\hline RATE & $10 \mathrm{c} / \mathrm{min}$ & RATE & $10 \mathrm{c} / \mathrm{min}$ \\
\hline TEMP & $420 \mathrm{C}$ & TEMP & $150 \mathrm{C}$ \\
\hline VAC & CONT & VAC & CONT \\
\hline GAS & 0 & GAS & 0 \\
\hline & & RATE & $10 \mathrm{c} / \mathrm{min}$ \\
\hline & & TEMP & $50 \mathrm{C}$ \\
\hline & & WAIT / TONE & 0 \\
\hline & & VAC & OFF \\
\hline & & END & \\
\hline
\end{tabular}

\subsection{Data: Lab Session 2}

The experiment was to produce $\mathrm{T}$ shape parts of the desired dimension, using the RX-1 machine and analyzing the change in dimensions of the parts produced after sintering by varying the saturation level, curing temperature and curing time. The parts were oriented in three different positions on the print bed as shown in Figure 3.3 on page 22. The dimensions of the parts in $\mathrm{X}, \mathrm{Y}$ and $\mathrm{Z}$ directions were measured using the tool makers microscope available in the Manufacturing Processes Lab located in G85 Engineering Science Building at WVU. 


\subsubsection{Run1:}

This run was performed at a saturation level of $46.24 \%$, curing temperature of $350^{\circ} \mathrm{F}$ and curing time of $2 \mathrm{hrs}$.

Results: All dimensions are in Inches.

Table 3.4:Run 1: Dimensions

\begin{tabular}{|c|c|c|}
\hline $\begin{array}{c}\text { Actual } \\
\text { dimensions }\end{array}$ & $\begin{array}{c}\text { Scaling } \\
\text { factor }\end{array}$ & $\begin{array}{c}\text { Scaled } \\
\text { dimensions }\end{array}$ \\
\hline $0.7 ”$ & 1.02 & $0.714 ”$ \\
\hline $0.5 ”$ & 1.02 & $0.51 ”$ \\
\hline $0.5 ”$ & 0.8 & $0.4 ”$ \\
\hline
\end{tabular}

Table 3.5:Run 1: Print Conditions

\begin{tabular}{|c|c|}
\hline Saturation Level & $46.24 \%$ \\
\hline Curing Temp & $350^{\circ} \mathrm{F}$ \\
\hline Curing Time & $2 \mathrm{hrs}$ \\
\hline
\end{tabular}

Table 3.6:Run 1: Position 1

\begin{tabular}{|c|c|c|c|}
\hline \multicolumn{2}{|l|}{ Position 1 } & \multicolumn{2}{l|}{} \\
\hline \multicolumn{2}{|c|}{ Dimensions after sintering } & Average \\
\hline X & $0.7268 ”$ & $0.7309 ”$ & $0.72885 ”$ \\
\hline Y & $0.5407 ”$ & $0.5282 ”$ & $0.53445 ”$ \\
\hline \multirow{2}{*}{ Z } & $0.4014 ”$ & $0.4019 ”$ & \\
\cline { 2 - 3 } & $0.4035 ”$ & $0.4023 ”$ & $0.402275 ”$ \\
\hline
\end{tabular}

Table 3.7:Run 1:Position 2

\begin{tabular}{|c|c|c|c|}
\hline \multicolumn{2}{|c|}{ Position 2 } & \multicolumn{2}{l|}{} \\
\hline \multicolumn{2}{|c|}{ Dimensions after sintering } & Average \\
\hline X & $0.7261 ”$ & $0.7244 ”$ & $0.72525 ”$ \\
\hline Y & $0.5161 ”$ & $0.5169 ”$ & $0.5165 ”$ \\
\hline \multirow{2}{*}{$Z$} & $0.4246 ”$ & $0.4102 ”$ & \multirow{2}{*}{$0.41295 ”$} \\
\cline { 2 - 4 } & $0.3990 ”$ & $0.4180 ”$ & \\
\hline
\end{tabular}


Table 3.8:Run 1: Position 3

\begin{tabular}{|c|c|c|c|}
\hline Position 3 & \multicolumn{2}{|c|}{} \\
\hline \multicolumn{2}{|c|}{ Dimensions after sintering } & Average \\
\hline X & $0.7249 ”$ & $0.7374 ”$ & $0.73115 ”$ \\
\hline Y & $0.5229 ”$ & $0.5276 ”$ & $0.52525 ”$ \\
\hline \multirow{2}{*}{ Z } & $0.4061 ”$ & $0.4092 ”$ & \multirow{2}{*}{$0.4074 ”$} \\
\cline { 2 - 3 } & $0.4078 ”$ & $0.4065 ”$ & \\
\hline
\end{tabular}

Final Averages of Dimensions at Run1:

Table 3.9:Run 1: Final Average Dimensions

\begin{tabular}{|l|c|c|c|}
\hline & X & Y & Z \\
\hline Position 1 & $0.72885 ”$ & $0.53445 ”$ & $0.402275 ”$ \\
\hline Position 2 & $0.72525 ”$ & $0.5165 ”$ & 0.41295 \\
\hline Position 3 & $0.73115 ”$ & $0.52525 ”$ & $0.4074 ”$ \\
\hline
\end{tabular}

Difference in Dimensions $(\Delta)$ : Dimensions after sintering - Scaled Dimensions.

Ex: Position $1 \Delta \mathrm{X} 1=0.72885-0.714=0.01485$

Position $2 \Delta$ Y $2=0.5165-0.51=0.0065$

Position $3 \Delta \mathrm{Z} 3=0.4074-0.4=0.0074$

$$
\text { Mean }(\Delta X)=(\Delta X 1+\Delta X 2+\Delta X 3) / 3
$$

Standard Deviation $=\sqrt{\Sigma(X \boldsymbol{x}-\mathbf{\Delta X})^{\wedge} \mathbf{2}} /(\mathbf{n}-\mathbf{1})$

$$
\% \text { Change }=\{(\text { Mean } \Delta X) / \text { Scaled Dimension }\} * 100
$$

Ex: \% Change $X=\{(0.014417) / 0.714\} * 100=2.02 \%$

$$
\mathrm{n}=1,2,3
$$

Table 3.10:Run 1: Change in Dimensions

\begin{tabular}{|c|c|c|c|}
\hline$\Delta$ & X & Y & Z \\
\hline Position 1 & 0.01485 & $0.02445 ”$ & $0.002275 ”$ \\
\hline Position 2 & $0.01125 ”$ & $0.0065 ”$ & $0.01295 ”$ \\
\hline Position 3 & $0.01715 ”$ & $0.01525 ”$ & $0.0074 ”$ \\
\hline Mean & $0.014417 ”$ & $0.0154 ”$ & $0.007542 ”$ \\
\hline St Deviation & 0.002974 & 0.008976 & 0.005339 \\
\hline \% Change & $2.02 \%$ & $3.02 \%$ & $1.89 \%$ \\
\hline
\end{tabular}




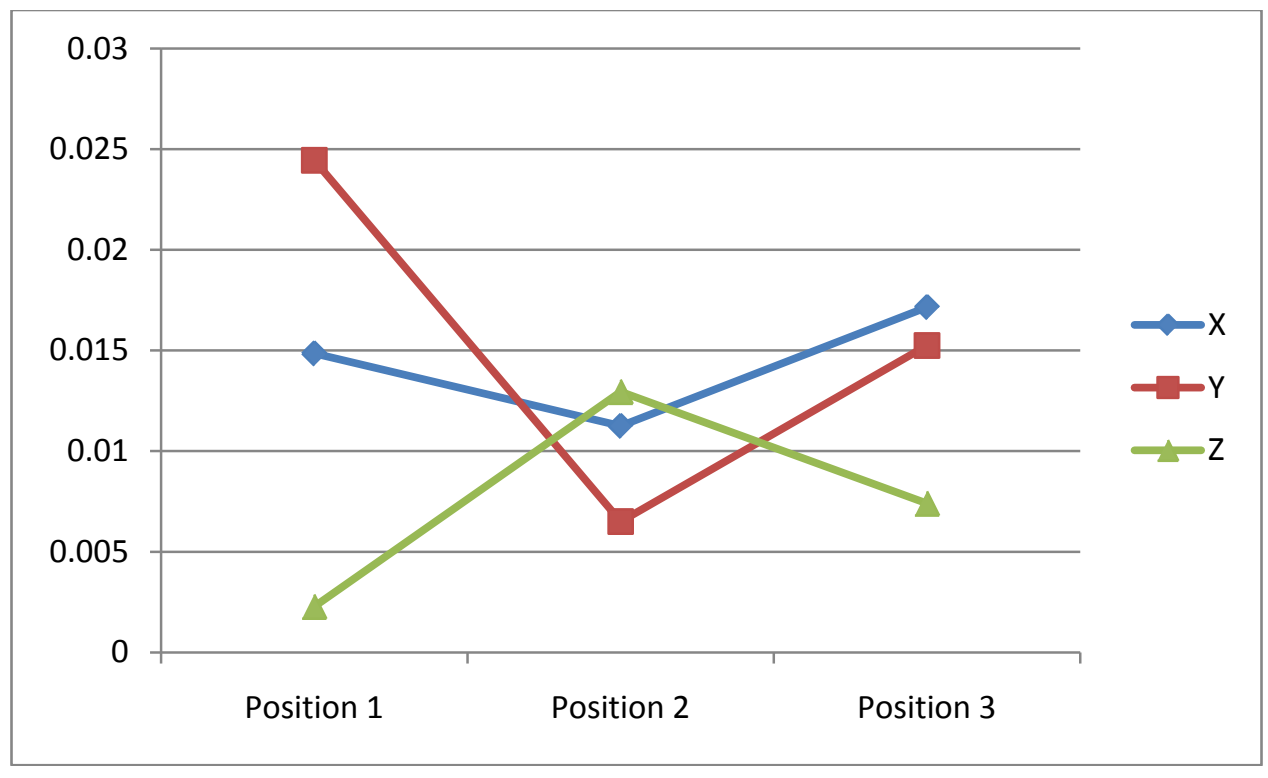

Figure 3.10 Run 1: Change in Dimension vs Part Orientation.

Based on the results obtained in the first run and the Figure 3.10 it was observed that at high saturation level of $46.24 \%$ and low curing temperature of $350^{\circ} \mathrm{F}$ and curing time of 2 hrs the change in dimension in the X direction was found to be 0.01485 and 0.01715 for position 1 and 3 respectively. For the Y direction it was found to be 0.02445 and 0.01525 for position 1 and 3 respectively. However for the same position along the $\mathrm{Z}$ direction the change in dimension was 0.002275 and 0.007542 respectively which is lower compared to the change in other two directions. Therefore it is observed that since the part is built along the $\mathrm{Z}$ axis the expansion along the $\mathrm{Z}$ direction is lower due to the weight of the part itself. Hence it can be concluded that part orientation effects the change in dimension of the part at higher saturation level, lower curing temperature and lower curing time.

\subsubsection{Run 2:}

This run was performed at a saturation level of $46.24 \%$, temperature of $400^{\circ} \mathrm{F}$ and curing time of 2.5 hrs.

\section{Results: All dimensions are in Inches.}


Table 3.11:Run 2: Dimensions

\begin{tabular}{|c|c|c|}
\hline $\begin{array}{c}\text { Actual } \\
\text { dimensions }\end{array}$ & $\begin{array}{c}\text { Scaling } \\
\text { factor }\end{array}$ & $\begin{array}{c}\text { Scaled } \\
\text { dimensions }\end{array}$ \\
\hline $0.7 ”$ & 1.02 & $0.714 ”$ \\
\hline $0.5 ”$ & 1.02 & $0.51 ”$ \\
\hline $0.5 ”$ & 0.8 & $0.4 ”$ \\
\hline
\end{tabular}

Table 3.12:Run 2: Print Conditions

\begin{tabular}{|c|c|}
\hline $\begin{array}{c}\text { Saturation } \\
\text { Level }\end{array}$ & $46.24 \%$ \\
\hline Curing Temp & $400^{\circ} \mathrm{F}$ \\
\hline Curing Time & $2.5 \mathrm{hrs}$ \\
\hline
\end{tabular}

Table 3.13:Run 2: Position 1

\begin{tabular}{|c|l|l|c|}
\hline Position 1 & \multicolumn{3}{|c|}{} \\
\hline \multicolumn{2}{|c|}{ Dimensions after sintering } & Average \\
\hline $\mathrm{X}$ & $0.7381 ”$ & $0.7395 ”$ & $0.7388 ”$ \\
\hline $\mathrm{Y}$ & $0.5274 ”$ & $0.5277 ”$ & $0.52755 ”$ \\
\hline \multirow{2}{*}{$\mathrm{Z}$} & $0.4446 ”$ & $0.4457 ”$ & \multirow{2}{*}{$0.43625 ”$} \\
\cline { 2 - 3 } & $0.4422 ”$ & $0.4125 ”$ & \\
\hline
\end{tabular}

Table 3.14:Run 2: Position 2

\begin{tabular}{|c|l|l|c|}
\hline \multicolumn{2}{|c|}{ Position 2 } & \multicolumn{2}{|c|}{} \\
\hline \multicolumn{2}{|c|}{ Dimensions after sintering } & Average \\
\hline X & $0.7344 ”$ & $0.7391 ”$ & $0.73675 ”$ \\
\hline Y & $0.5334 ”$ & $0.5325 ”$ & $0.53295 ”$ \\
\hline \multirow{2}{*}{ Z } & $0.4441 ”$ & $0.4415 ”$ & \multirow{2}{*}{$0.441425 ”$} \\
\cline { 2 - 3 } & $0.4409 ”$ & $0.4392 ”$ & \\
\hline
\end{tabular}


Table 3.15: Run 2: Position 3

\begin{tabular}{|c|c|c|c|}
\hline Position 3 & \multicolumn{3}{|l|}{} \\
\hline \multicolumn{2}{|c|}{ Dimensions after sintering } & Average \\
\hline X & $0.7407 ”$ & $0.7395 ”$ & $0.7401 ”$ \\
\hline Y & $0.5302 ”$ & $0.5272 ”$ & $0.5287 ”$ \\
\hline \multirow{2}{*}{$Z$} & $0.4271 ”$ & $0.4247 ”$ & \\
\cline { 2 - 4 } & $0.4101 ”$ & $0.4128 ”$ & $0.418675 ”$ \\
\hline
\end{tabular}

Final Averages of Dimensions at Run2:

Table 3.16:Run 2: Final Average Dimensions

\begin{tabular}{|c|c|c|c|}
\hline & X & Y & Z \\
\hline Position 1 & $0.7388 ”$ & $0.52755 ”$ & $0.43625 ”$ \\
\hline Position 2 & $0.73675 ”$ & $0.53295 ”$ & $0.441425 ”$ \\
\hline Position 3 & $0.7401 ”$ & $0.5287 ”$ & $0.418675 ”$ \\
\hline
\end{tabular}

Difference in Dimensions $(\Delta)$ : Dimensions after sintering - Scaled Dimensions.

Ex: Position $1 \Delta \mathrm{X} 1=0.7388-0.714=0.0248$

Position $2 \Delta \mathrm{Y} 2=0.53295-0.51=0.02295$

Position $3 \Delta \mathrm{Z} 3=0.418675-0.4=0.018675$

$$
\text { Mean }(\Delta X)=(\Delta X 1+\Delta X 2+\Delta X 3) / 3
$$

Standard Deviation $=\sqrt{\boldsymbol{\Sigma}(\boldsymbol{X} \boldsymbol{n}-\boldsymbol{\Delta} \mathbf{X})^{\wedge} \mathbf{2}} /(\mathbf{n}-\mathbf{1})$

$$
\mathrm{n}=1,2,3
$$

$$
\% \text { Change }=\{(\text { Mean } \Delta \mathrm{X}) / \text { Scaled Dimension }\} * 100
$$

Ex: \% Change $X=\{(0.02455) / 0.714\} * 100=3.44 \%$

Table 3.17:Run 2: Change in Dimensions

\begin{tabular}{|c|c|c|c|}
\hline$\Delta$ & X & Y & Z \\
\hline Position 1 & $0.0248 ”$ & $0.01755 ”$ & $0.03625 ”$ \\
\hline Position 2 & $0.02275 ”$ & $0.02295 ”$ & $0.041425 ”$ \\
\hline Position 3 & $0.02610 ”$ & $0.0187 ”$ & $0.018675 ”$ \\
\hline Mean & $0.02455 ”$ & $0.019733 ”$ & $0.032117 ”$ \\
\hline St Deviation & 0.001689 & 0.002844 & 0.011925 \\
\hline \% Change & $3.44 \%$ & $3.87 \%$ & $8.03 \%$ \\
\hline
\end{tabular}




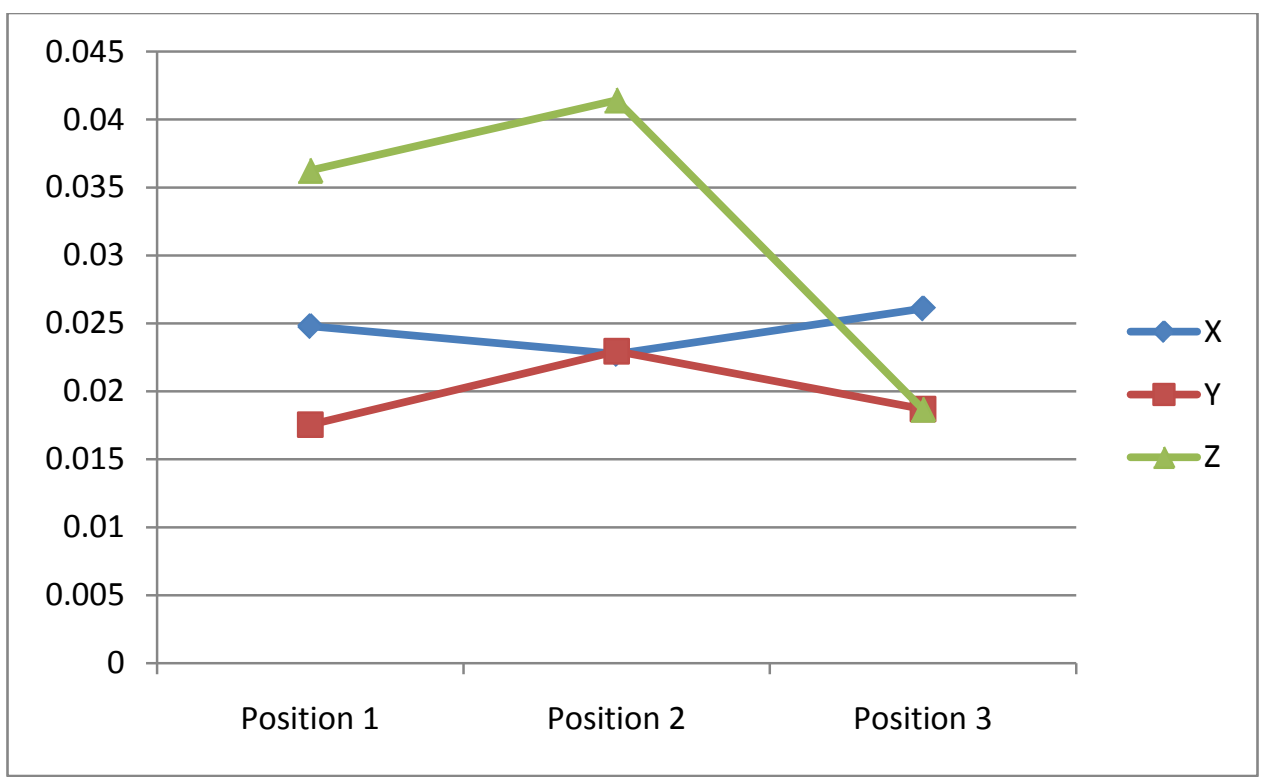

Figure 3.11:Run 2: Change in Dimensions vs Part Orientation

Based on the data obtained and the Figure 3.11 it may be observed that at higher saturation level of $46.24 \%$, higher curing temperature of $400^{\circ} \mathrm{F}$ and higher time of $2.5 \mathrm{hrs}$, the change in dimension in the $\mathrm{Z}$ direction is similar for Position 1 and 2. This means that with increase in time and temperature the expansion increases along the $\mathrm{Z}$ axis where as the expansion of the part comparatively lower in the $\mathrm{X}$ and $\mathrm{Y}$ direction.

\subsubsection{Run 3:}

This run was performed at a saturation level of $46.24 \%$, temperature of $400^{\circ} \mathrm{F}$ and curing time of 2 hrs.

\section{Results: All dimensions are in Inches.}

Table 3.18:Run 3: Dimensions

\begin{tabular}{|c|c|c|}
\hline $\begin{array}{c}\text { Actual } \\
\text { dimensions }\end{array}$ & $\begin{array}{c}\text { Scaling } \\
\text { factor }\end{array}$ & $\begin{array}{c}\text { Scaled } \\
\text { dimensions }\end{array}$ \\
\hline $0.7 ”$ & 1.02 & $0.714 ”$ \\
\hline $0.5 ”$ & 1.02 & $0.51 ”$ \\
\hline $0.5 ”$ & 0.8 & $0.4 ”$ \\
\hline
\end{tabular}


Table 3.19:Run 3: Print Conditions

\begin{tabular}{|c|c|}
\hline Saturation Level & $46.24 \%$ \\
\hline Curing Temp & $400^{\circ} \mathrm{F}$ \\
\hline Curing Time & $2 \mathrm{hrs}$ \\
\hline
\end{tabular}

Table 3.20:Run 3: Position 1

\begin{tabular}{|c|c|c|c|}
\hline \multicolumn{2}{|c|}{ Position 1 } & \multicolumn{2}{l|}{} \\
\hline \multicolumn{2}{|c|}{ Dimensions after sintering } & Average \\
\hline X & $0.7248 ”$ & $0.7276 ”$ & $0.7262 ”$ \\
\hline Y & $0.5427 ”$ & $0.5432 ”$ & $0.54295 ”$ \\
\hline \multirow{2}{*}{ Z } & $0.4046 ”$ & $0.4073 ”$ & \multirow{2}{*}{$0.406075 ”$} \\
\cline { 2 - 3 } & $0.4095 ”$ & $0.4029 ”$ & \\
\hline
\end{tabular}

Table 3.21:Run 3: Position 2

\begin{tabular}{|c|c|c|c|}
\hline \multicolumn{2}{|c|}{ Position 2 } & \multicolumn{2}{|c|}{} \\
\hline \multicolumn{2}{|c|}{ Dimensions after sintering } & Average \\
\hline X & $0.7286 ”$ & $0.7282 ”$ & $0.7284 ”$ \\
\hline Y & $0.5400 ”$ & $0.5403 ”$ & $0.54015 ”$ \\
\hline \multirow{2}{*}{ Z } & $0.4086 ”$ & $0.4098 ”$ & \multirow{2}{*}{$0.4101 ”$} \\
\cline { 2 - 3 } & $0.4139 ”$ & $0.4081 ”$ & \\
\hline
\end{tabular}

Table 3.22:Run 3: Position 3

\begin{tabular}{|c|c|c|c|}
\hline \multicolumn{2}{|c|}{ Position 3 } & \multicolumn{2}{|c|}{} \\
\hline \multicolumn{2}{|c|}{ Dimensions after sintering } & Average \\
\hline X & $0.7316 ”$ & $0.7348 ”$ & $0.7332 ”$ \\
\hline Y & $0.5227 ”$ & $0.5249 ”$ & $0.5238 ”$ \\
\hline \multirow{2}{*}{ Z } & $0.4111 ”$ & $0.4120 ”$ & \multirow{2}{*}{$0.418475 ”$} \\
\cline { 2 - 3 } & $0.4298 ”$ & $0.4210 ”$ & \\
\hline
\end{tabular}


Final Averages of Dimensions at Run3:

Table 3.23:Run 3: Final Average Dimensions

\begin{tabular}{|c|c|c|c|}
\hline & X & Y & Z \\
\hline Position 1 & $0.7262 ”$ & $0.54295 ”$ & $0.406075 ”$ \\
\hline Position 2 & $0.7284 ”$ & $0.54015 ”$ & $0.4101 ”$ \\
\hline Position 3 & $0.7332 ”$ & $0.5238 ”$ & $0.418475 ”$ \\
\hline
\end{tabular}

Difference in Dimensions $(\Delta)$ : Dimensions after sintering - Scaled Dimensions.

Ex: Position $1 \Delta \mathrm{X} 1=0.7262-0.714=0.0122$

Position $2 \Delta$ Y $2=0.54015-0.51=0.03015$

Position $3 \Delta \mathrm{Z} 3=0.418475-0.4=0.018475$

$$
\text { Mean }(\Delta X)=(\Delta X 1+\Delta X 2+\Delta X 3) / 3
$$

Standard Deviation $=\sqrt{\boldsymbol{\Sigma}(\boldsymbol{X} \boldsymbol{n}-\mathbf{\Delta} \mathbf{X})^{\wedge} \mathbf{2}} /(\mathbf{n}-\mathbf{1})$

$$
\mathrm{n}=1,2,3
$$$$
\% \text { Change }=\{(\text { Mean } \Delta X) / \text { Scaled Dimension }\} * 100
$$

Ex: \% Change $X=\{(0.015267) / 0.714\} * 100=2.14 \%$

Table 3.24:Run 3: Change in Dimensions

\begin{tabular}{|c|c|c|c|}
\hline $\boldsymbol{\Delta}$ & $\mathrm{X}$ & $\mathrm{Y}$ & $\mathrm{Z}$ \\
\hline Position 1 & $0.0122 ”$ & $0.03295 ”$ & $0.006075 ”$ \\
\hline Position 2 & $0.0144 ”$ & $0.03015 ”$ & $0.0101 ”$ \\
\hline Position 3 & $0.0192 ”$ & $0.0138 ”$ & $0.018475 ”$ \\
\hline Mean & $0.015267 ”$ & $0.025633 ”$ & $0.01155 ”$ \\
\hline St Deviation & 0.00358 & 0.010343 & 0.006326 \\
\hline \% Change & $2.14 \%$ & $5.03 \%$ & $2.89 \%$ \\
\hline
\end{tabular}




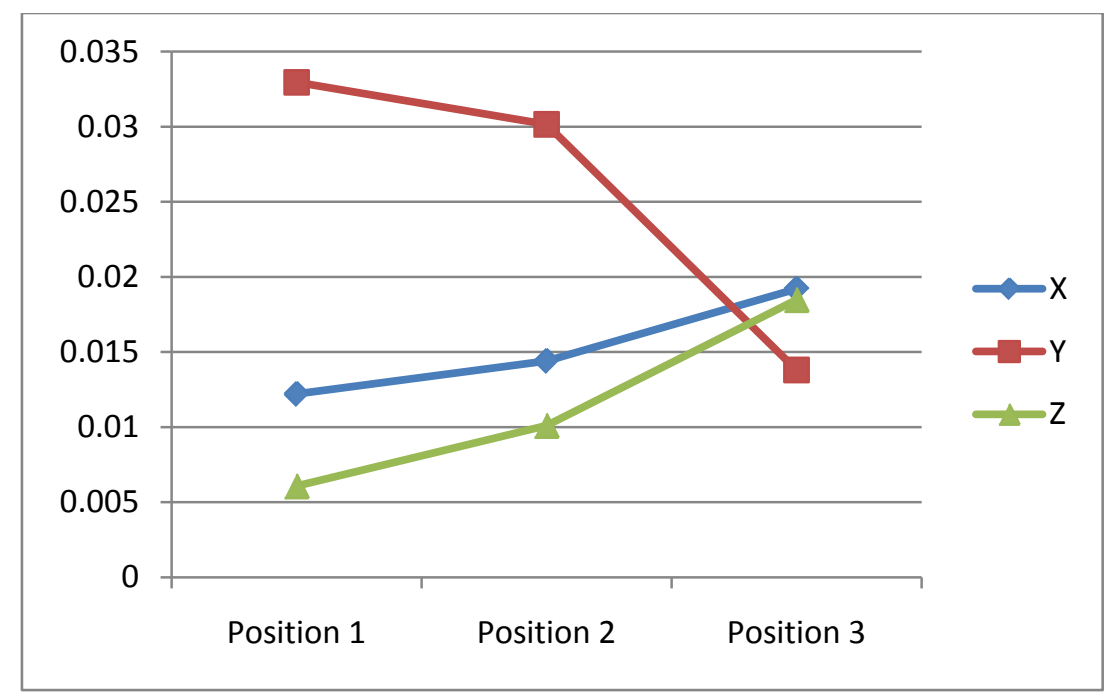

Figure 3.12:Run 3:Change in Dimensions vs Part Orientation

Based on the data obtained and from the Figure 3.12 it is observed that at higher saturation level of $46.24 \%$, curing temperature of $400^{\circ} \mathrm{F}$ and curing time of 2 hrs the change in dimension of the part along the $\mathrm{Y}$ direction is 0.03295 and 0.03015 for positions 1 and 2. Whereas the change in dimension along the $\mathrm{X}$ and $\mathrm{Z}$ direction is not as significant in the positions 1 and 2, however in position 3 the change in $\mathrm{X}$ and $\mathrm{Z}$ is higher compared to the change in $\mathrm{Y}$. Thus it can be concluded that at higher curing temperature effects the change in dimension along the $\mathrm{Y}$ axis.

\subsubsection{Run 4:}

This run was performed at a saturation level of $46.24 \%$, temperature of $350^{\circ} \mathrm{F}$ and curing time of $2.5 \mathrm{hrs}$.

\section{Results: All dimensions are in Inches.}

Table 3.25:Run 4: Dimensions

\begin{tabular}{|c|c|c|}
\hline $\begin{array}{c}\text { Actual } \\
\text { dimensions }\end{array}$ & $\begin{array}{c}\text { Scaling } \\
\text { factor }\end{array}$ & $\begin{array}{c}\text { Scaled } \\
\text { dimensions }\end{array}$ \\
\hline $0.7 ”$ & 1.02 & $0.714 ”$ \\
\hline $0.5 ”$ & 1.02 & $0.51 ”$ \\
\hline $0.5 ”$ & 0.8 & $0.4 ”$ \\
\hline
\end{tabular}


Table 3.26:Run 4: Print Conditions

\begin{tabular}{|c|c|}
\hline Saturation Level & $46.24 \%$ \\
\hline Curing Temp & $350^{\circ} \mathrm{F}$ \\
\hline Curing Time & $2.5 \mathrm{hrs}$ \\
\hline
\end{tabular}

Table 3.27:Run 4: Position 1

\begin{tabular}{|l|l|l|r|}
\hline \multicolumn{3}{|l|}{ Position 1 } & \multicolumn{2}{|l|}{} \\
\hline \multicolumn{2}{|l|}{ Dimensions after sintering } & Average \\
\hline X & $0.7586 ”$ & $0.7518 ”$ & $0.7552 ”$ \\
\hline Y & $0.5281 ”$ & $0.5272 ”$ & $0.52765 ”$ \\
\hline \multirow{2}{*}{ Z } & $0.4415 ”$ & $0.4406 ”$ & \multirow{2}{*}{$0.436175 ”$} \\
\cline { 2 - 3 } & $0.4212 ”$ & $0.4414 ”$ & \\
\hline
\end{tabular}

Table 3.28:Run 4: Position 2

\begin{tabular}{|l|c|c|c|}
\hline \multicolumn{2}{|l|}{ Position 2 } & \multicolumn{2}{|l|}{} \\
\hline \multicolumn{2}{|l|}{ Dimensions after sintering } & Average \\
\hline X & $0.7378 ”$ & $0.7386 ”$ & $0.7382 ”$ \\
\hline$Y$ & $0.5345 ”$ & $0.5326 ”$ & $0.53355 ”$ \\
\hline Z & $0.4394 ”$ & $0.4212 ”$ & \multirow{2}{*}{$0.428825 ”$} \\
\cline { 2 - 3 } & $0.4295 ”$ & $0.4252 ”$ & \\
\hline
\end{tabular}

Table 3.29:Run 4: Position 3

\begin{tabular}{|l|r|r|c|}
\hline \multicolumn{3}{|l|}{ Position 3 } & \multicolumn{2}{l|}{} \\
\hline Dimensions after sintering & Average \\
\hline X & $0.7419 ”$ & $0.7206 ”$ & $0.73125 ”$ \\
\hline$Y$ & $0.534 ”$ & $0.5393 ”$ & $0.53665 ”$ \\
\hline Z & $0.4295 ”$ & $0.4290 ”$ & \multirow{2}{*}{$0.4280 ”$} \\
\cline { 2 - 3 } & $0.4269 ”$ & $0.4266 ”$ & \\
\hline
\end{tabular}


Final Averages of Dimensions at Run4:

Table 3.30:Run 4: Final Average Dimensions

\begin{tabular}{|c|c|c|c|}
\hline & X & Y & Z \\
\hline Position 1 & $0.7552 ”$ & $0.52765 ”$ & $0.436175 ”$ \\
\hline Position 2 & $0.7382 ”$ & $0.53355 ”$ & $0.428825 ”$ \\
\hline Position 3 & $0.73125 ”$ & $0.53665 ”$ & $0.4280 ”$ \\
\hline
\end{tabular}

Difference in Dimensions $(\Delta)$ : Dimensions after sintering - Scaled Dimensions.

Ex: Position $1 \Delta \mathrm{X} 1=0.7552-0.714=0.0412$

Position $2 \Delta$ Y $2=0.53355-0.51=0.02355$

Position $3 \Delta \mathrm{Z} 3=0.428-0.4=0.028$

$$
\text { Mean }(\Delta X)=(\Delta X 1+\Delta X 2+\Delta X 3) / 3
$$

Standard Deviation $=\sqrt{\boldsymbol{\Sigma}(\boldsymbol{X} \boldsymbol{n}-\mathbf{\Delta} \mathbf{X})^{\wedge} \mathbf{2}} /(\mathbf{n}-\mathbf{1})$

$$
\mathrm{n}=1,2,3
$$

$\%$ Change $=\{($ Mean $\Delta X) /$ Scaled Dimension $\} * 100$

Ex: \% Change $X=\{(0.02755) / 0.714\} * 100=3.86 \%$

Table 3.31:Run 4: Change in Dimensions

\begin{tabular}{|l|r|r|r|}
\hline \multicolumn{1}{|c|}{$\boldsymbol{\Delta}$} & \multicolumn{1}{l|}{ X } & \multicolumn{1}{l|}{ Y } & \multicolumn{1}{l|}{ Z } \\
\hline Position 1 & $0.0412 ”$ & $0.01765 ”$ & $0.036175 ”$ \\
\hline Position 2 & $0.0242 ”$ & $0.02355 ”$ & $0.028825 ”$ \\
\hline Position 3 & $0.01725 ”$ & $0.02665 ”$ & $0.0280 ”$ \\
\hline Mean & $0.02755 ”$ & $0.022617 ”$ & $0.0310 ”$ \\
\hline St Deviation & 0.012321 & 0.004572 & 0.004501 \\
\hline \% Change & $3.86 \%$ & $4.43 \%$ & $7.75 \%$ \\
\hline
\end{tabular}




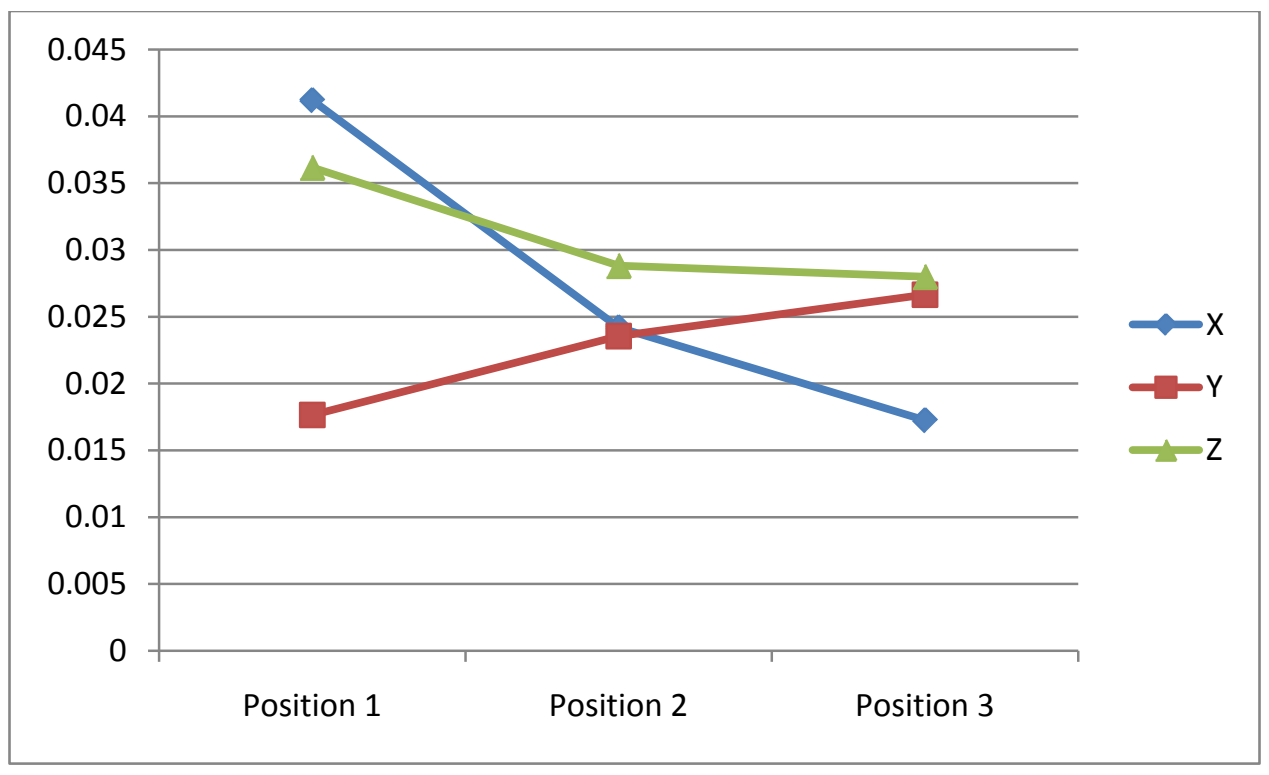

Figure 3.13:Run 4: Change in Dimensions vs Part Orientation

Based on the results obtained and the Figure 3.13 it may be observed that at higher saturation level of $46.24 \%$, curing temperature of $350^{\circ} \mathrm{F}$ and curing time of $2.5 \mathrm{hrs}$ the change in dimension along the $\mathrm{X}$ direction shows a gradual decrease with the position such as $0.0412,0.0242$ and 0.01725 for position 1, 2 and 3 respectively. Also a gradual decrease is observed in dimension along the $\mathrm{Z}$ direction of $0.036175,0.028825$ and 0.028 for the 3 positions respectively. However along the $\mathrm{Y}$ direction the change in dimension has a gradual increase of $0.01765,0.02355$ and 0.02665 for positions 1,2 and 3 respectively. Therefore it can be concluded that increase in saturation level and curing time has and at a low curing temperature of $350^{\circ} \mathrm{F}$ the increases the change in dimension along the $\mathrm{Y}$ axis whereas it decreases the change in dimension along the $\mathrm{X}$ and $\mathrm{Z}$ axis based on the part orientation.

\subsubsection{Run 5:}

This run was performed at a Saturation level of $45.00 \%$, Curing temperature of $350^{\circ} \mathrm{F}$ and curing time of $2 \mathrm{hrs}$.

\section{Results: All dimensions are in Inches.}


Table 3.32:Run 5: Dimensions

\begin{tabular}{|c|c|c|}
\hline $\begin{array}{c}\text { Actual } \\
\text { dimensions }\end{array}$ & $\begin{array}{c}\text { Scaling } \\
\text { factor }\end{array}$ & Scaled dimensions \\
\hline $0.7 ”$ & 1.02 & 0.714 ” \\
\hline $0.5 ”$ & 1.02 & $0.51 ”$ \\
\hline $0.5 ”$ & 0.8 & $0.4 ”$ \\
\hline
\end{tabular}

Table 3.33:Run 5: Print Conditions

\begin{tabular}{|c|c|}
\hline Saturation Level & $45.00 \%$ \\
\hline Curing Temp & $350^{\circ} \mathrm{F}$ \\
\hline Curing Time & $2 \mathrm{hrs}$ \\
\hline
\end{tabular}

Table 3.34:Run 5: Position 1

\begin{tabular}{|c|c|c|c|}
\hline Position 1 & \multicolumn{2}{|c|}{} \\
\hline \multicolumn{2}{|c|}{ Dimensions after sintering } & Average \\
\hline $\mathrm{X}$ & $0.7071 ”$ & $0.7078 ”$ & $0.70745 ”$ \\
\hline $\mathrm{Y}$ & $0.5289 ”$ & $0.533 ”$ & $0.53095 ”$ \\
\hline \multirow{2}{*}{$\mathrm{Z}$} & $0.4215 ”$ & $0.4454 ”$ & \multirow{2}{*}{$0.437925 ”$} \\
\cline { 2 - 3 } & $0.4423 ”$ & $0.4425 ”$ & \\
\hline
\end{tabular}

Table 3.35:Run 5: Position 2

Position 2

\begin{tabular}{|c|c|c|c|}
\hline \multicolumn{2}{|c|}{ Dimensions after sintering } & Average \\
\hline $\mathrm{X}$ & $0.7124 ”$ & $0.7134 ”$ & $0.7129 ”$ \\
\hline $\mathrm{Y}$ & 0.5354 & $0.5358 ”$ & $0.5356 ”$ \\
\hline \multirow{2}{*}{$\mathrm{Z}$} & $0.4454 ”$ & $0.4231 ”$ & \multirow{2}{*}{$0.4285 ”$} \\
\cline { 2 - 4 } & $0.4216 ”$ & $0.4239 ”$ & \\
\hline
\end{tabular}

Table 3.36:Run 5: Position 3

\begin{tabular}{|l|l|l|r|}
\hline \multicolumn{3}{|l|}{ Position 3 } & \multicolumn{2}{l|}{} \\
\hline \multicolumn{2}{|l|}{ Dimensions after sintering } & Average \\
\hline X & $0.7028 ”$ & $0.6994 ”$ & $0.7011 ”$ \\
\hline Y & $0.5322 ”$ & $0.5354 ”$ & $0.5338 ”$ \\
\hline \multirow{2}{*}{ Z } & $0.4273 ”$ & $0.4269 ”$ & \multirow{2}{*}{$0.427625 ”$} \\
\cline { 2 - 3 } & $0.4294 ”$ & $0.4269 ”$ & \\
\hline
\end{tabular}


Final Averages of Dimensions at Run5:

Table 3.37:Run 5: Final Average Dimensions

\begin{tabular}{|l|r|r|r|}
\hline & X & Y & \multicolumn{1}{l|}{ Z } \\
\hline Position 1 & $0.70745 ”$ & $0.53095 ”$ & $0.437925 ”$ \\
\hline Position 2 & $0.7129 ”$ & $0.5356 ”$ & $0.4285 ”$ \\
\hline Position 3 & $0.7011 ”$ & $0.5338 ”$ & $0.427625 ”$ \\
\hline
\end{tabular}

Difference in Dimensions $(\Delta)$ : Dimensions after sintering - Scaled Dimensions.

Ex: Position $1 \Delta \mathrm{X} 1=0.70745-0.714=-0.00655$

Position $2 \Delta$ Y $2=0.5356-0.51=0.0256$

Position $3 \Delta Z 3=0.427625-0.4=0.027625$

$$
\text { Mean }(\Delta X)=(\Delta X 1+\Delta X 2+\Delta X 3) / 3
$$

Standard Deviation $=\sqrt{\boldsymbol{\Sigma}(\boldsymbol{X} \boldsymbol{n}-\boldsymbol{\Delta} \mathbf{X})^{\wedge} \mathbf{2}} /(\mathbf{n}-\mathbf{1})$

$$
\mathrm{n}=1,2,3
$$

$\%$ Change $=\{($ Mean $\Delta X) /$ Scaled Dimension $\} * 100$

Ex: \% Change $X=\{(-0.00685) / 0.714\} * 100=-0.96 \%$

Table 3.38:Run 5: Change in Dimensions

\begin{tabular}{|l|r|r|r|}
\hline \multicolumn{1}{|c|}{$\Delta$} & \multicolumn{1}{l|}{ X } & \multicolumn{1}{l|}{ Y } & \multicolumn{1}{l|}{ Z } \\
\hline Position 1 & \multicolumn{1}{c|}{$-0.00655 ”$} & $0.02095 ”$ & $0.037925 ”$ \\
\hline Position 2 & $-0.0011 ”$ & $0.0256 ”$ & $0.0285 ”$ \\
\hline Position 3 & $-0.0129 ”$ & $0.0238 ”$ & $0.027625 ”$ \\
\hline Mean & $-0.00685 ”$ & $0.02345 ”$ & $0.03135 ”$ \\
\hline St Deviation & 0.005906 & 0.002345 & 0.005711 \\
\hline \% Change & $-0.96 \%$ & $4.60 \%$ & $7.84 \%$ \\
\hline
\end{tabular}




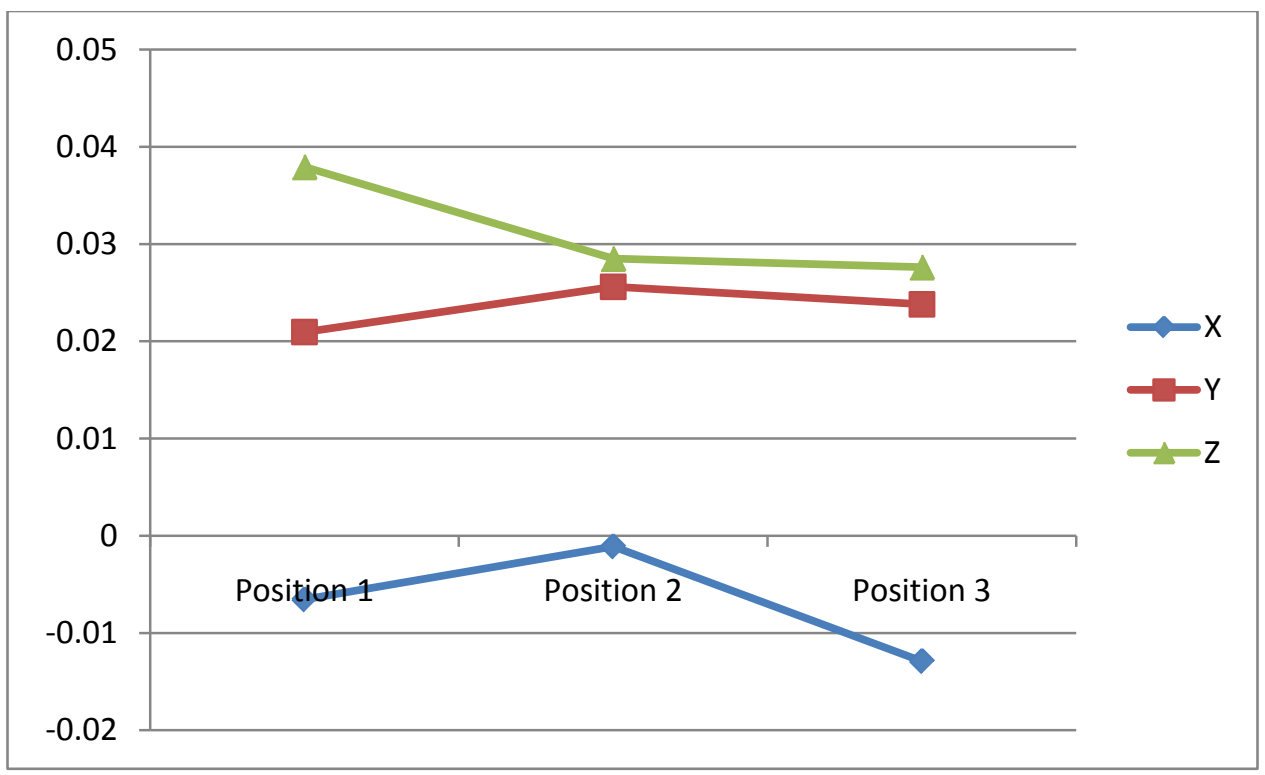

Figure 3.14:Run 5: Change in Dimensions vs Part Orientation

Based on the data obtained and the Figure 3.14 it may be observed that at low saturation level of $45 \%$, low curing temperature of $350^{\circ} \mathrm{F}$ and low curing time of $2 \mathrm{hrs}$ changes the dimension of the part along the $\mathrm{X}$ direction for positions 1 and 3 is -0.00655 ” and -0.0129 ” respectively which is higher compared to that for the position 2 . However the change in $\mathrm{Y}$ and $\mathrm{Z}$ direction is similar for positions 2 and 3. Therefore it can be concluded that there is higher shrinkage in positions 1 and 3 along the $\mathrm{X}$ direction at lower saturation level, lower curing temperature and lower curing time.

\subsubsection{Run 6:}

This run was performed at a saturation level of $45.00 \%$, temperature of $400^{\circ} \mathrm{F}$ and curing time of $2.5 \mathrm{hrs}$.

\section{Results: All dimensions are in Inches}

Table 3.39:Run 6: Dimensions

\begin{tabular}{|c|c|c|}
\hline $\begin{array}{c}\text { Actual } \\
\text { dimensions }\end{array}$ & $\begin{array}{c}\text { Scaling } \\
\text { factor }\end{array}$ & $\begin{array}{c}\text { Scaled } \\
\text { dimensions }\end{array}$ \\
\hline $0.7 ”$ & 1.02 & $0.714 ”$ \\
\hline $0.5 ”$ & 1.02 & $0.51 ”$ \\
\hline $0.5 ”$ & 0.8 & $0.4 ”$ \\
\hline
\end{tabular}


Table 3.40: Run 6: Print Conditions

\begin{tabular}{|c|c|}
\hline Saturation Level & $45.00 \%$ \\
\hline Curing Temp & $400^{\circ} \mathrm{F}$ \\
\hline Curing Time & $2.5 \mathrm{hrs}$ \\
\hline
\end{tabular}

Table 3.41:Run 6 : Position 1

\begin{tabular}{|c|l|l|l|}
\hline Position 1 & \multicolumn{3}{|l|}{} \\
\hline \multicolumn{2}{|c|}{ Dimensions after sintering } & Average \\
\hline X & $0.6973 ”$ & $0.7071 ”$ & $0.7022 ”$ \\
\hline Y & $0.5671 ”$ & $0.5599 ”$ & $0.5635 ”$ \\
\hline \multirow{2}{*}{ Z } & $0.4245 ”$ & $0.4456 ”$ & \multirow{2}{*}{$0.4388 ”$} \\
\cline { 2 - 3 } & $0.4377 ”$ & $0.4474 ”$ & \\
\hline
\end{tabular}

Table 3.42:Run 6: Position 2

\begin{tabular}{|c|c|c|c|}
\hline \multicolumn{2}{|c|}{ Position 2 } & \multicolumn{2}{|l|}{} \\
\hline \multicolumn{2}{|c|}{ Dimensions after sintering } & Average \\
\hline X & $0.6973 ”$ & $0.7065 ”$ & $0.7019 ”$ \\
\hline Y & $0.5582 ”$ & $0.565 ”$ & $0.5616 ”$ \\
\hline \multirow{2}{*}{ Z } & $0.4324 ”$ & $0.4228 ”$ & \multirow{2}{*}{$0.425325 ”$} \\
\cline { 2 - 3 } & $0.4221 ”$ & $0.424 ”$ & \\
\hline
\end{tabular}

Table 3.43:Run 6: Position 3

\begin{tabular}{|c|l|l|c|}
\hline Position 3 & \multicolumn{3}{|c|}{} \\
\hline \multicolumn{3}{|c|}{ Dimensions after sintering } & Average \\
\hline X & $0.7085 ”$ & $0.7061 ”$ & $0.7073 ”$ \\
\hline Y & $0.5614 ”$ & $0.5697 ”$ & $0.56555 ”$ \\
\hline \multirow{2}{*}{ Z } & $0.4269 ”$ & $0.4312 ”$ & \multirow{2}{*}{$0.4277 ”$} \\
\cline { 2 - 3 } & $0.4256 ”$ & $0.4271 ”$ & \\
\hline
\end{tabular}


Final Averages of Dimensions at Run6:

Table 3.44:Run 6: Final Average Dimensions

\begin{tabular}{|l|l|r|r|}
\hline & X & Y & Z \\
\hline Position 1 & $0.7022 ”$ & $0.5635 ”$ & $0.4388 ”$ \\
\hline Position 2 & $0.7019 ”$ & $0.5616 ”$ & $0.425325 ”$ \\
\hline Position 3 & $0.7073 ”$ & $0.56555 ”$ & $0.4277 ”$ \\
\hline
\end{tabular}

Difference in Dimensions $(\Delta)$ : Dimensions after sintering - Scaled Dimensions.

Ex: Position $1 \Delta \mathrm{X} 1=0.7022-0.714=-0.0118$

Position $2 \Delta$ Y $2=0.5616-0.51=0.0516$

Position $3 \Delta \mathrm{Z} 3=0.4277-0.4=0.0277$

$$
\text { Mean }(\Delta X)=(\Delta X 1+\Delta X 2+\Delta X 3) / 3
$$

Standard Deviation $=\sqrt{\boldsymbol{\Sigma}(\boldsymbol{X} \boldsymbol{n}-\boldsymbol{\Delta} \mathbf{X})^{\wedge} \mathbf{2}} /(\mathbf{n}-\mathbf{1})$

$$
\mathrm{n}=1,2,3
$$

$\%$ Change $=\{($ Mean $\Delta X) /$ Scaled Dimension $\} * 100$

Ex: \% Change $X=\{(-0.0102) / 0.714\} * 100=-1.65 \%$

\section{Table 3.45:Run 6: Change in Dimensions}

\begin{tabular}{|l|r|r|r|}
\hline \multicolumn{1}{|c|}{$\boldsymbol{\Delta}$} & \multicolumn{1}{|l|}{ X } & \multicolumn{1}{l|}{ Y } & \multicolumn{1}{l|}{ Z } \\
\hline Position 1 & $-0.0118 ”$ & $0.0535 ”$ & $0.0388 ”$ \\
\hline Position 2 & $-0.0121 ”$ & $0.0516 ”$ & $0.025325 ”$ \\
\hline Position 3 & $-0.0067 ”$ & $0.05555 ”$ & $0.0277 ”$ \\
\hline Mean & $-0.0102 ”$ & $0.05355 ”$ & $0.030608 ”$ \\
\hline St Deviation & 0.003035 & 0.001975 & 0.007193 \\
\hline \% Change & $-1.65 \%$ & $10.49 \%$ & $9.70 \%$ \\
\hline
\end{tabular}




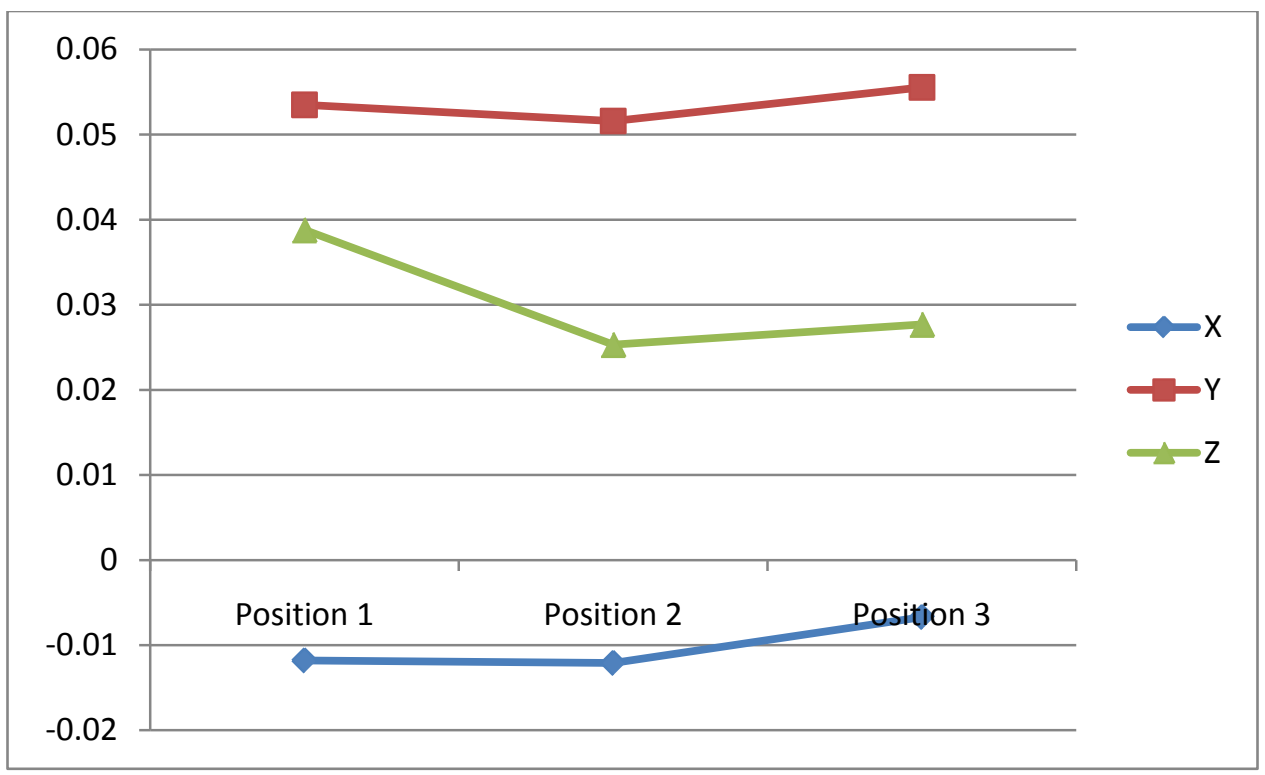

Figure 3.15:Run 6: Change in Dimensions vs Part Orientation.

Based on the data obtained and the Figure 3.15 it may be observed that at low saturation level of $45 \%$, higher curing temperature of $400^{\circ} \mathrm{F}$ and higher curing time of 2.5hrs, the change in dimension along the $\mathrm{Y}$ and $\mathrm{Z}$ direction is higher for positions 1 and 3. Whereas the part shrunk along the $\mathrm{X}$ axis for all three positions. Therefore higher curing temperature and curing time effects the dimension of the part along the $\mathrm{Y}$ and $\mathrm{Z}$ axis and causes it to expand which is seen from the mean change of 0.05355 ” and 0.030608 ” along Y and Z respectively.

\subsubsection{Run 7:}

This run was performed at a saturation level of $45.00 \%$, temperature of $400^{\circ} \mathrm{F}$ and curing time of 2 hrs.

\section{Results: All dimensions are in Inches.}

Table 3.46:Run 7: Dimensions

\begin{tabular}{|c|c|c|}
\hline $\begin{array}{c}\text { Actual } \\
\text { dimensions }\end{array}$ & $\begin{array}{c}\text { Scaling } \\
\text { factor }\end{array}$ & $\begin{array}{c}\text { Scaled } \\
\text { dimensions }\end{array}$ \\
\hline $0.7 ”$ & 1.02 & $0.714 ”$ \\
\hline $0.5 ”$ & 1.02 & $0.51 ”$ \\
\hline $0.5 ”$ & 0.8 & $0.4 ”$ \\
\hline
\end{tabular}


Table 3.47:Run 7: Print Conditions

\begin{tabular}{|c|c|}
\hline Saturation Level & $45.00 \%$ \\
\hline Curing Temp & $400^{\circ} \mathrm{F}$ \\
\hline Curing Time & $2 \mathrm{hrs}$ \\
\hline
\end{tabular}

Table 3.48:Run 7: Position 1

\begin{tabular}{|c|l|l|c|}
\hline \multicolumn{2}{|c|}{ Position 1 } & \multicolumn{2}{|c|}{} \\
\hline \multicolumn{2}{|c|}{ Dimensions after sintering } & Average \\
\hline X & $0.6983 ”$ & $0.6971 ”$ & $0.6977 ”$ \\
\hline Y & $0.5402 ”$ & $0.5408 ”$ & $0.5405 ”$ \\
\hline \multirow{2}{*}{ Z } & $0.4268 ”$ & $0.4272 ”$ & \multirow{2}{*}{$0.429375 ”$} \\
\cline { 2 - 3 } & $0.4292 ”$ & $0.4343 ”$ & \\
\hline
\end{tabular}

Table 3.49:Run 7: Position 2

\begin{tabular}{|c|c|c|c|}
\hline Position 2 & \multicolumn{3}{|c|}{} \\
\hline \multicolumn{3}{|c|}{ Dimensions after sintering } & Average \\
\hline $\mathrm{X}$ & $0.7074 ”$ & $0.6998 ”$ & $0.7036 ”$ \\
\hline $\mathrm{Y}$ & $0.5440 ”$ & $0.5405 ”$ & $0.54225 ”$ \\
\hline \multirow{2}{*}{$\mathrm{Z}$} & $0.4285 ”$ & $0.4274 ”$ & \multirow{2}{*}{$0.4281 ”$} \\
\cline { 2 - 3 } & $0.4321 ”$ & $0.4244 ”$ & \\
\hline
\end{tabular}

Table 3.50:Run 7: Position 3

\begin{tabular}{|c|c|c|c|}
\hline Position 3 & \multicolumn{3}{|c|}{} \\
\hline \multicolumn{3}{|c|}{ Dimensions after sintering } & Average \\
\hline X & $0.7055 ”$ & $0.7029 ”$ & $0.7042 ”$ \\
\hline Y & $0.5415 ”$ & $0.5445 ”$ & $0.5430 ”$ \\
\hline \multirow{2}{*}{ Z } & $0.4264 ”$ & $0.4413 ”$ & \multirow{2}{*}{$0.43665 ”$} \\
\cline { 2 - 3 } & $0.4431 ”$ & $0.4358 ”$ & \\
\hline
\end{tabular}


Final Averages of Dimensions at Run7:

Table 3.51:Run 7: Final Average Dimensions

\begin{tabular}{|c|c|c|c|}
\hline & X & Y & Z \\
\hline Position 1 & $0.6977 ”$ & $0.5405 ”$ & $0.429375 ”$ \\
\hline Position 2 & $0.7036 ”$ & $0.54225 ”$ & $0.4281 ”$ \\
\hline Position 3 & $0.7042 ”$ & $0.5430 ”$ & $0.43665 ”$ \\
\hline
\end{tabular}

Difference in Dimensions $(\Delta)$ : Dimensions after sintering - Scaled Dimensions.

Ex: Position $1 \Delta \mathrm{X} 1=0.6977-0.714=-0.0163$

Position $2 \Delta$ Y $2=0.54225-0.51=0.03225$

Position $3 \Delta \mathrm{Z} 3=0.43665-0.4=0.03665$

$$
\text { Mean }(\Delta X)=(\Delta X 1+\Delta X 2+\Delta X 3) / 3
$$

Standard Deviation $=\sqrt{\boldsymbol{\Sigma}(\boldsymbol{X} \boldsymbol{n}-\boldsymbol{\Delta} \mathbf{X})^{\wedge} \mathbf{2}} /(\mathbf{n}-\mathbf{1})$

$$
\mathrm{n}=1,2,3
$$

$\%$ Change $=\{($ Mean $\Delta X) /$ Scaled Dimension $\} * 100$

Ex: \% Change $X=\{(-0.01217) / 0.714\} * 100=2.28 \%$

Table 3.52:Run 7: Change in Dimensions

\begin{tabular}{|l|r|r|r|}
\hline \multicolumn{1}{|c|}{$\boldsymbol{\Delta}$} & \multicolumn{1}{l|}{ X } & \multicolumn{1}{l|}{ Y } & \multicolumn{1}{l|}{ Z } \\
\hline Position 1 & \multicolumn{1}{|c|}{$-0.0163 ”$} & $0.0305 ”$ & $0.029375 ”$ \\
\hline Position 2 & $-0.0104 ”$ & $0.03225 ”$ & $0.0281 ”$ \\
\hline Position 3 & $-0.0098 ”$ & $0.0330 ”$ & $0.03665 ”$ \\
\hline Mean & $-0.01217 ”$ & $0.031917 ”$ & $0.031375 ”$ \\
\hline St Deviation & 0.003592 & 0.001283 & 0.00306 \\
\hline \% Change & $-2.28 \%$ & $5.98 \%$ & $7.34 \%$ \\
\hline
\end{tabular}




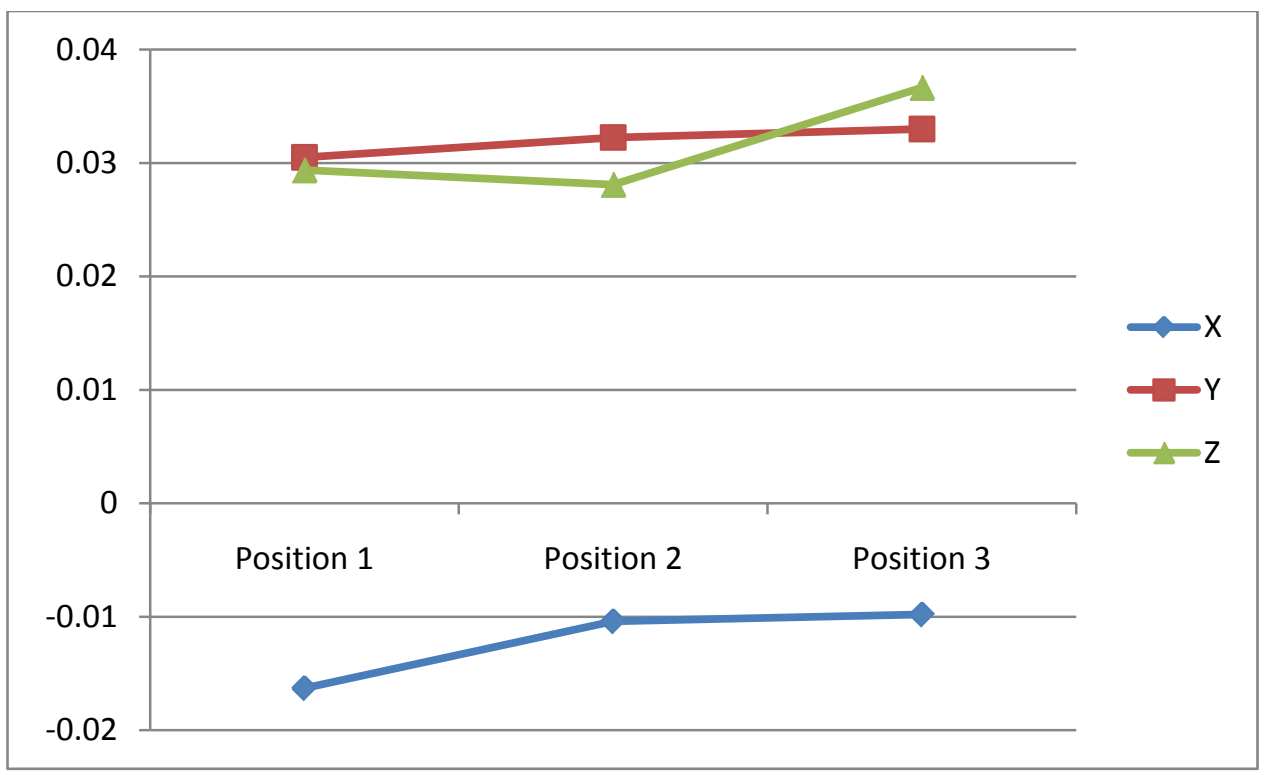

Figure 3.16:Run 7: Change in Dimensions vs Part Orientation

Based on the data obtained and the Figure 3.16 it may be observed that at higher curing temperature of $400^{\circ} \mathrm{F}$ and lower curing time of 2 hrs at $45 \%$ saturation level, the part shrinks in the $\mathrm{X}$ direction, however there is expansion in the $\mathrm{Y}$ and $\mathrm{Z}$ directions. The increase in the percentage shrinkage at $400^{\circ} \mathrm{F}$ and $2 \mathrm{hrs}$ is higher at $-2.28 \%$ compared to that of $-1.65 \%$ at $400^{\circ} \mathrm{F}$ and 2.5 hrs. Whereas the expansion in $\mathrm{Y}$ and $\mathrm{Z}$ direction is higher at $400^{\circ} \mathrm{F}$ and 2.5 hrs from Table 3.45 at $10.49 \%$ and $9.70 \%$ respectively compared to $5.98 \%$ and $7.34 \%$ in $\mathrm{Y}$ and $\mathrm{Z}$ direction at $400^{\circ} \mathrm{F}$ and 2 hrs. Therefore it can be concluded that with higher curing time is inversely proportional to the percentage change in dimensions in $\mathrm{Y}$ and $\mathrm{Z}$ direction. Whereas, it is directly proportional to the percentage change in dimension in the $\mathrm{X}$ direction.

\subsubsection{Run 8:}

This run was performed at a saturation level of $45.00 \%$, temperature of $350^{\circ} \mathrm{F}$ and curing time of 2.5 hrs.

\section{Results: All dimensions are in Inches.}


Table 3.53:Run 8: Dimensions

\begin{tabular}{|c|c|c|}
\hline $\begin{array}{c}\text { Actual } \\
\text { dimensions }\end{array}$ & $\begin{array}{c}\text { Scaling } \\
\text { factor }\end{array}$ & $\begin{array}{c}\text { Scaled } \\
\text { dimensions }\end{array}$ \\
\hline $0.7 ”$ & 1.02 & $0.714 ”$ \\
\hline $0.5 ”$ & 1.02 & $0.51 ”$ \\
\hline $0.5 ”$ & 0.8 & $0.4 ”$ \\
\hline
\end{tabular}

Table 3.54:Run 8:Print Conditions

\begin{tabular}{|l|c|}
\hline Saturation Level & $45.00 \%$ \\
\hline Curing Temp & $350^{\circ} \mathrm{F}$ \\
\hline Curing Time & $2.5 \mathrm{hrs}$ \\
\hline
\end{tabular}

Table 3.55:Run 8: Position 1

\begin{tabular}{|c|c|c|c|}
\hline Position 1 & \multicolumn{3}{|l|}{} \\
\hline \multicolumn{3}{|c|}{ Dimensions after sintering } & Average \\
\hline $\mathrm{X}$ & $0.702 ”$ & $0.7029 ”$ & $0.70245 ”$ \\
\hline $\mathrm{Y}$ & $0.5466 ”$ & $0.5516 ”$ & $0.5491 ”$ \\
\hline \multirow{2}{*}{$\mathrm{Z}$} & $0.4342 ”$ & $0.4286 ”$ & \multirow{2}{*}{$0.43455 ”$} \\
\cline { 2 - 3 } & $0.4375 ”$ & $0.4379 ”$ & \\
\hline
\end{tabular}

Table 3.56: Run 8: Position 2

\begin{tabular}{|c|c|c|c|}
\hline Position 2 & \multicolumn{3}{|c|}{} \\
\hline \multicolumn{3}{|c|}{ Dimensions after sintering } & Average \\
\hline $\mathrm{X}$ & $0.7036 ”$ & $0.7083 ”$ & 0.70595 \\
\hline $\mathrm{Y}$ & $0.5522 ”$ & $0.5520 ”$ & $0.5521 ”$ \\
\hline \multirow{2}{*}{$\mathrm{Z}$} & $0.4425 ”$ & $0.4392 ”$ & \multirow{2}{*}{$0.4398 ”$} \\
\cline { 2 - 3 } & $0.4360 ”$ & $0.4415 ”$ & \\
\hline
\end{tabular}

Table 3.57:Run 8: Position 3

\begin{tabular}{|c|c|c|c|}
\hline Position 3 & \multicolumn{2}{|l|}{} \\
\hline \multicolumn{2}{|c|}{ Dimensions after sintering } & Average \\
\hline $\mathrm{X}$ & $0.7094 ”$ & $0.7110 ”$ & $0.7102 ”$ \\
\hline $\mathrm{Y}$ & $0.5552 ”$ & $0.5679 ”$ & $0.56155^{\prime}$ \\
\hline \multirow{2}{*}{$\mathrm{Z}$} & $0.4405 ”$ & $0.4436 ”$ & \multirow{2}{*}{$0.44185 ”$} \\
\cline { 2 - 3 } & $0.4418 ”$ & $0.4415 ”$ & \\
\hline
\end{tabular}


Final Averages of Dimensions at Run8:

Table 3.58:Run 8: Final Average Dimensions

\begin{tabular}{|c|c|c|c|}
\hline & $\mathrm{X}$ & $\mathrm{Y}$ & $\mathrm{Z}$ \\
\hline Position 1 & $0.70245 ”$ & $0.5491 ”$ & $0.43455 ”$ \\
\hline Position 2 & $0.70595 ”$ & $0.5521 ”$ & $0.4398 ”$ \\
\hline Position 3 & $0.7102 ”$ & $0.56155 ”$ & $0.44185 ”$ \\
\hline
\end{tabular}

Difference in Dimensions $(\Delta)$ : Dimensions after sintering - Scaled Dimensions.

Ex: Position $1 \Delta \mathrm{X} 1=0.70245-0.714=-0.01155$

Position $2 \Delta$ Y $2=0.5521-0.51=0.0421$

Position $3 \Delta \mathrm{Z} 3=0.44185-0.4=0.04185$

$$
\text { Mean }(\Delta \mathrm{X})=(\Delta \mathrm{X} 1+\Delta \mathrm{X} 2+\Delta \mathrm{X} 3) / 3
$$

Standard Deviation $=\sqrt{\boldsymbol{\Sigma}(\boldsymbol{X} \boldsymbol{n}-\boldsymbol{\Delta} \mathbf{X})^{\wedge} \mathbf{2}} /(\mathbf{n}-\mathbf{1})$

$$
\mathrm{n}=1,2,3
$$

$\%$ Change $=\{($ Mean $\Delta X) /$ Scaled Dimension $\} * 100$

Ex: \% Change $X=\{(-0.0078) / 0.714\} * 100=-1.09 \%$

Table 3.59:Run 8: Change in Dimensions

\begin{tabular}{|c|c|c|c|}
\hline $\boldsymbol{\Delta}$ & $\mathrm{X}$ & $\mathrm{Y}$ & $\mathrm{Z}$ \\
\hline Position 1 & $0.01155 ”$ & $0.0391 ”$ & $0.03455 ”$ \\
\hline Position 2 & $0.00805 ”$ & $0.0421 ”$ & $0.0398 ”$ \\
\hline Position 3 & $0.00380 ”$ & $0.05155 ”$ & $0.04185 ”$ \\
\hline Mean & $-0.0078 ”$ & $0.04425 ”$ & $0.038733 ”$ \\
\hline St Deviation & 0.003881 & 0.006497 & 0.003765 \\
\hline \% Change & $-1.09 \%$ & $8.68 \%$ & $9.68 \%$ \\
\hline
\end{tabular}




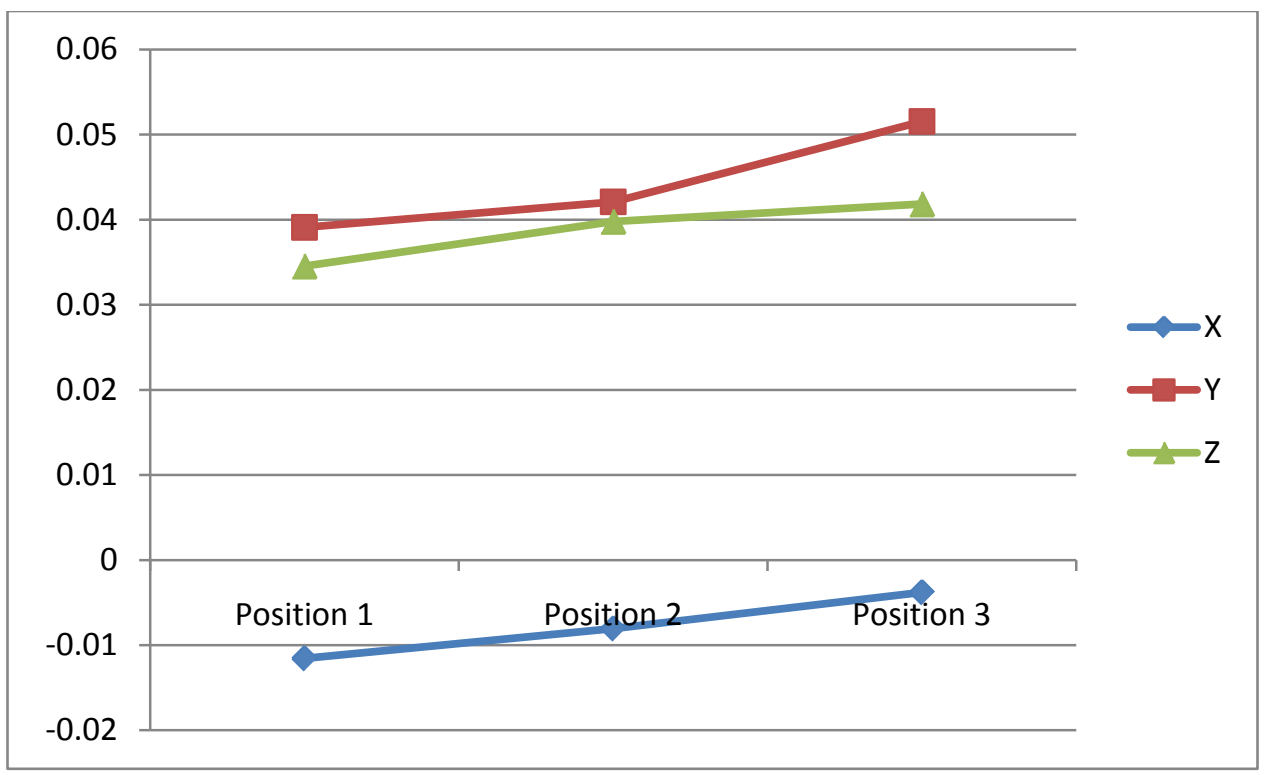

Figure 3.17:Run 8:Change in Dimensions vs Part Orientation

Based on the data obtained and the Figure 3.17 it can be concluded that at $45 \%$ saturation level, $350^{\circ} \mathrm{F}$ curing temperature and 2.5 hrs of curing time the dimension in the $\mathrm{X}$ direction has observed shrinkage, whereas in $\mathrm{Y}$ and $\mathrm{Z}$ direction it has observed expansion. This supports the previous conclusion made about the parts produced at $400^{\circ} \mathrm{F}$ and $2.5 \mathrm{hrs}$ of curing time that the curing time is inversely proportional to the percentage change in dimension in $\mathrm{Y}$ and $\mathrm{Z}$ as shown in Table 3.59. The percentage change in dimension along the $\mathrm{X}$ direction also indicates that the curing time is directly proportional to it.

\subsection{Layering Error Analysis:}

In this section dimensions in $\mathrm{X}, \mathrm{Y}$ and $\mathrm{Z}$ direction were analyzed based on the saturation level, curing temp and curing time. Since the layer thickness used by the RX-1 $\mathrm{RP}$ machine was found to be 0.002inches in section 3.3.1.1, it was used as layering error to study the effect of time, temperature and saturation level on the dimensions of the part. In Table 3.60 the change in the dimension of the sintered parts before and after the layering error have been calculated. The percentages indicate the percent change in the dimension of the $\mathrm{T}$ shape part after sintering from the scaled dimensions. The change in dimensions before and after removing the layering error are in Inches.

In the case of X the scaled dimension used was 0.714 ” 
In the case of $\mathrm{Y}$ the scaled dimension used was 0.51 ”

In the case of $\mathrm{Z}$ the scaled dimension used was 0.4 ”

Table 3.60: Change in dimensions after layering error at $350^{\circ} \mathrm{F}$ and $2 \mathrm{hrs.}$

\begin{tabular}{|c|c|c|c|c|c|c|c|c|c|c|}
\hline \multicolumn{3}{|c|}{ Change in dimensions before error } & & \multicolumn{3}{|c|}{ Change in dimensions after the error } & & \multicolumn{3}{|c|}{$\%$ change after error } \\
\hline$x$ & $46.24 \%$ & $45.00 \%$ & Layering error & $x$ & $46.24 \%$ & $45.00 \%$ & Scaled X & $x$ & $46.24 \%$ & $45.00 \%$ \\
\hline Position 1 & 0.01485 & -0.00655 & 0.002 & Position 1 & 0.01285 & -0.00855 & 0.714 & Position 1 & $1.80 \%$ & $-1.20 \%$ \\
\hline Position 2 & 0.01125 & -0.0011 & 0.002 & Position 2 & 0.00925 & -0.0031 & 0.714 & Position 2 & $1.30 \%$ & $-0.43 \%$ \\
\hline Position 3 & 0.01715 & -0.0129 & 0.002 & Position 3 & 0.01515 & -0.0149 & 0.714 & Position 3 & $2.12 \%$ & $-2.09 \%$ \\
\hline \multicolumn{3}{|c|}{ Change in dimensions before error } & & \multicolumn{3}{|c|}{ Change in dimensions after the error } & & \multicolumn{3}{|c|}{$\%$ change after error } \\
\hline Y & $46.24 \%$ & $45.00 \%$ & Layering error & Y & $46.24 \%$ & $45.00 \%$ & Scaled Y & Y & $46.24 \%$ & $45.00 \%$ \\
\hline Position 1 & 0.02445 & 0.02095 & 0.002 & Position 1 & 0.02245 & 0.01895 & 0.51 & Position 1 & $4.40 \%$ & $3.72 \%$ \\
\hline Position 2 & 0.0065 & 0.0256 & 0.002 & Position 2 & 0.0045 & 0.0236 & 0.51 & Position 2 & $0.88 \%$ & $4.63 \%$ \\
\hline Position 3 & 0.01525 & 0.0238 & 0.002 & Position 3 & 0.01325 & 0.0218 & 0.51 & Position 3 & $2.60 \%$ & $4.27 \%$ \\
\hline \multicolumn{3}{|c|}{ Change in dimensions before error } & & \multicolumn{3}{|c|}{ Change in dimensions after the error } & & \multicolumn{3}{|c|}{$\%$ change after error } \\
\hline 2 & $46.24 \%$ & $45.00 \%$ & Layering error & $z$ & $46.24 \%$ & $45.00 \%$ & Scaled Z & $z$ & $46.24 \%$ & $45.00 \%$ \\
\hline Position 1 & 0.002275 & 0.037925 & 0.002 & Position 1 & 0.000275 & 0.035925 & 0.4 & Position 1 & $0.07 \%$ & $8.98 \%$ \\
\hline Position 2 & 0.01295 & 0.0285 & 0.002 & Position 2 & 0.01095 & 0.0265 & 0.4 & Position 2 & $2.74 \%$ & $6.62 \%$ \\
\hline Position 3 & 0.0074 & 0.027625 & 0.002 & Position 3 & 0.0054 & 0.025625 & 0.4 & Position 3 & $1.35 \%$ & $6.41 \%$ \\
\hline
\end{tabular}

1. Based on the results in Table 3.60, it was observed that there is a average $1.74 \%$ expansion in the dimension in the $\mathrm{X}$ direction at a curing temp of $350^{\circ} \mathrm{F}$ and curing time of 2 hrs at $46.24 \%$ saturation level and an average shrinkage of $1.24 \%$ at same temp and time but at $45 \%$ saturation level, after the layering error was subtracted from the resultant dimensions after sintering.

2. The percentage change in the dimensions in the $\mathrm{Y}$ direction was observed to be higher with a mean of $2.62 \%$ (expansion) at $46.24 \%$ saturation level whereas a mean of $4.20 \%$ (expansion) was observed at $45 \%$ saturation level. This indicated that at lower saturation level, curing temperature and time the expansion in the $\mathrm{Y}$ direction is higher compared to the $\mathrm{X}$ direction.

3. Where as in $\mathrm{Z}$ direction it was observed that at $46.24 \%$ saturation level, the percent change in dimension after subtracting the layering error had a mean of 1.38\% expansion. This low expansion in the $\mathrm{Z}$ direction at higher saturation level 
was due to the weight of the part itself. Whereas at low saturation level of $45 \%$ the expansion was higher with a mean of $7.33 \%$

Table 3.61: Change in dimensions after layering error at $400^{\circ} \mathrm{F}$ and $2 \mathrm{hrs}$

\begin{tabular}{|c|c|c|c|c|c|c|c|c|c|c|}
\hline \multicolumn{3}{|c|}{ Change in dimensions before error } & & \multicolumn{3}{|c|}{ Change in dimensions after the error } & & \multicolumn{3}{|c|}{$\%$ change after error } \\
\hline$x$ & $46.24 \%$ & $45.00 \%$ & Layering error & $x$ & $46.24 \%$ & $45.00 \%$ & ScaledX & $x$ & $46.24 \%$ & $45.00 \%$ \\
\hline Position 1 & 0.0122 & -0.0163 & 0.002 & Position 1 & 0.0102 & -0.0183 & 0.714 & Position 1 & $1.43 \%$ & $-2.56 \%$ \\
\hline Position 2 & 0.0144 & -0.0104 & 0.002 & Position 2 & 0.0124 & -0.0124 & 0.714 & Position 2 & $1.74 \%$ & $-1.74 \%$ \\
\hline Position 3 & 0.0192 & $-0,0098$ & 0.002 & Position 3 & 0.0172 & -0.0118 & 0.714 & Position 3 & $2.41 \%$ & $-1.65 \%$ \\
\hline \multicolumn{3}{|c|}{ Change in dimensions before error } & & \multicolumn{3}{|c|}{ Change in dimensions after the error } & & \multicolumn{3}{|c|}{$\%$ change after error } \\
\hline Y & $46.24 \%$ & $45.00 \%$ & Layering error & Y & $46.24 \%$ & $45.00 \%$ & Scaled Y & y & $46.24 \%$ & $45.00 \%$ \\
\hline Position 1 & 0.03295 & 0.0305 & 0.002 & Position 1 & 0.03095 & 0.0285 & 0.51 & Position 1 & $6.07 \%$ & $5.59 \%$ \\
\hline Position 2 & 0.03015 & 0.03225 & 0.002 & Position 2 & 0.02815 & 0.03025 & 0.51 & Position 2 & $5.52 \%$ & $5.93 \%$ \\
\hline Position 3 & 0.0138 & 0.033 & 0.002 & Position 3 & 0.0118 & 0.031 & 0.51 & Position 3 & $2.31 \%$ & $6.08 \%$ \\
\hline \multicolumn{3}{|c|}{ Change in dimensions before error } & & \multicolumn{3}{|c|}{ Change in dimensions after the error } & & \multicolumn{3}{|c|}{$\%$ change after error } \\
\hline 2 & $46.24 \%$ & $45.00 \%$ & Layering error & 2 & $46.24 \%$ & $45.00 \%$ & Scaled Z & 2 & $46.24 \%$ & $45.00 \%$ \\
\hline Position 1 & 0.006075 & 0.029375 & \begin{tabular}{|l|l}
0.002 \\
\end{tabular} & Position 1 & 0.004075 & 0.027375 & 0.4 & Position 1 & $1.02 \%$ & $6.84 \%$ \\
\hline Position 2 & 0.0101 & 0.0281 & 0.002 & Position 2 & 0.0081 & 0.0261 & 0.4 & Position 2 & $2.03 \%$ & $6.53 \%$ \\
\hline Position 3 & 0.018475 & 0.03665 & 0.002 & Position 3 & 0.016475 & 0.03465 & 0.4 & Position 3 & $4.12 \%$ & $8.66 \%$ \\
\hline
\end{tabular}

4. Based on the results calculated in Table 3.61, it was observed that at higher saturation level of $46.24 \%$, curing temperature of $400^{\circ} \mathrm{F}$ and curing time of 2 hrs the percentage change in dimension in the $\mathrm{X}$ direction after removing the layering error from the dimensions of the sintered parts in all the three positions it was observed to have a mean of $1.86 \%$ (expansion). Whereas at a saturation level of $45 \%$ it was observed to have a mean of $-1.98 \%$ indicating a shrinkage in the part after sintering.

5. At the same level of curing at a saturation level of $46.24 \%$ it was observed that the percentage change in dimension in the $\mathrm{Y}$ direction was observed to have a mean of $4.63 \%$ (expansion). Whereas at $45 \%$ saturation level it was observed to have a mean of 5.86\% (expansion). 
6. The same calculations when performed for the percentage change in the dimension in the $\mathrm{Z}$ direction at all the three positions, it was observed to have a mean of $2.39 \%$ (expansion) at $46.24 \%$ saturation level. Whereas at $45 \%$ saturation level it was observed to have a mean of $7.34 \%$ (expansion)

Table 3.62: Change in dimensions after layering error at temp $350^{\circ} \mathrm{F}$ and $2.5 \mathrm{hrs}$

\begin{tabular}{|c|c|c|c|c|c|c|c|c|c|c|}
\hline \multicolumn{3}{|c|}{ Change in dimensions before error } & \multirow[b]{2}{*}{ Layering error } & \multicolumn{3}{|c|}{ Change in dimensions after the error } & \multirow[b]{2}{*}{ Scaled X } & \multicolumn{3}{|c|}{$\%$ change after error } \\
\hline$x$ & $46.24 \%$ & $45.00 \%$ & & $x$ & $46.24 \%$ & $45.00 \%$ & & $x$ & $46.24 \%$ & $45.00 \%$ \\
\hline Position 1 & 0.0412 & $-0,01155$ & 0.002 & Position 1 & 0.0392 & -0.01355 & 0.714 & Position 1 & $5.49 \%$ & $-1.90 \%$ \\
\hline Position 2 & 0.0242 & -0.00805 & 0.002 & Position 2 & 0.0222 & -0.01005 & 0.714 & Position 2 & $3.11 \%$ & $-1,41 \%$ \\
\hline Position 3 & 0.01725 & -0.0038 & 0.002 & Position 3 & 0.01525 & -0.0058 & 0.714 & Position 3 & $2,14 \%$ & $-0.81 \%$ \\
\hline \multicolumn{3}{|c|}{ Change in dimensions before error } & & \multicolumn{3}{|c|}{ Change in dimensions after the error } & & \multicolumn{3}{|c|}{$\%$ change after error } \\
\hline Y & $46.24 \%$ & $45.00 \%$ & Layering error & Y & $46.24 \%$ & $45.00 \%$ & Scaled Y & Y & $46.24 \%$ & $45.00 \%$ \\
\hline Position 1 & 0.01765 & 0.0391 & 0.002 & Position 1 & 0.01565 & 0.0371 & 0.51 & Position 1 & $3.07 \%$ & $7.27 \%$ \\
\hline Position 2 & 0.02355 & 0.0421 & 0.002 & Position 2 & 0.02155 & 0.0401 & 0.51 & Position 2 & $4.23 \%$ & $7.86 \%$ \\
\hline Position 3 & 0.02665 & 0.05155 & 0.002 & Position 3 & 0.02465 & 0.04955 & 0.51 & Position 3 & $4.83 \%$ & $9.72 \%$ \\
\hline \multicolumn{3}{|c|}{ Change in dimensions before error } & & \multicolumn{3}{|c|}{ Change in dimensions after the error } & & \multicolumn{3}{|c|}{$\%$ change after error } \\
\hline 2 & $46.24 \%$ & $45.00 \%$ & Layering error & 2 & $46.24 \%$ & $45.00 \%$ & Scaled Z & 2 & $46.24 \%$ & $45.00 \%$ \\
\hline Position 1 & 0.036175 & 0.03455 & 0.002 & Position 1 & 0.034175 & 0.03255 & 0.4 & Position 1 & $8.54 \%$ & $8.14 \%$ \\
\hline Position 2 & 0.028825 & 0.0398 & 0.002 & Position 2 & 0.026825 & 0.0378 & 0.4 & Position 2 & $6.71 \%$ & $9.45 \%$ \\
\hline Position 3 & 0.028 & 0.04185 & 0.002 & Position 3 & 0.026 & 0.03985 & 0.4 & Position 3 & $6.50 \%$ & $9.96 \%$ \\
\hline
\end{tabular}

7. Based on results calculated in Table 3.62 it was observed that at a curing temperature of $350^{\circ} \mathrm{F}$ and curing time of $2.5 \mathrm{hrs}$ the percentage change in the dimension in the $\mathrm{X}$ direction after removing the layering error for all the three positions was at a mean of 3.57\% (expansion). Whereas at $45 \%$ saturation level the mean was observed to be at $-1.37 \%$ (shrinkage) from the scaled dimensions.

8. The percentage change dimension of the part in the $Y$ direction at the same curing settings was observed to be at an average of $4.04 \%$ (expansion). Whereas at $45 \%$ saturation level the percentage change was observed to be at 8.28\% (expansion). Indicating the effect of higher curing time on the increase in expansion in the $\mathrm{Y}$ direction at lower saturation levels.

9. For the percentage change in dimensions in the $\mathrm{Z}$ direction, it was observed that at a saturation level of $46.24 \%$ under the same curing settings, the mean change was 
at $7.25 \%$ (expansion). Whereas at a saturation level of $45 \%$ the mean change was observed to be at $9.18 \%$ (expansion).

Table 3.63: Change in dimensions after layering error at $400^{\circ} \mathrm{F}$ and $2.5 \mathrm{hrs}$

\begin{tabular}{|c|c|c|c|c|c|c|c|c|c|c|}
\hline \multicolumn{3}{|c|}{ Change in dimensions before error } & & \multicolumn{3}{|c|}{ Change in dimensions after the error } & & \multicolumn{3}{|c|}{$\%$ change after error } \\
\hline$x$ & $46.24 \%$ & $45.00 \%$ & Layering error & $x$ & $46.24 \%$ & $45.00 \%$ & ScaledX & $x$ & $46.24 \%$ & $45.00 \%$ \\
\hline Position 1 & 0.0248 & -0.0118 & 0.002 & Position 1 & 0.0228 & -0.0138 & 0.714 & Position 1 & $3.19 \%$ & $-1.93 \%$ \\
\hline Position 2 & 0.02275 & -0.0121 & 0.002 & Position 2 & 0.02075 & -0.0141 & 0.714 & Position 2 & $2.91 \%$ & $-1.97 \%$ \\
\hline Position 3 & 0.0261 & -0.0067 & 0.002 & Position 3 & 0.0241 & -0.0087 & 0.714 & Position 3 & $3.38 \%$ & $-1.22 \%$ \\
\hline \multicolumn{3}{|c|}{ Change in dimensions before error } & & \multicolumn{3}{|c|}{ Change in dimensions after the error } & & \multicolumn{3}{|c|}{$\%$ change after error } \\
\hline Y & $46.24 \%$ & $45.00 \%$ & Layering error & Y & $46.24 \%$ & $45.00 \%$ & Scaled Y & y & $46.24 \%$ & $45.00 \%$ \\
\hline Position 1 & 0.01755 & 0.0535 & 0.002 & Position 1 & 0.01555 & 0.0515 & 0.51 & Position 1 & $3.05 \%$ & $10.10 \%$ \\
\hline Position 2 & 0.02295 & 0.0516 & 0.002 & Position 2 & 0.02095 & 0.0496 & 0.51 & Position 2 & $4.11 \%$ & $9.73 \%$ \\
\hline Position 3 & 0.0187 & 0.05555 & 0.002 & Position 3 & 0.0167 & 0.05355 & 0.51 & Position 3 & $3.27 \%$ & $10.50 \%$ \\
\hline \multicolumn{3}{|c|}{ Change in dimensions before error } & & \multicolumn{3}{|c|}{ Change in dimensions after the error } & & \multicolumn{3}{|c|}{$\%$ change after error } \\
\hline 2 & $46.24 \%$ & $45.00 \%$ & Layering error & 2 & $46.24 \%$ & $45.00 \%$ & Scaled Z & Z & $46.24 \%$ & $45.00 \%$ \\
\hline Position 1 & 0.03625 & 0.0388 & 0.002 & Position 1 & 0.03425 & 0.0368 & 0.4 & Position 1 & $8.56 \%$ & $9.20 \%$ \\
\hline Position 2 & 0.041425 & 0.025325 & 0.002 & Position 2 & 0.039425 & 0.023325 & 0.4 & Position 2 & $9.86 \%$ & $5.83 \%$ \\
\hline Position 3 & 0.018675 & 0.0277 & 0.002 & Position 3 & 0.016675 & 0.0257 & 0.4 & Position 3 & $4.17 \%$ & $6.43 \%$ \\
\hline
\end{tabular}

10. Based on the results calculated in Table 3.63 the percentage change in the dimension of part in $\mathrm{X}$ direction at a saturation level of $46.24 \%$, curing temperature of $400^{\circ} \mathrm{F}$ and curing time of 2.5 hrs and after removing the layering error was found to be an average of $3.16 \%$ (expansion) for all the three positions. Whereas the average percentage change was found to be at $-1.70 \%$ (shrinkage).

11. For the same experimental set up when the results were calculated for the dimension along the $\mathrm{Y}$ direction it was found that at saturation level of $46.24 \%$ the average percentage change was 3.47\% (expansion). Whereas for a saturation level of $45 \%$ the average percentage change was $10.11 \%$ (expansion)

12. The change in dimension along the $\mathrm{Z}$ direction for the same experimental set up it was found that the average percentage change for a saturation level of $46.24 \%$ was at $7.53 \%$ (expansion). Whereas for $45 \%$ saturation level the average percentage change was at 7.15\% (expansion). 


\subsection{Summary}

The percentage change in the dimension along the $\mathrm{X}, \mathrm{Y}$ and $\mathrm{Z}$ direction are summarized in the Table 3.64

Table 3.64:Percentage change in dimension along XYZ direction at all levels.

\begin{tabular}{|c|c|c|c|c|c|c|}
\hline Run & $\begin{array}{c}\text { Curing } \\
\text { Temp }\end{array}$ & $\begin{array}{c}\text { Curing } \\
\text { Time }\end{array}$ & $\begin{array}{c}\text { Saturation } \\
\text { Level }\end{array}$ & $\mathrm{X}$ & $\mathrm{Y}$ & $\mathrm{Z}$ \\
\hline Run 1 & $350^{\circ} \mathrm{F}$ & $2 \mathrm{hrs}$ & $46.24 \%$ & $2.02 \%$ & $3.02 \%$ & $1.89 \%$ \\
\hline Run 2 & $400^{\circ} \mathrm{F}$ & $2.5 \mathrm{hrs}$ & $46.24 \%$ & $3.44 \%$ & $3.87 \%$ & $8.03 \%$ \\
\hline Run 3 & $400^{\circ} \mathrm{F}$ & $2 \mathrm{hrs}$ & $46.24 \%$ & $2.14 \%$ & $5.03 \%$ & $2.89 \%$ \\
\hline Run 4 & $350^{\circ} \mathrm{F}$ & $2.5 \mathrm{hrs}$ & $46.24 \%$ & $3.86 \%$ & $4.43 \%$ & $7.75 \%$ \\
\hline Run 5 & $350^{\circ} \mathrm{F}$ & $2 \mathrm{hrs}$ & $45.00 \%$ & $-0.96 \%$ & $4.60 \%$ & $7.84 \%$ \\
\hline Run 6 & $400^{\circ} \mathrm{F}$ & $2.5 \mathrm{hrs}$ & $45.00 \%$ & $-1.65 \%$ & $10.49 \%$ & $9.70 \%$ \\
\hline Run 7 & $400^{\circ} \mathrm{F}$ & $2 \mathrm{hrs}$ & $45.00 \%$ & $-2.28 \%$ & $5.98 \%$ & $7.34 \%$ \\
\hline Run 8 & $350^{\circ} \mathrm{F}$ & $2.5 \mathrm{hrs}$ & $45.00 \%$ & $-1.09 \%$ & $8.68 \%$ & $9.68 \%$ \\
\hline
\end{tabular}

1. Based on the result obtained and as shown in Table 3.64 it can be summarized that at $46.24 \%$ saturation level the curing time of 2.5 hrs at any curing temperature results in higher expansion along the $\mathrm{X}$ and $\mathrm{Z}$ direction as seen in Run 2 and Run 4.

2. Under the same print conditions the lower expansion along the $\mathrm{Z}$ axis for Run 1 and Run 3 can be attributed to the weight of the part itself due to higher saturation.

3. At a saturation level of $45.00 \%$, shrinkage can be observed along the $\mathrm{X}$ direction at all levels of curing time and curing temperature.

4. However at a saturation level of $45.00 \%$, curing time of 2.5 hrs at curing temperature of $400^{\circ} \mathrm{F}$ and $350^{\circ} \mathrm{F}$ results in higher expansion along the $\mathrm{Y}$ and $\mathrm{Z}$ direction as shown in Run 6 and Run 7 from Table 3.64.

5. Therefore based on the summary it can be concluded that saturation level, curing time and curing temperature have an effect in the change in dimension of the part. 


\section{CHAPTER 4:CONCLUSIONS AND FUTURE WORK}

\subsection{Conclusions:}

1. Based on the data it can be concluded that at higher saturation level the part orientation effects the change in dimension of the part due to the weight of the part itself as seen in Figure 3.10. Therefore saturation level is inversely proportional to the change in dimension of the part along the build axis in this case the $\mathrm{Z}$ axis.

2. From the data obtained from the parts produced at high saturation level of $46.24 \%$ and high curing temperature of $400^{\circ} \mathrm{F}$ and curing time of 2 hrs it can be concluded that higher temperature effects the change in dimension in the $\mathrm{Y}$ direction from Figure 3.12.

3. From Figure 3.13 it can be concluded that the increase in curing time to $2.5 \mathrm{hrs}$ at $46.24 \%$ saturation level is directly proportional to the change in dimension in the $\mathrm{Y}$ direction whereas it is inversely proportional in the $\mathrm{X}$ and $\mathrm{Z}$ direction.

4. Based on Figure 3.15 and Figure 3.17 it can be concluded that the change in curing time is directly proportional to the percentage change in dimensions in the $\mathrm{X}$ direction whereas it is inversely proportional to the percentage change in $\mathrm{Y}$ and $\mathrm{Z}$ direction for positions 1 and 3.

5. The Figure 4.1: shows the average of the percentage change in dimension in $\mathrm{X}, \mathrm{Y}$ and $\mathrm{Z}$ direction for all the three positions under different curing temperatures and curing times but the same saturation level of $46.24 \%$.

6. It was found that at higher saturation level of $46.24 \%$, the percentage change in dimension in $\mathrm{X}, \mathrm{Y}$ and $\mathrm{Z}$ direction after removing the layering error was similar for curing temperature $350^{\circ} \mathrm{F}$ and $400^{\circ} \mathrm{F}$. However the curing time was constant for the two settings 2 hrs.

7. Hence it was concluded that at lower curing time and higher saturation level, there was lower expansion of the part in $\mathrm{X}$ and $\mathrm{Z}$ direction which may be observed from the data in Table 3.60: and Table 3.61: whereas in Y direction the expansion was observed to be higher. 
8. According to the data obtained in Table 3.62: and Table 3.63 higher curing time of 2.5 hrs, increases expansion of the part in $\mathrm{Z}$ direction compared to that of the $\mathrm{X}$ and $\mathrm{Y}$ direction.

9. It also must be noted that even though the machine was able to print all the parts successfully, the nozzles on the print head would misfire on a few layers resulting in varying results. However as this is an uncontrollable factor it has not been considered in the analysis.

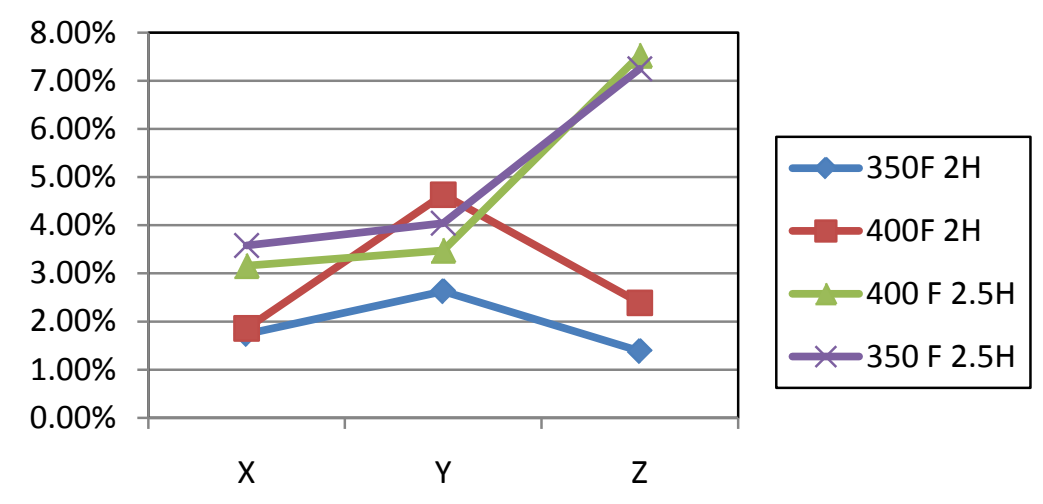

Figure 4.1:Percentage change in Dimensions vs XYZ axis

10. As seen from Figure 4.2 at $45 \%$ Saturation level, the percentage change in dimension increases with increase in curing time.

11. However the percentage change in dimension in the $\mathrm{X}$ direction indicates the shrinkage in the part. This is due to low saturation of the part.

12. Therefore lower saturation level results in higher shrinkage at higher temperatures as seen in Table 3.61 and Table 3.63.

13. Change in dimension along the $\mathrm{Y}$ direction at $45.00 \%$ saturation level was found to be at $10.11 \%$ and $8.28 \%$ for a curing time of 2.5 hrs. Whereas $4.21 \%$ and $5.87 \%$ were the percentage expansion for a curing time of $2 \mathrm{hrs}$. This indicates the effect of increase in curing time on the dimensional change along $\mathrm{Y}$ direction of the part built.

14. The $9.18 \%$ change in dimension along the $\mathrm{Z}$ direction was attributed to the misfiring jets during the printing process. 
15. Finally as the entire RP process is time consuming the experiment in the lab must only limited to a single saturation level, however the curing time and curing temperature can be varied to analyze the effect on the dimensions of the part produced.

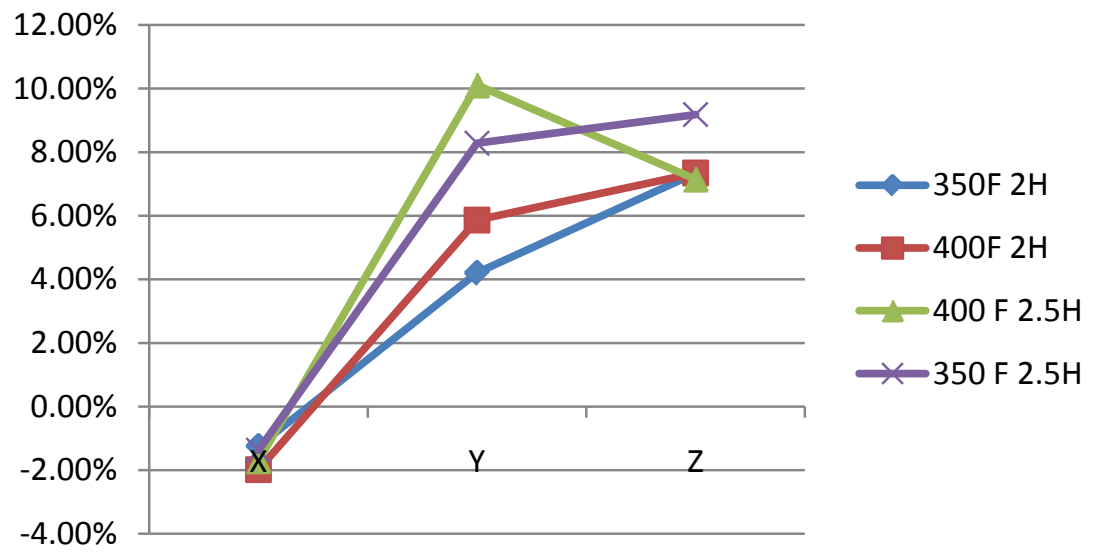

Figure 4.2:Percentage change in dimensions vs XYZ axis

\subsection{Future Work:}

Although this thesis aims at introducing the students to Rapid Prototyping technology, the future work may include the following:

1. The expansion in the parts has been explained to accommodate the filling up of bronze into the pores of the sintered parts. Incorporating the infiltration process in examining the final dimension of the parts produced using bronze would complete the production process and give more insight into the surface finish and dimensional tolerance of the final product.

2. The parts sintered during the experiments were buckled under their own weight at high sintering temperatures. This may be studied by changing the orientation of the part during the sintering process.

3. The one step process may also be studied by producing parts by that method.

4. Different production conditions may also be considered under the experimental set up and used to analyze the parts produced. 
5. Changing the design of the part to include curves and smooth edges may also be studied for deformation and dimensional tolerances.

6. The actual accuracy of the machine may also be studied by nullifying the scaling factor to produce the parts without scaling and measuring the change in dimensions. 


\section{REFERENCES}

1. Terry Wohlers, Wohlers Report, Wohlers Associates, 2005. pg 11 - pg 40.

2. Terry Wohlers, Wohlers Report, Wohlers Associates, 2005. pg 15.

3. Terry Wohlers, Wohlers Report, Wohlers Associates, 2005. pg 20.

4. D.Raker and H.Rice, Inside AutoCAD, Sixth Edition. Pg 1-3.

5. Retrieved September 21, 2008 from the World Wide Web: http://en.wikipedia.org/wiki/Rapid_prototyping\#Technologies.

6. Retrieved September 21, 2008 from the World Wide Web: http://blog.mindtribe.com/usercontent/2009/06/SLS_blg11.gif

7. Retrieved September 21, 2008 from the World Wide Web: http://www.emeraldinsight.com/fig/1560080405001.png

8. Retrieved September 21, 2008 from the World Wide Web: http://www.princeton.edu/ cml/assets/images/stereo02.gif

9. Retrieved September 21, 2008 from the World Wide Web: http://home.att.net/ castleisland/lom.gif

10. Retrieved September 21, 2008 from the World Wide Web: http://home.att.net/ castleisland/lens.gif

11. Retrieved September 21, 2008 from the World Wide Web: http://www.rpc.msoe.edu/images/3dp_process.jpg

12. Xiuzi, Y, Wei, P., Zhiyang, C. and Yi-Yu, C., Today’s students, tomorrow’s engineers: an industrial perspective on CAD education, Computer-Aided Design, Vol. 36, 2004,pp 1451-1460.

13. Retrieved September 30, 2008 from the World Wide Web: http://alibre.typepad.com/alibre_ceo_blog/2007/11/the-evolution-o.html

14. Retrieved September 30, 2008 from the World Wide Web: http://www.eng-tips.com/faqs.cfm?fid=838

15. Retrieved September 30, 2008 from the World Wide Web: http:/people.moreheadstate.edu/students/rxpati02/images/

16. Processing Technology: Rapid Manufacturing Part 1: The Technologies, www.compositesworld.com 
17. Processing Technology: Rapid Manufacturing Part 1: The Technologies www.compositesworld.com

18. Retrieved August 10, 2008 from the World Wide Web: http://www.princeton.edu/ cml/assets/images/stereo02.gif

19. Advanced Materials \& Processes, May 1, 2001, Laser Engineered Net Shaping, Pg. 35, Volume 159, No. 5, ISSN: 0882 - 7958..

20. Retrieved August 10, 2008 from the World Wide Web: http://home.att.net/ castleisland/lens.gif

21. Terry Wohlers, Wohlers Report, Wohlers Associates, 2005. pg 229

22. Retrieved August 10, 2008 from the World Wide Web: http://www.xpress3d.com/images/3dp_process.jpg

23. Divesh R. Sahatoo, Boppana V. Chowdary, Fahraz F. Ali, Raj Bhatti "Slicing Issues in CAD Translation to STL in Rapid Prototyping” Proceedings of The 2008 IAJCIJME International Conference ISBN 978-1-60643-379-9

24. Retrieved November 25, 2009 from the World Wide Web: http://www.rapidtoday.com/get_prototyping_education.html

25. Retrieved November 25, 2009 from the World Wide Web: http://www.deskartes.com 


\section{APPENDIX A: AUTOCAD INSTRUCTIONS}

Start with a new drawing window on AutoCAD 2008 as shown in Figure A.1:

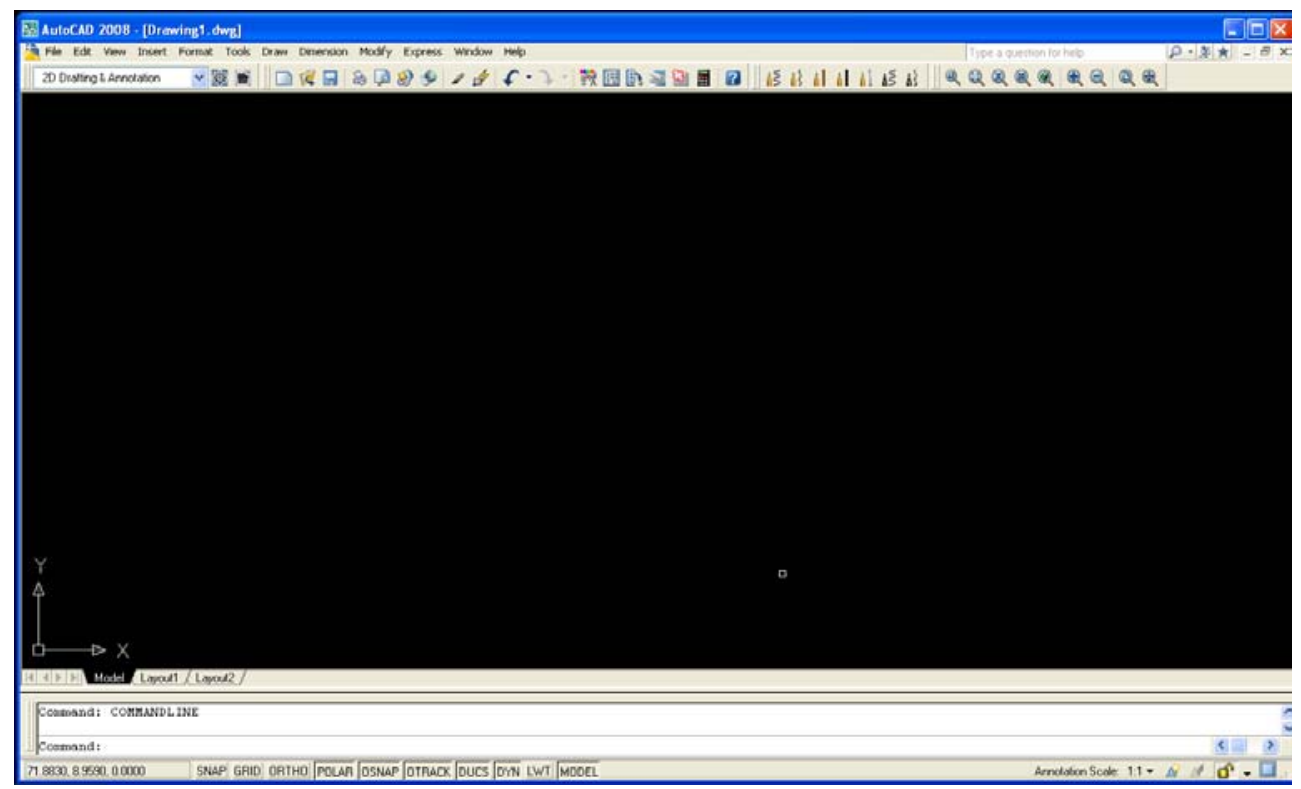

Figure A.1: AutoCAD 2008 New drawing window

The first step after opening a new drawing is to define the units the drawing would be in.

* Use the command UNITS in the command prompt and change the Length type to Engineering and the precision to 0'-0.00” and units to scale inserted content to inches as shown Figure A.2: 


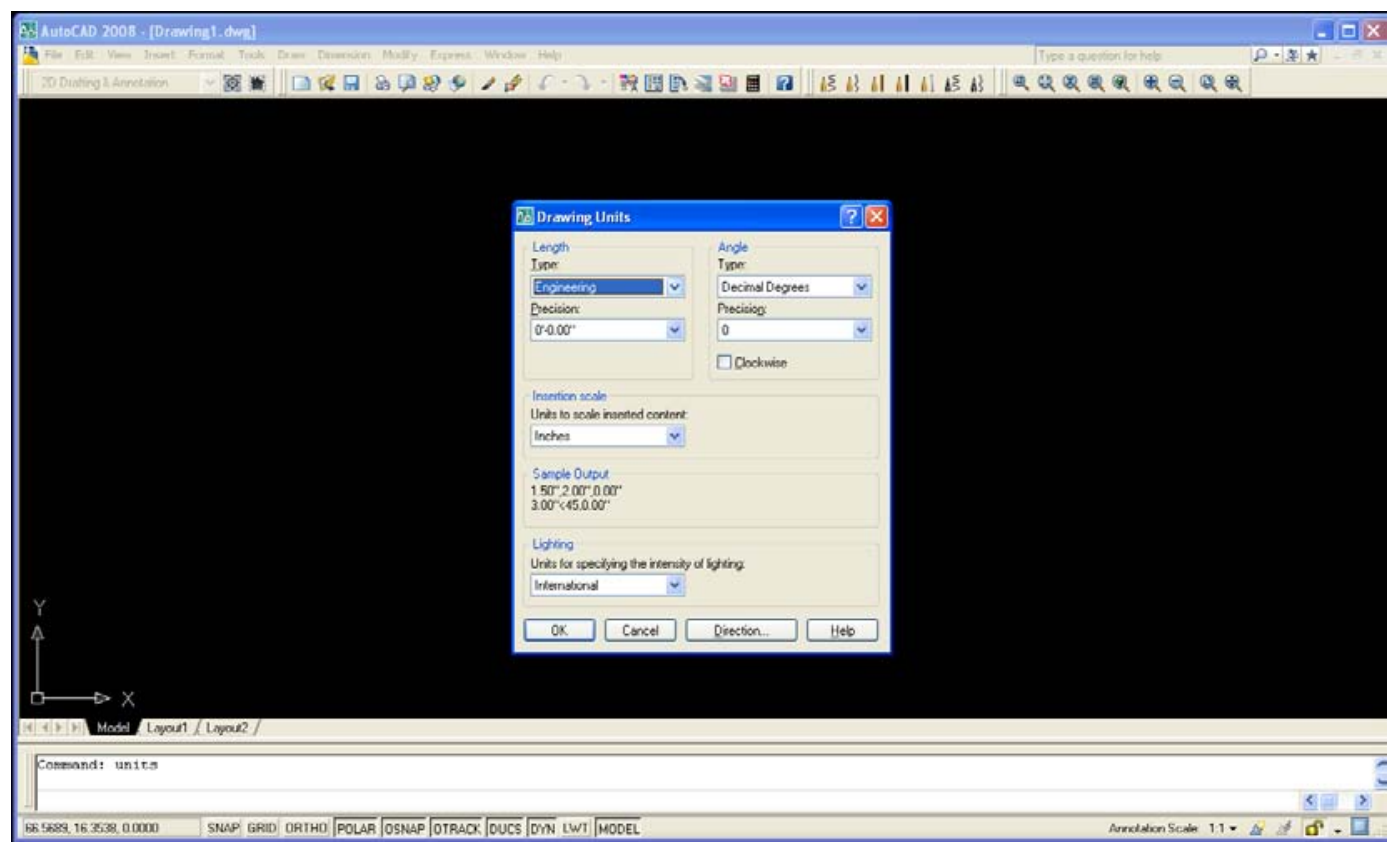

Figure A.2: AutoCAD 2008 Drawing Units Screen

* The length of the overhang of the T bracket is 0.7 "

* Start off with a rectangle with the length 0.7 " and width 0.2 " as shown Figure A.3:

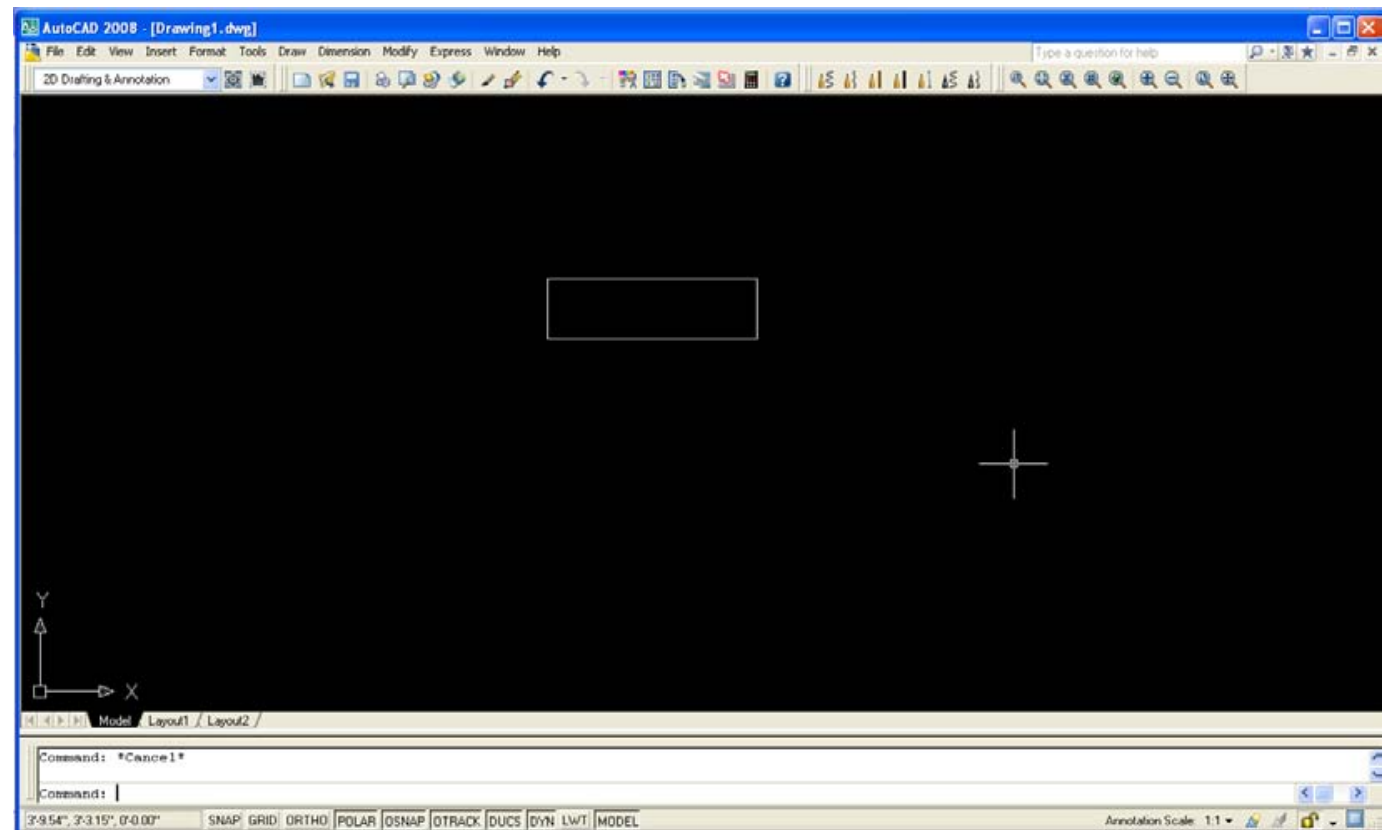

Figure A.3: AutoCAD 2008 Overhang design 
Then design the second rectangle as the column of the $\mathrm{T}$ bracket with length as 0.2 ” and width 0.3” as shown Figure A.4:

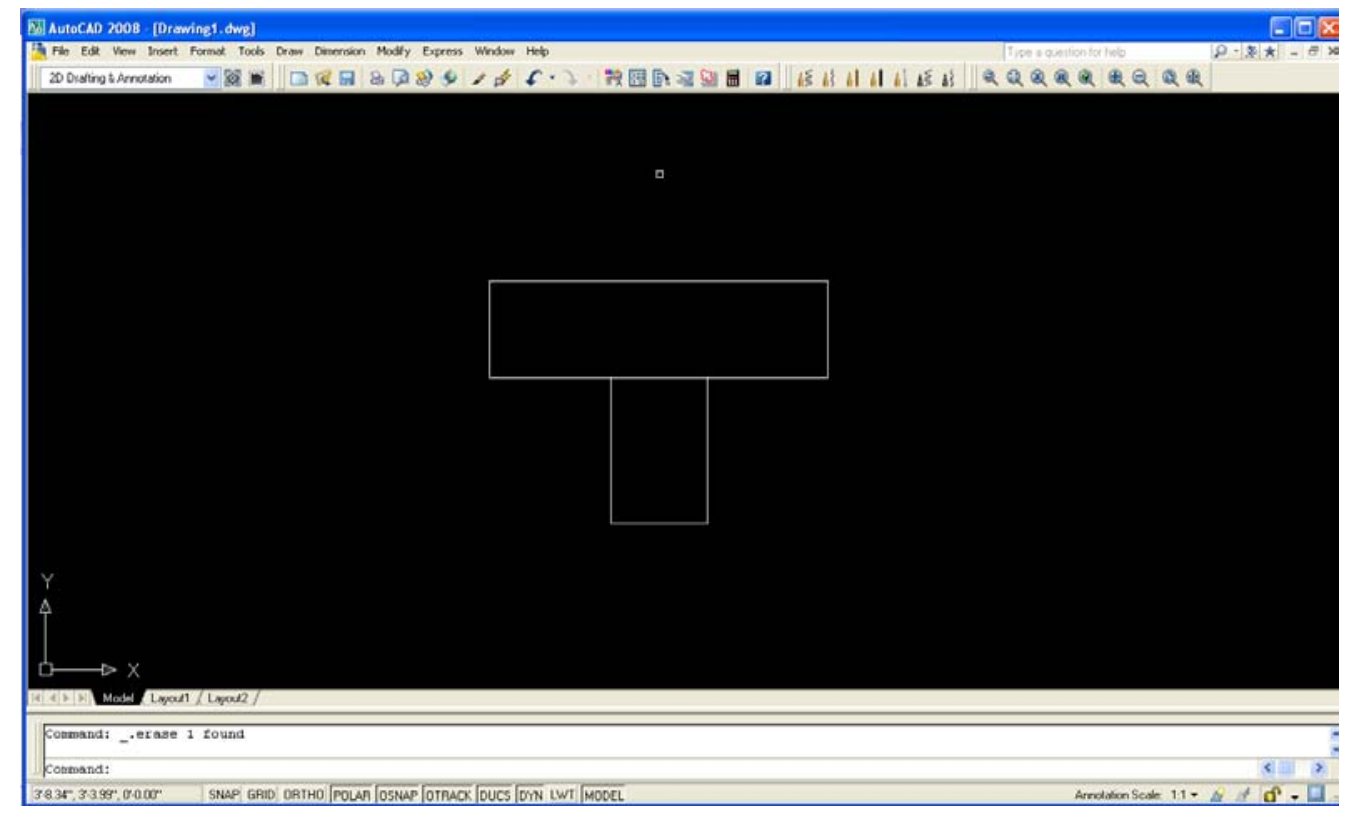

Figure A.4: AutoCAD 2008 Column of T design

* Use the TRIM command to trim the intersecting parts of the T bracket.

* After the desired T shape is produced the next step is to extrude the $\mathrm{T}$ to give it a thickness of 0.5” as shown in Figure A.5.

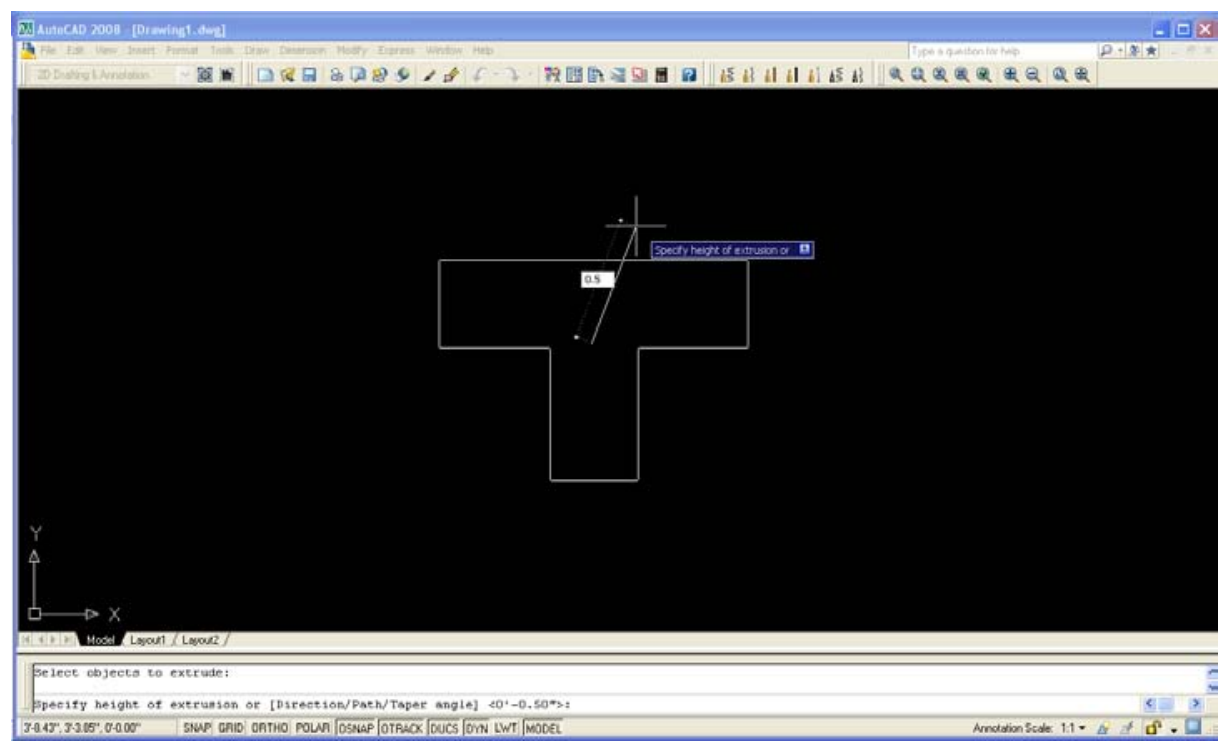

Figure A.5: AutoCAD 2008 Extrusion Command 
After extruding the $\mathrm{T}$ bracket, change the view to conceptual to get a better understanding of the design as shown in Figure A.6.

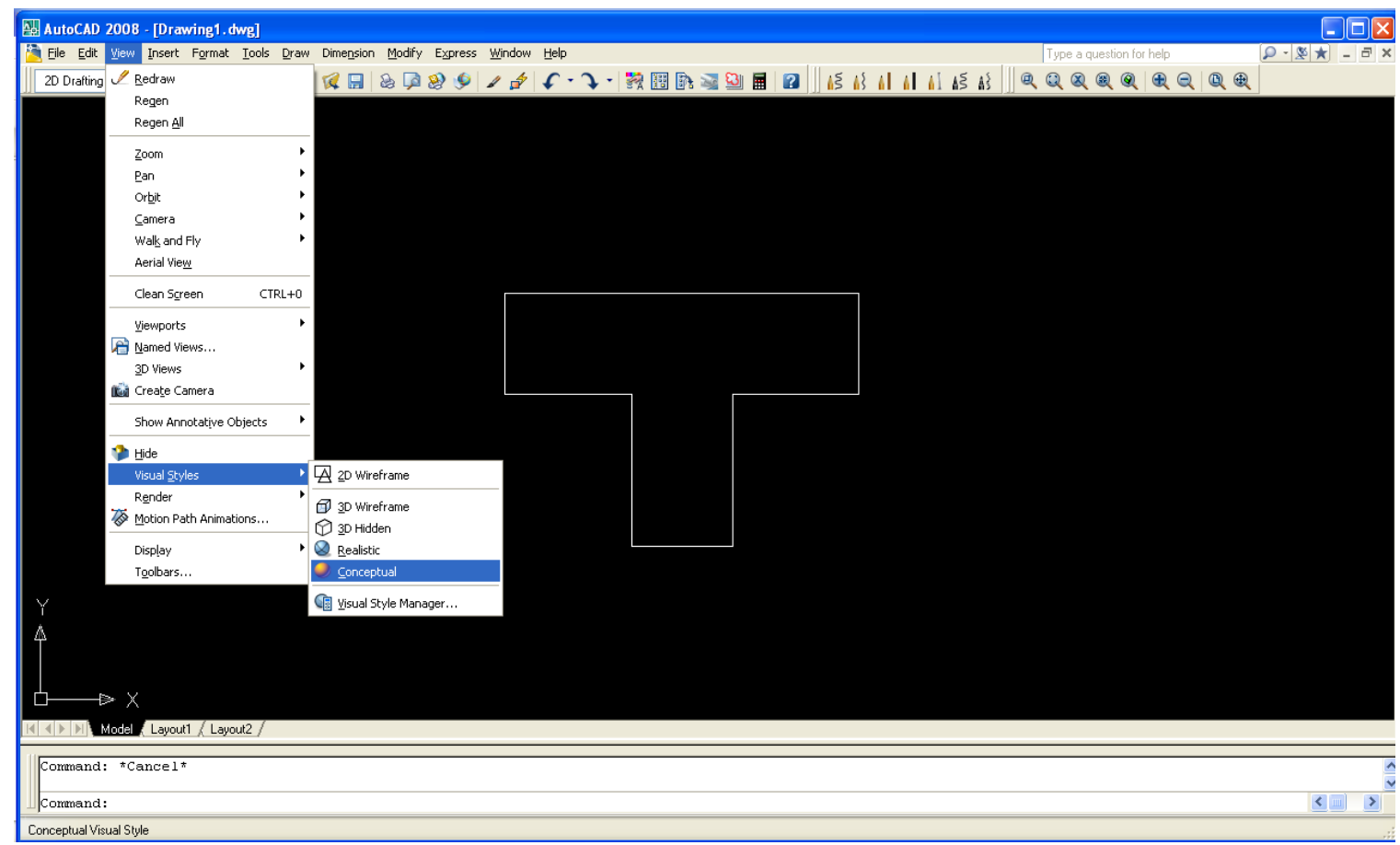

Figure A.6:AutoCAD 2008 Completed T design

Use the command 3DORBIT to rotate the part and get a multi view of the part as shown in Figure A.7. 


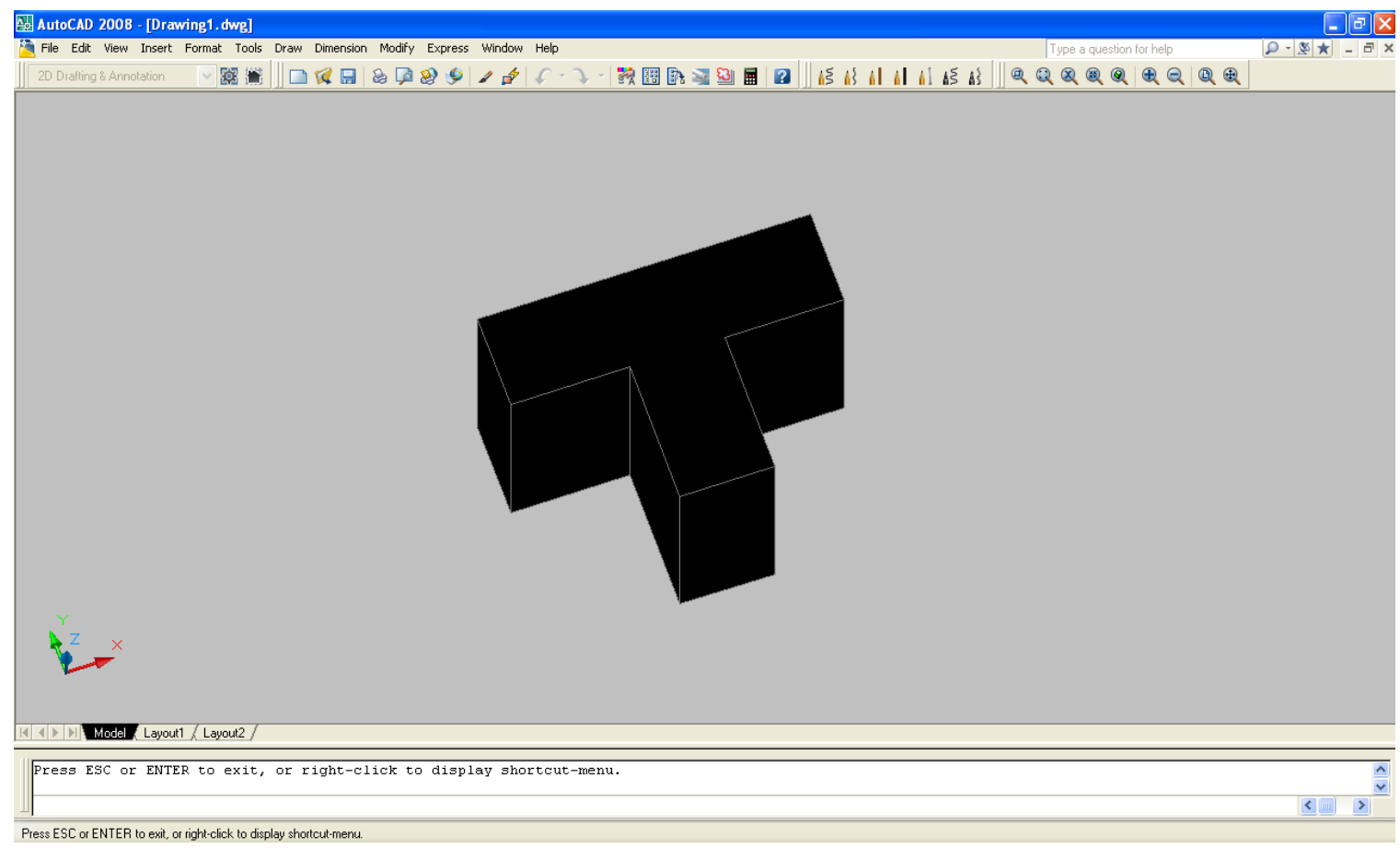

Figure A.7: AutoCAD 2008 3DORBIT view of the solid T bracket

* After the designing the part, change the view back to the 2D view to give the drawing the dimensions as shown in Figure A.8. 


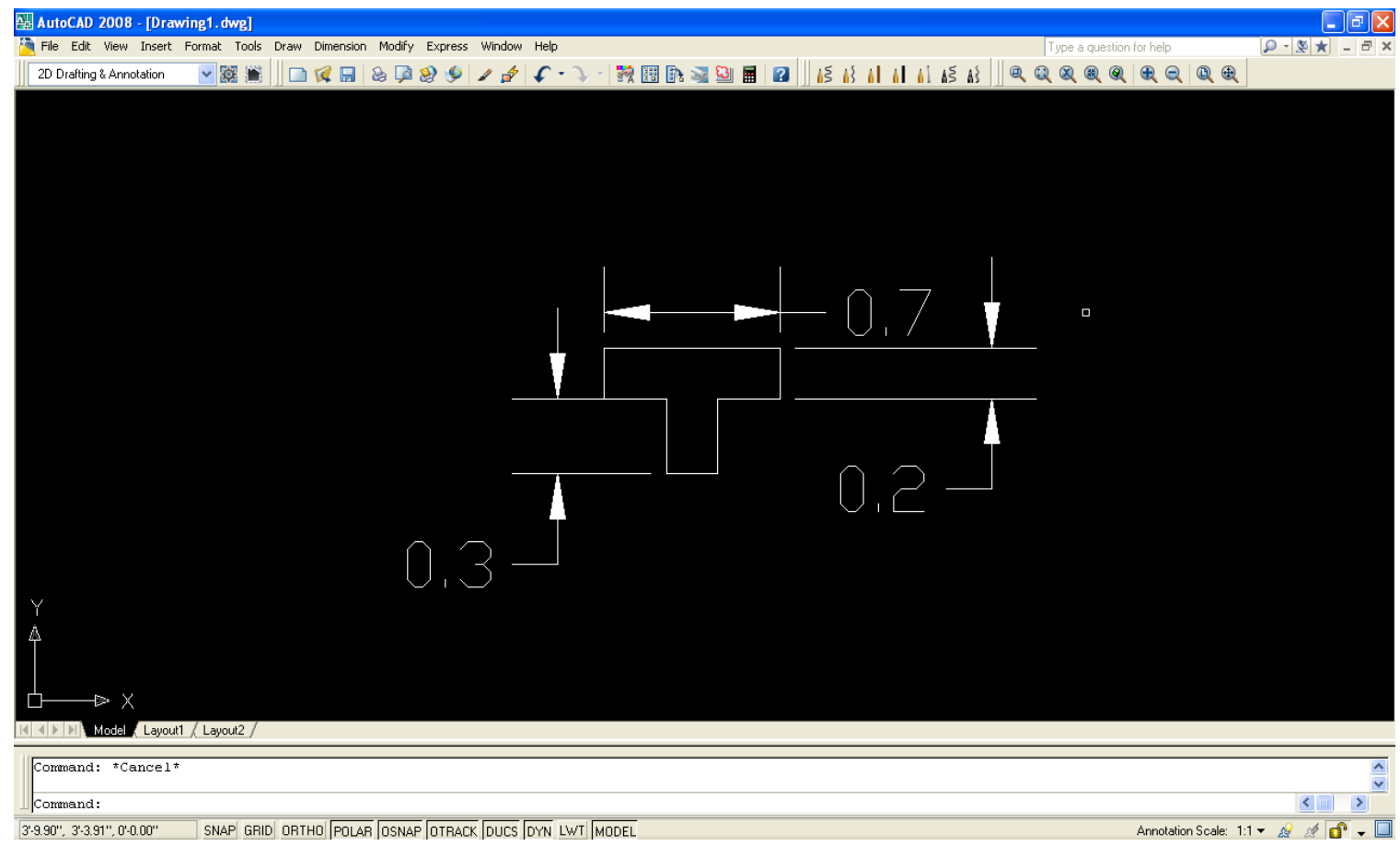

Figure A.8: AutoCAD 2008 T bracket dimensions in 2D view.

* The next step of the design stage is to convert the drawing into an STL (Stereolithography) file format which is the only file format used as an input into the $\mathrm{RX}-1$ rapid prototyping machine. 


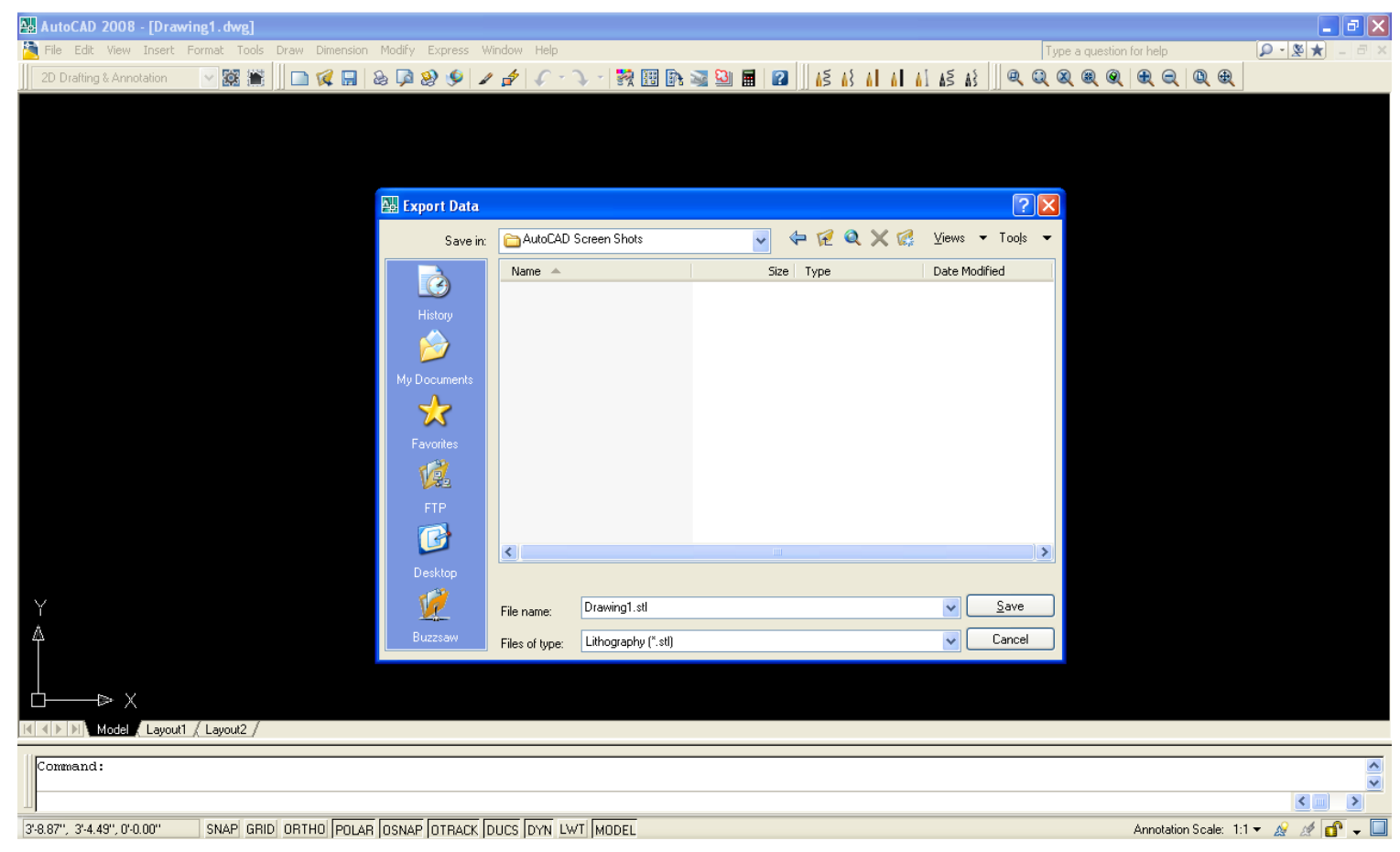

Figure A.9: AutoCAD 2008 STL conversion window

* After saving the file as Drawing1.stl, it would ask the user to select the desired part for conversion. (In this case select the T bracket).

* The STL file would then be created in the desired location on the computer.

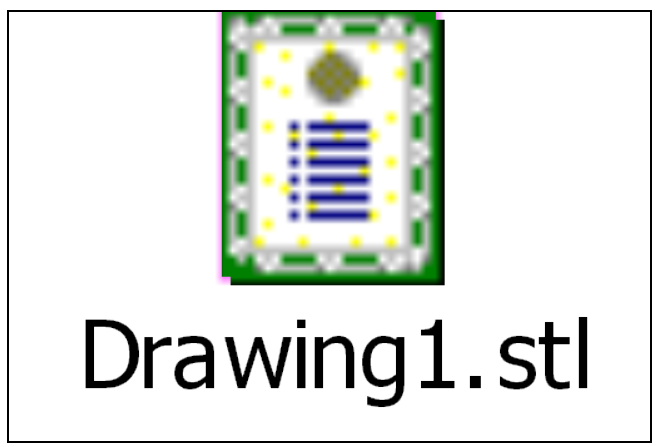

Figure A.10: Drawing 1 Stereolithography file 


\section{APPENDIX B: PRO METAL SOFTWARE INSTRUCTIONS}

\section{Pro Metal Software Operating Procedure:}

* The Drawing1.stl file created on the computer should then be transferred into the print files folder of the RX-1 machine's Pro Metal software as shown in Figure B. 1:

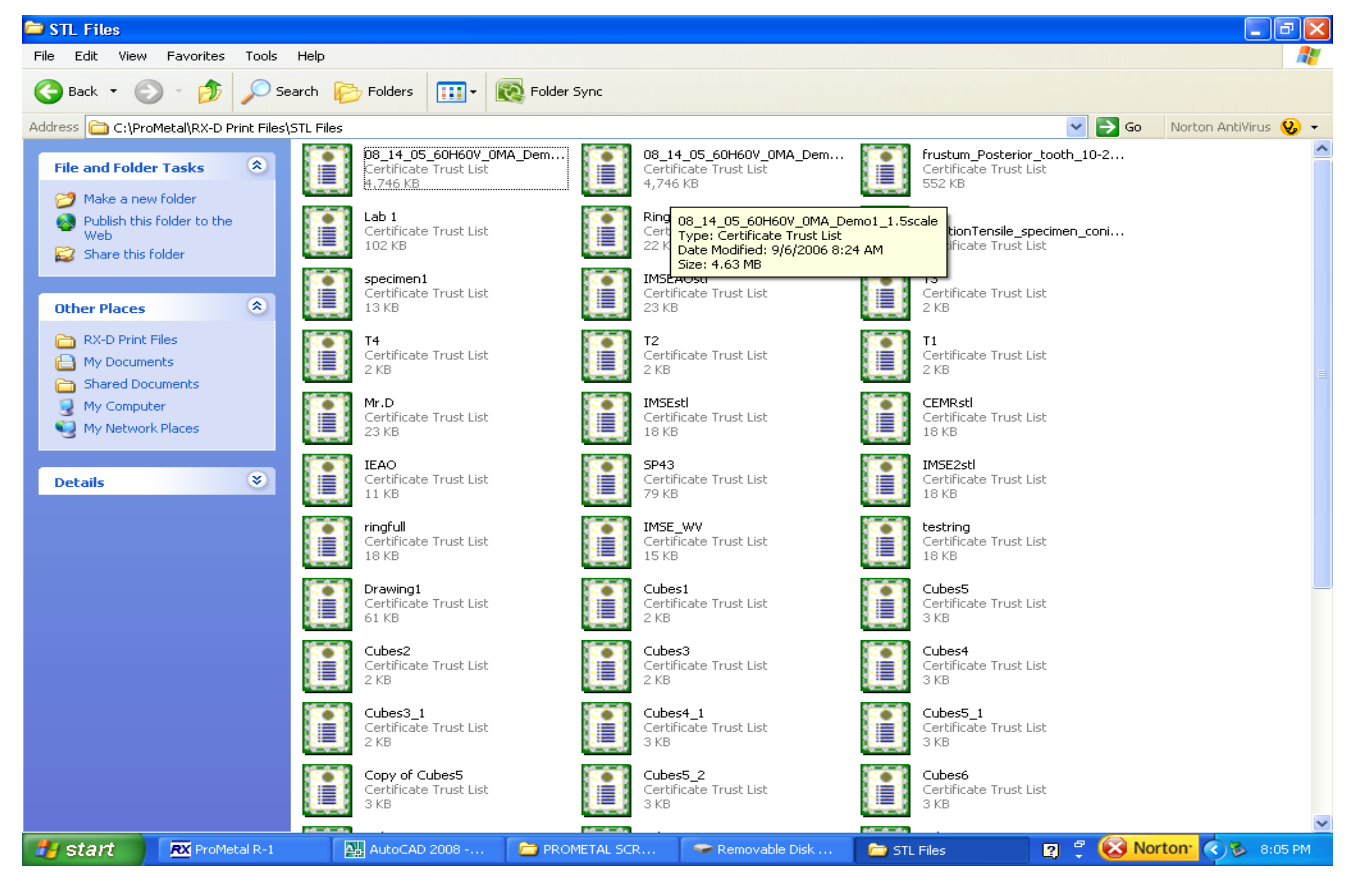

Figure B. 1: STL files folder

Follow the path C: $\backslash$ ProMetal $\backslash R X-D$ Print Files $\backslash S T L$ Files.

Open up the program Pro Metal from the start Menu.

* Initialize the machine as shown in Figure B. 2: 


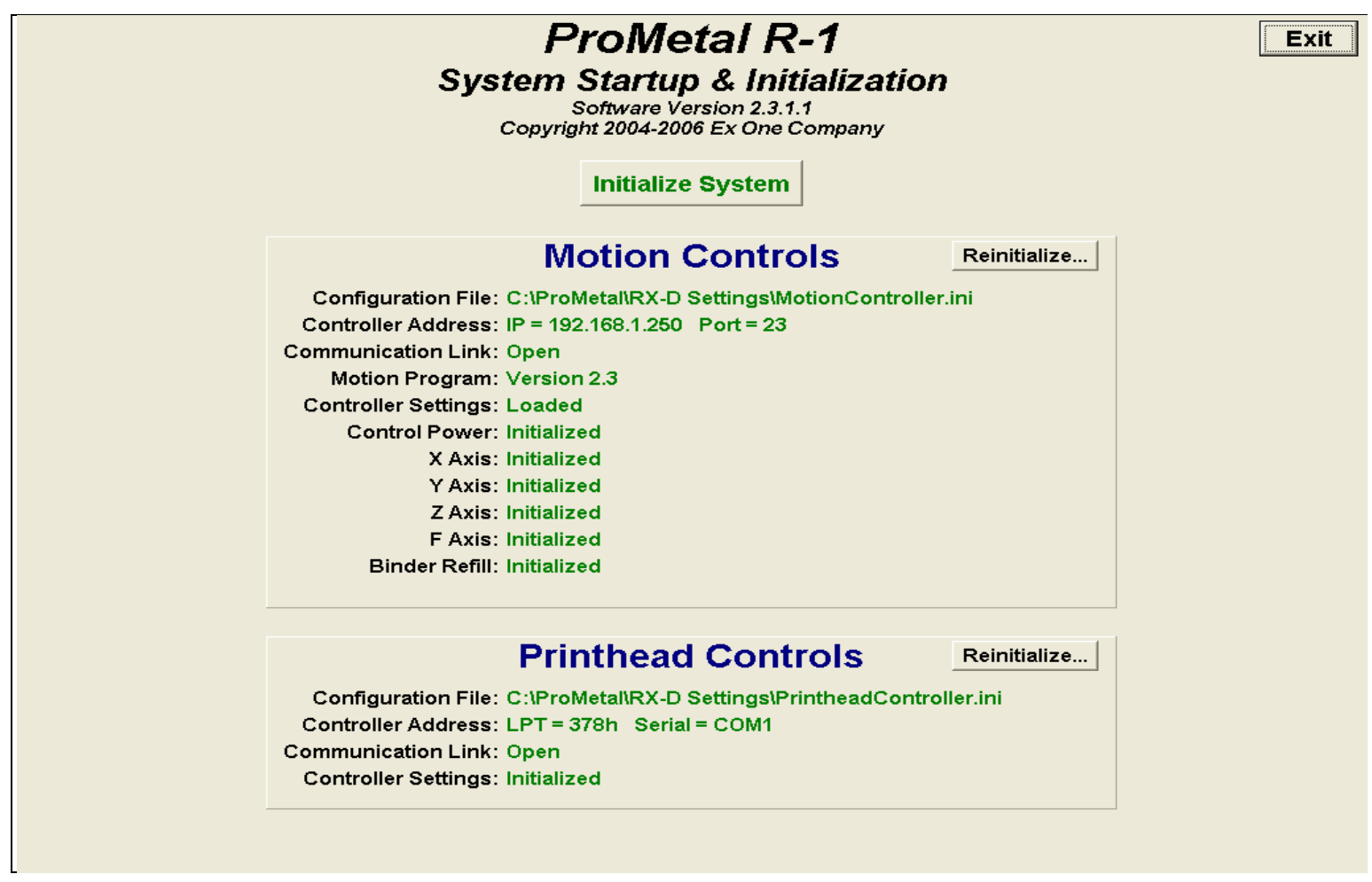

Figure B. 2: ProMetal System Startup \& Initialization Screen

* After the system is initialized the main menu would be displayed with all the options as shown in Figure B.3: 


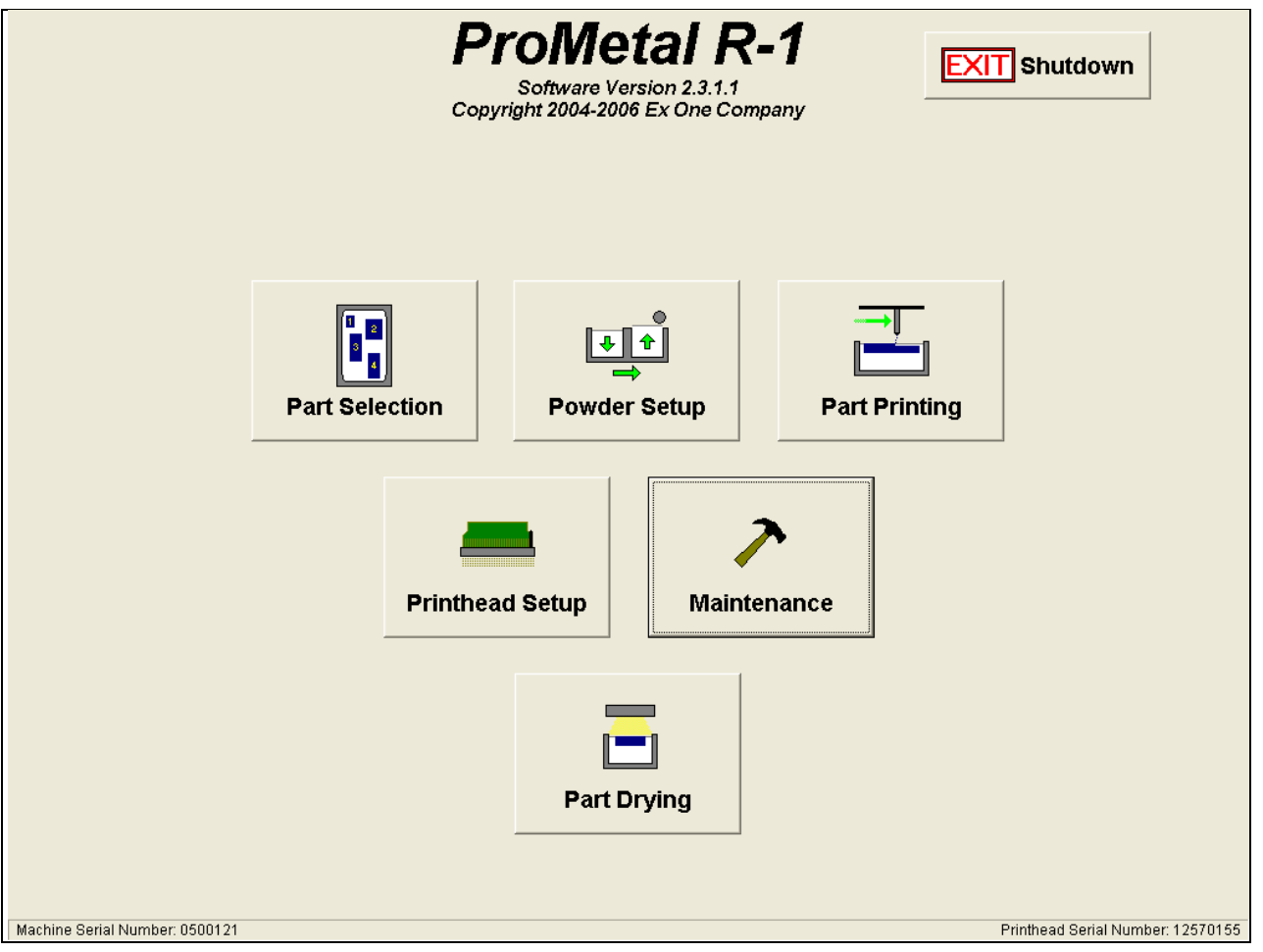

Figure B.3: ProMetal Main menu

* The most important part of the RX-1 rapid prototyping machine is the print head $(\mathrm{PH})$.

* PH set up is very critical to the outcome and the characteristic properties of the part being produced.

* The maximum printable dimensions of the print bed are 1.6” * 2.4” * 1.0"

* Print head set up screen is as shown in Figure B.4: 


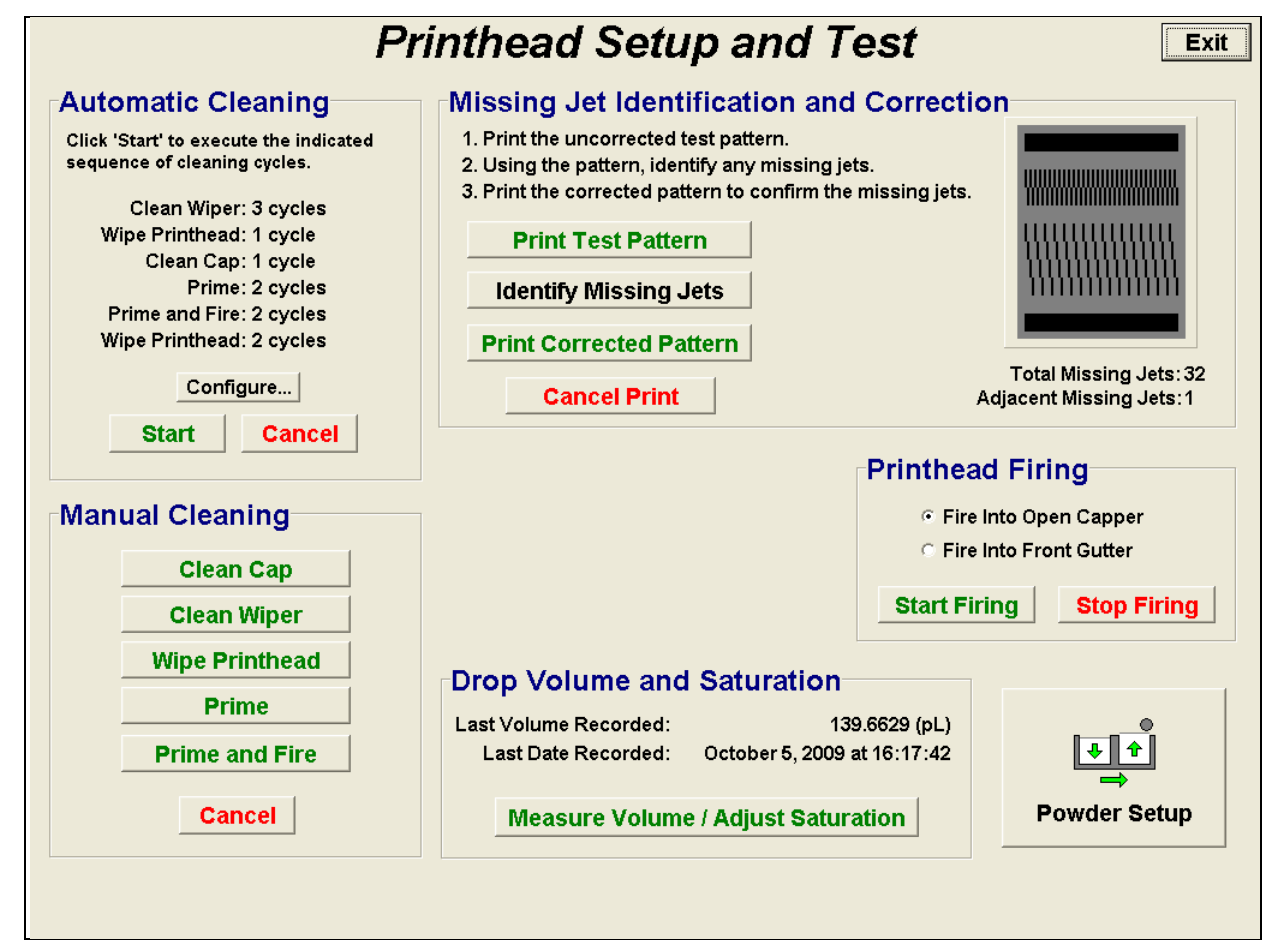

Figure B.4: Pro Metal Printhead Setup and Test Screen

Click Start under the Automatic Cleaning option and let the machine go through the entire automatic cleaning process as listed on the screen.

* After the cleaning, click the print test pattern and compare the print samples to the image on the top right corner of the screen.

* After identifying the missing jets disable the jets in this case a set of even numbered 32 jets as shown in Figure B.5: 


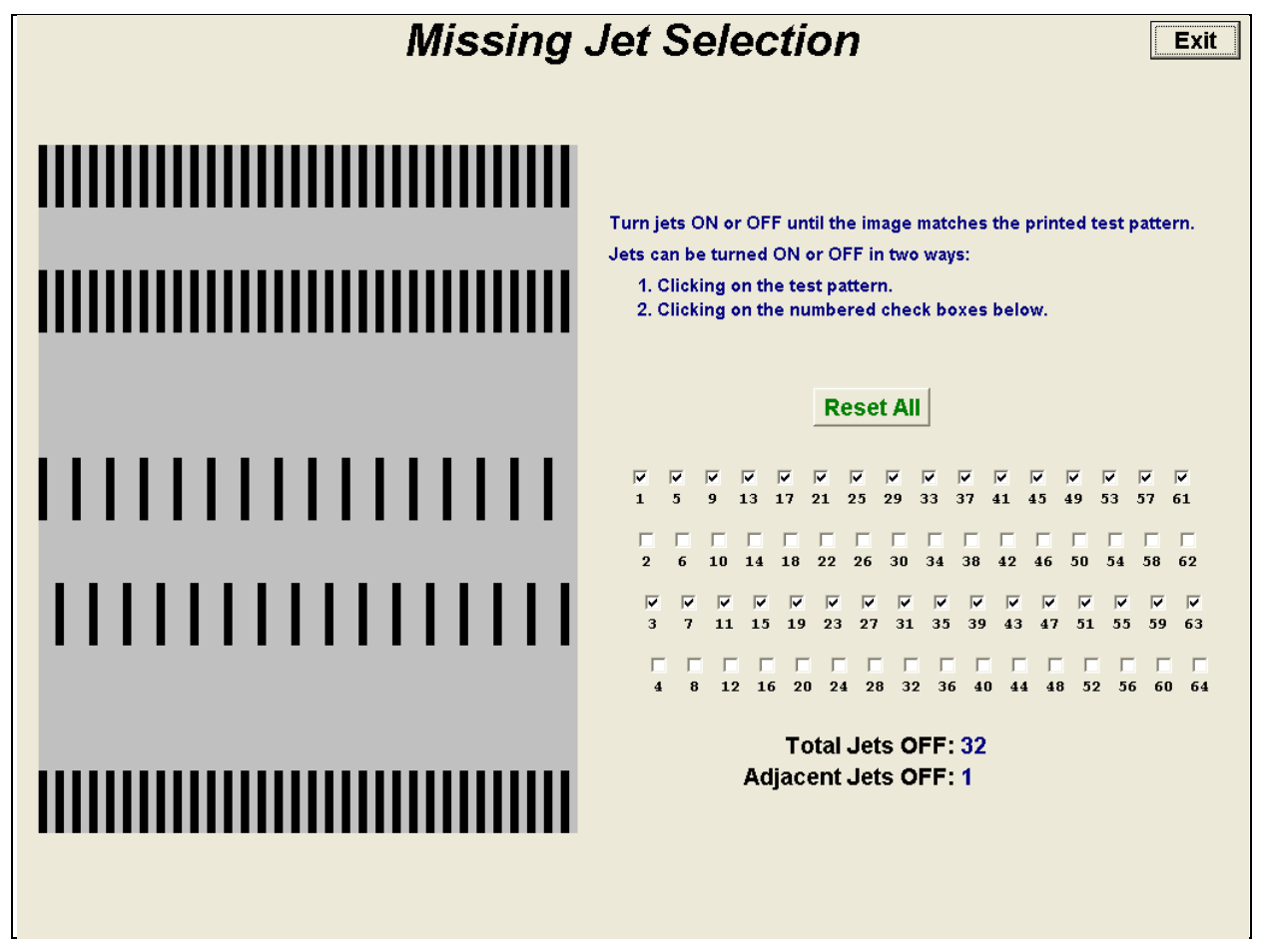

Figure B.5: Missing Jet Selection Screen

* After turning off the missing jets try the Print Corrected Test Pattern.

* This would print the test pattern identical to the print pattern shown in the image as shown in Figure B. 6.

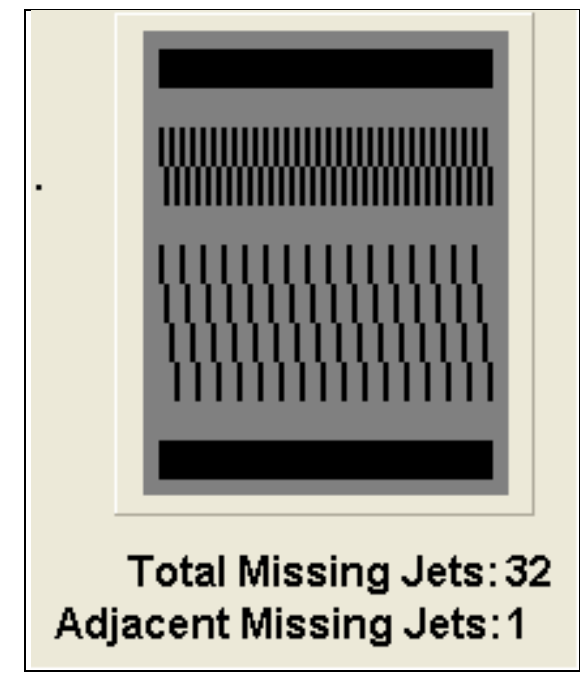

Figure B. 6:Print Head Test Pattern Format

* The next step is to set up the powder on the print bed as shown in Figure B.7. 
Always make sure that the build side of the print bed is dropped to $4.000 \mathrm{~mm}$ position to use the build plate as the base. This is very important as the plate gives firm support to the building layers.

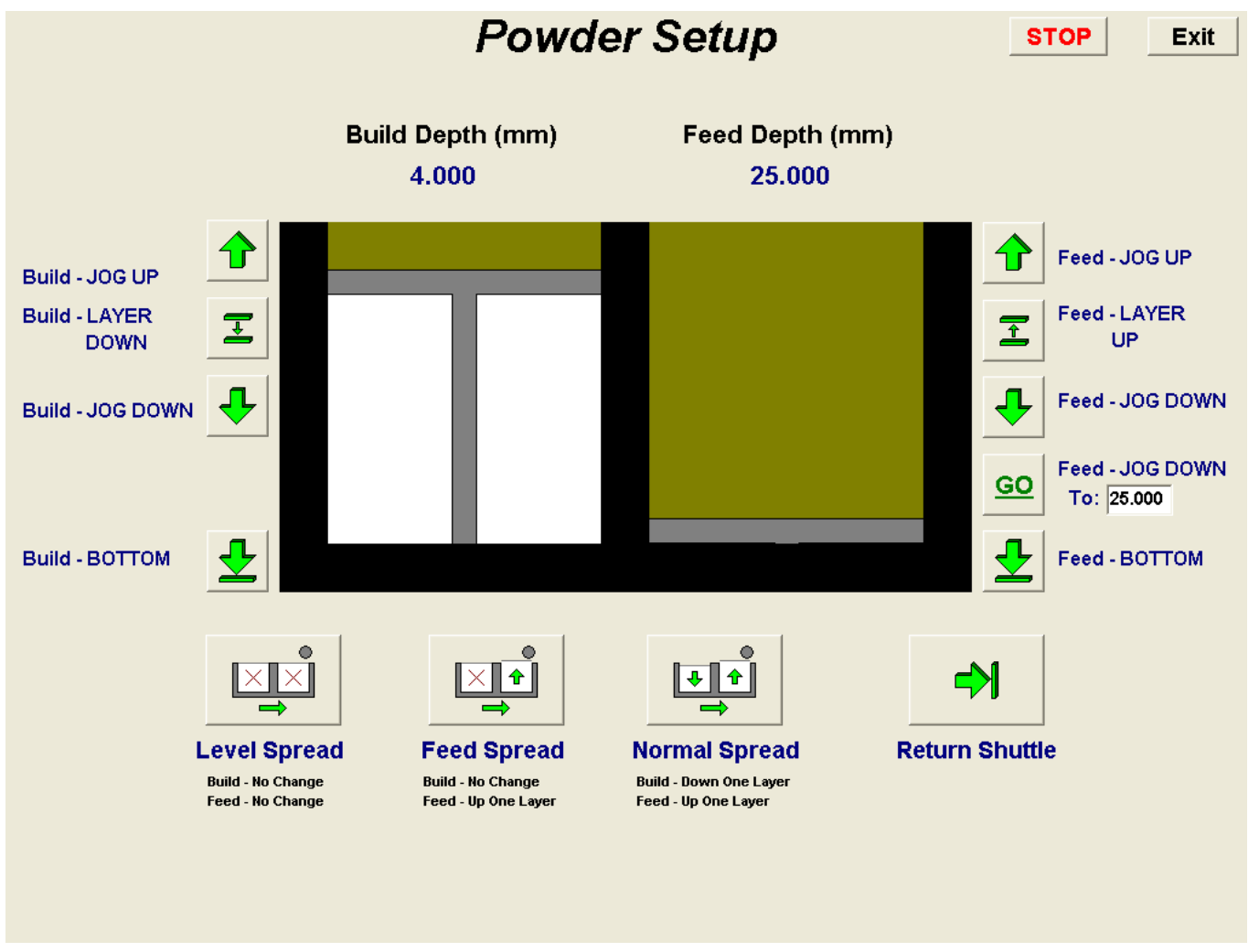

Figure B.7: Pro Metal Powder Set up Screen

The next step is to select the part to be printed under part selection option as shown in Figure B.8. 


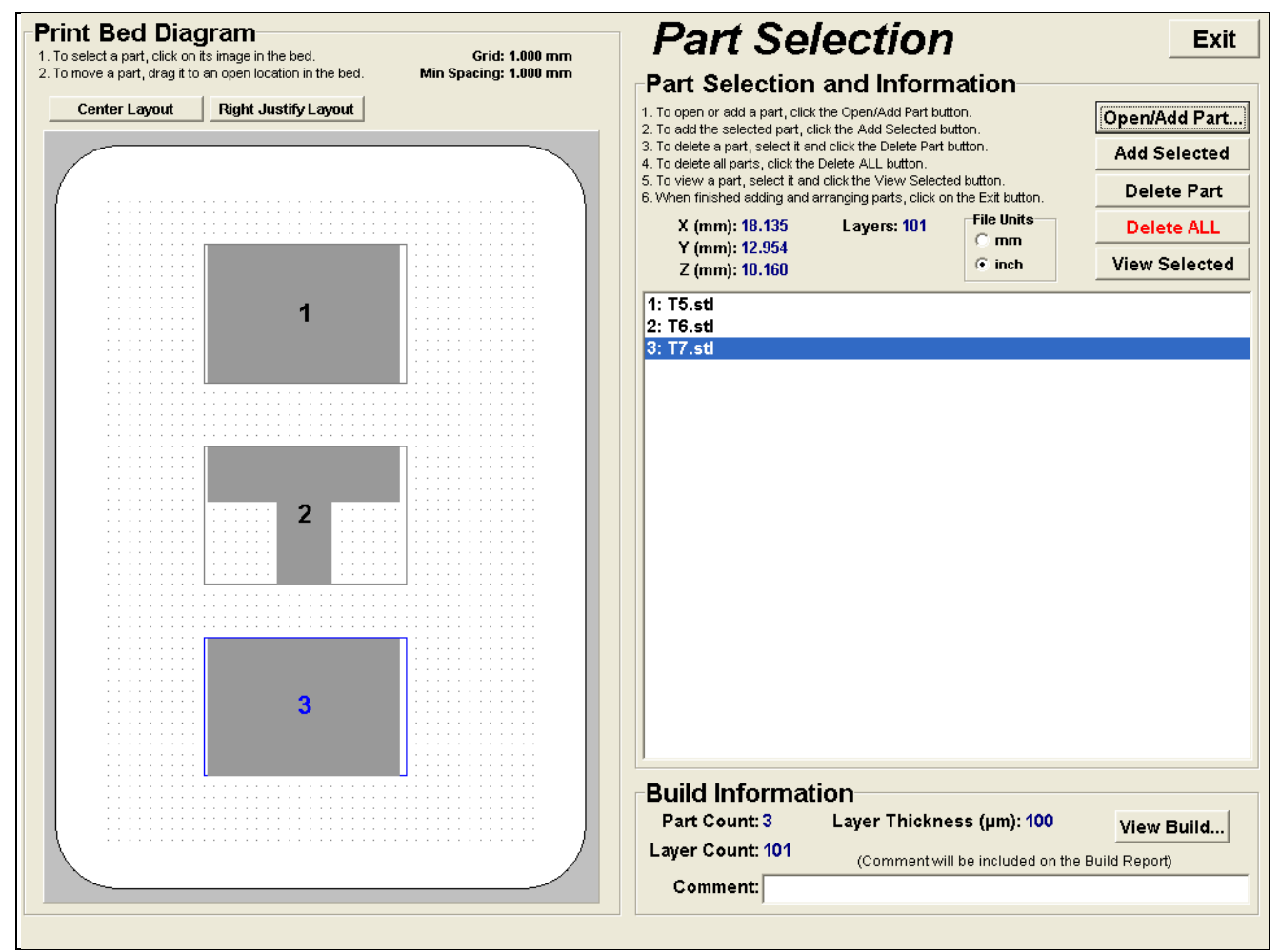

Figure B.8:Pro Metal Part Selection Screen

* The T brackets which are to be produced must be oriented differently to understand the effect of saturation level, temperature and time on the parts being produced.

* After all the initial steps have carefully been examined, the printing process should be started. From the main menu, select part printing and the checklist would appear on the screen as in Figure B.9. 


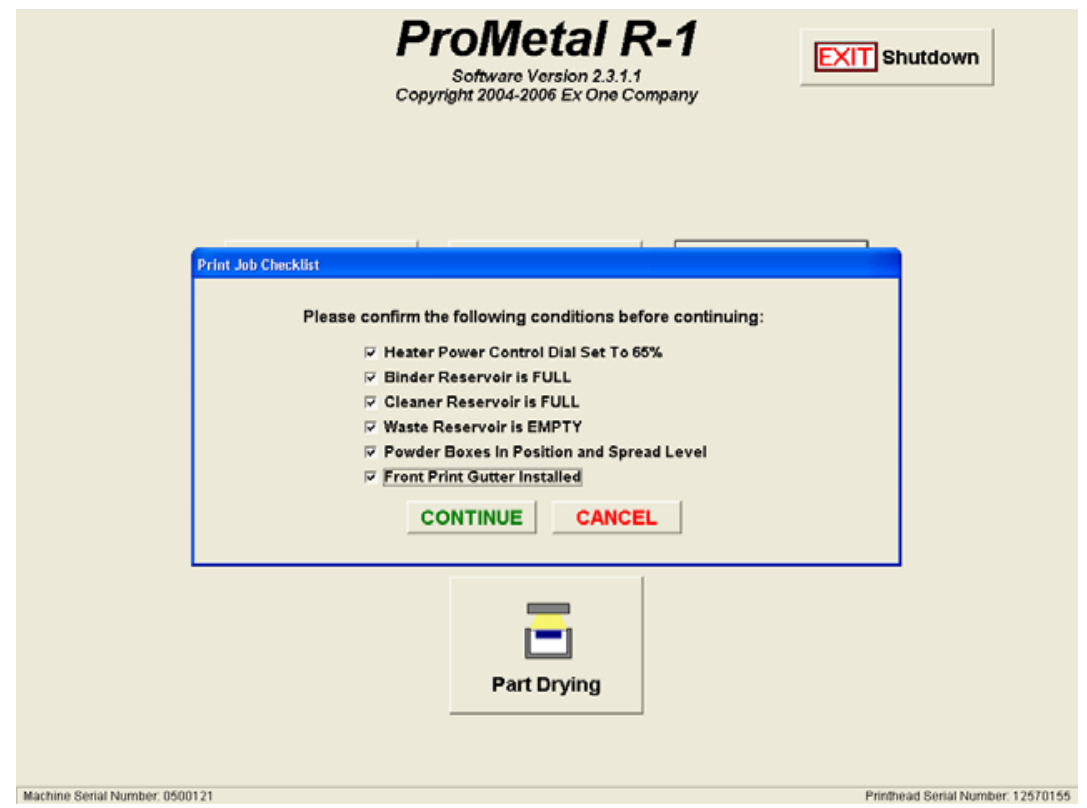

Figure B.9: Pro Metal Print Job Checklist Screen

It is very important to go through each and every option mentioned on the checklist to avoid any unforeseen interruptions during the printing process.

- The printing screen would appear on the screen as shown in Figure B.10.

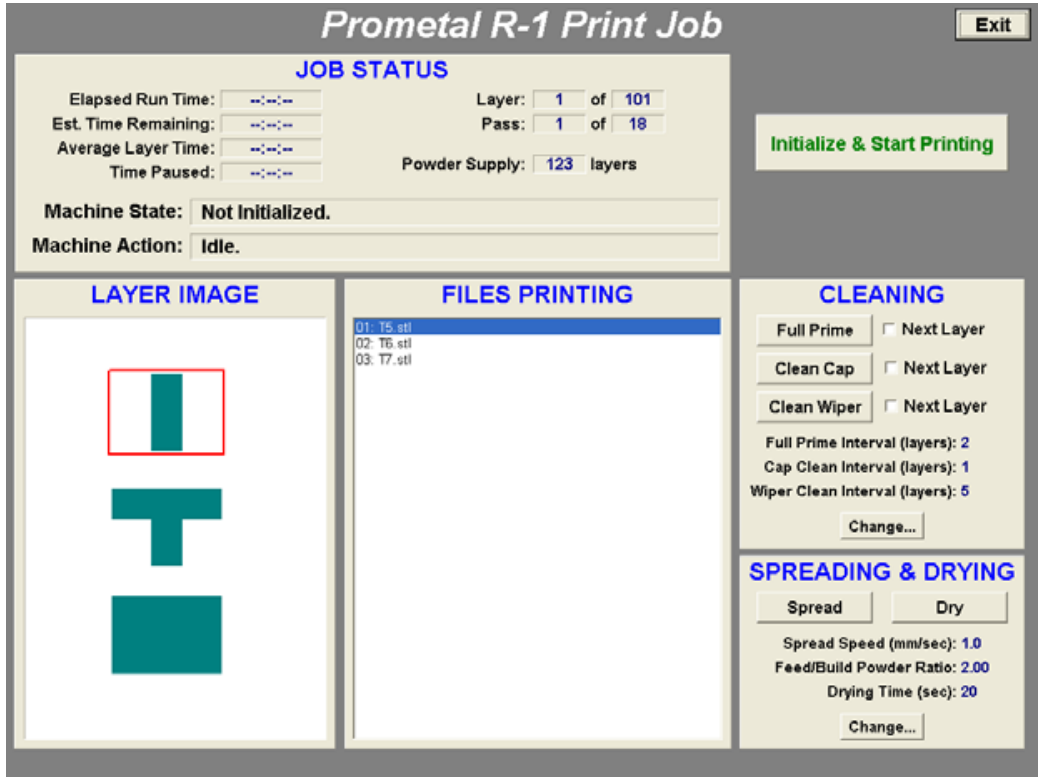

Figure B.10:Pro Metal Print Job Screen 


\section{Maintenance}

* It is very important for the TA or the instructor to maintain the print head in proper working condition. Otherwise it may incur huge expenses to the department to get the print head cleaned or replaced.

* To avoid these expenses, this section has been specifically been included which would give the TA a better understanding of keeping the RX-1 machine in proper working condition.

* The very first step is to make sure that the machine has enough cleaner in the bottle and the waste bottle is emptied at regular intervals.

* Failure to do so would cause the cleaner liquid to overflow on to the print bed if the waste bottle is full.

* Although not a lot of binder refill is needed for a small run, it is always a good practice to have the binder bottled full up to half way through.

* On the main menu there would be a section for Maintenance.

* Under Maintenance, the basic functions enabled would be:

* Manual Control.

* Print head setup.

* Process Settings.

* Initialize Machine.

* If there is any problem with any of the stepper motors of the machine which enable the flow of the binder, cleaner from the bottle and the waste to the bottle, then the TA or the instructor must use the administrative option under maintenance.

* The procedure to get into the administrator settings is to use the keys Ctrl + L.

* This would prompt for a password which is “service” (case sensitive) 


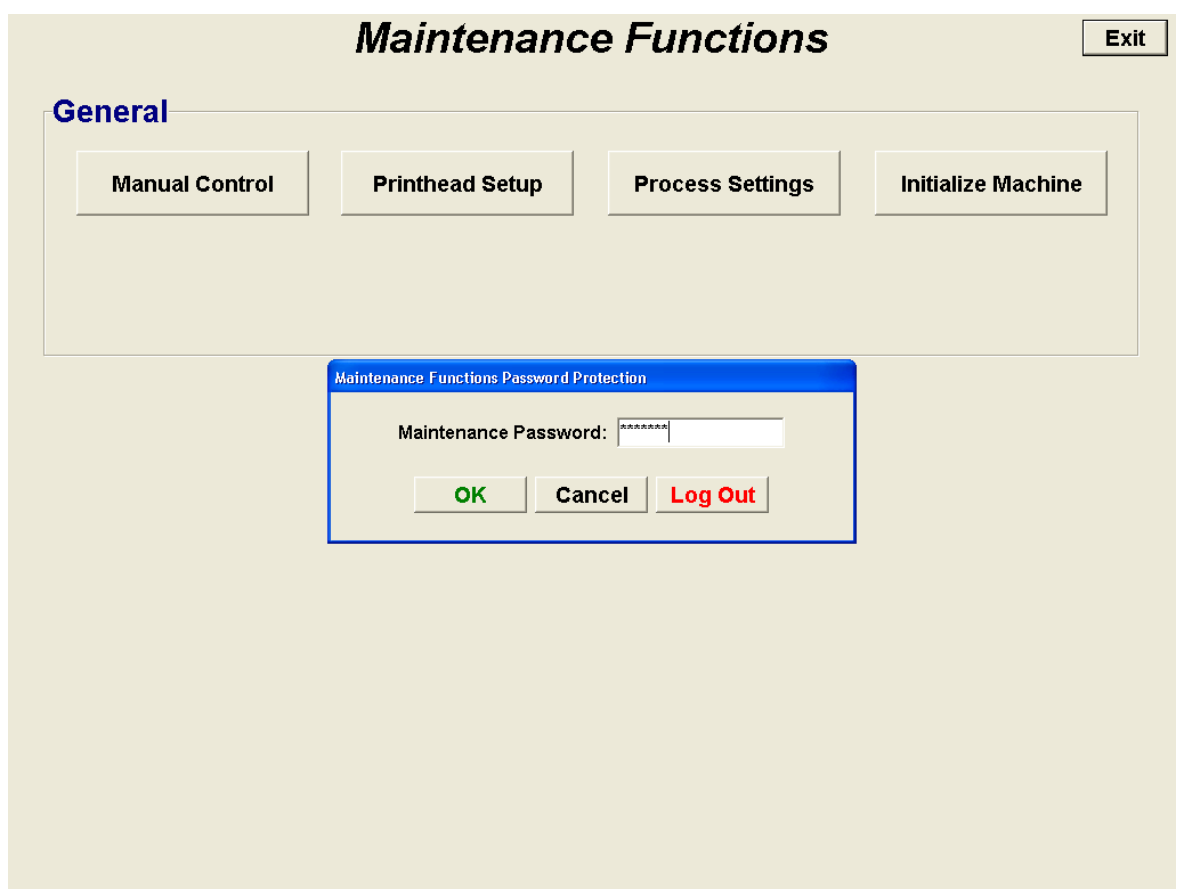

Figure B. 11: Pro Metal Maintenance Functions Screen.

* The administrator maintenance screen would then appear with enhanced options for the TA/instructor as shown in Figure B.12 For further information on maintenance refer to the video demo for instructors.

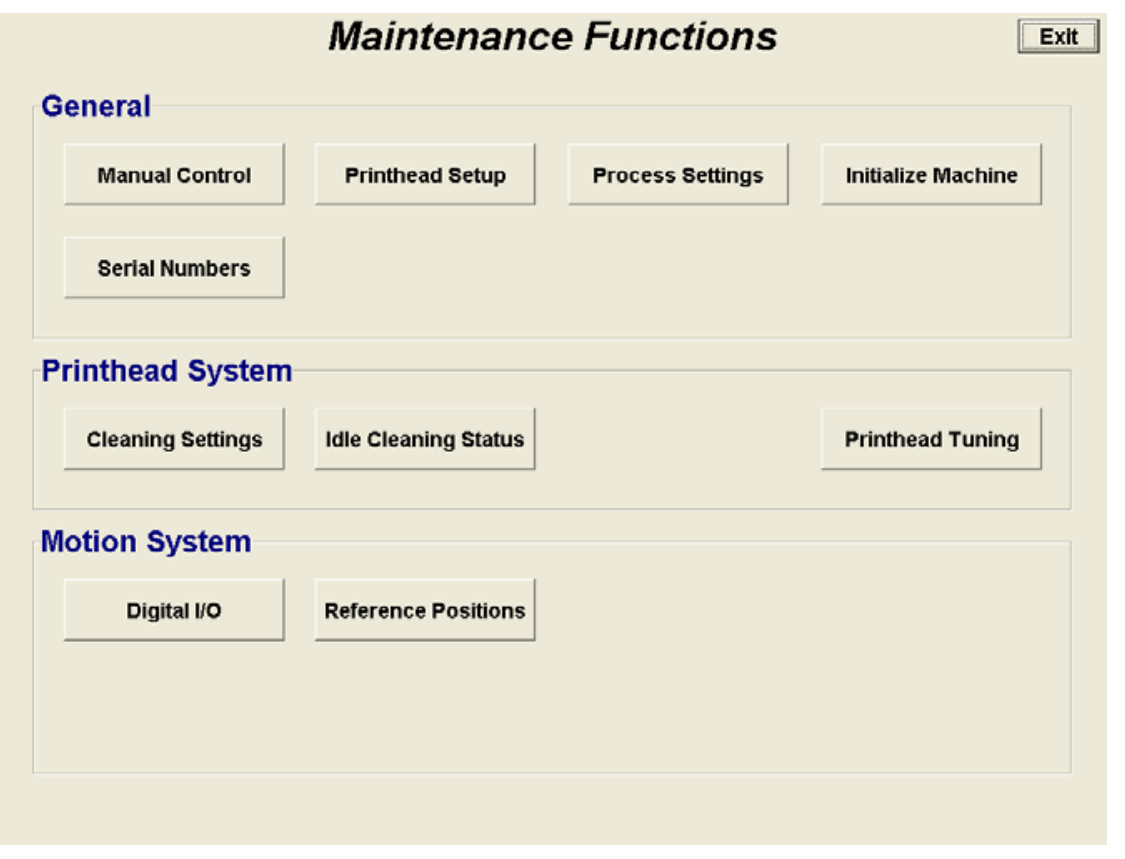

Figure B.12: Pro Metal Advanced Maintenance Functions Screen. 


\section{APPENDIX C : MATERIAL SAFETY DATA SHEET FOR BINDER.}

TPROMETAL

MATERIAL SAFETY DATA SHEET

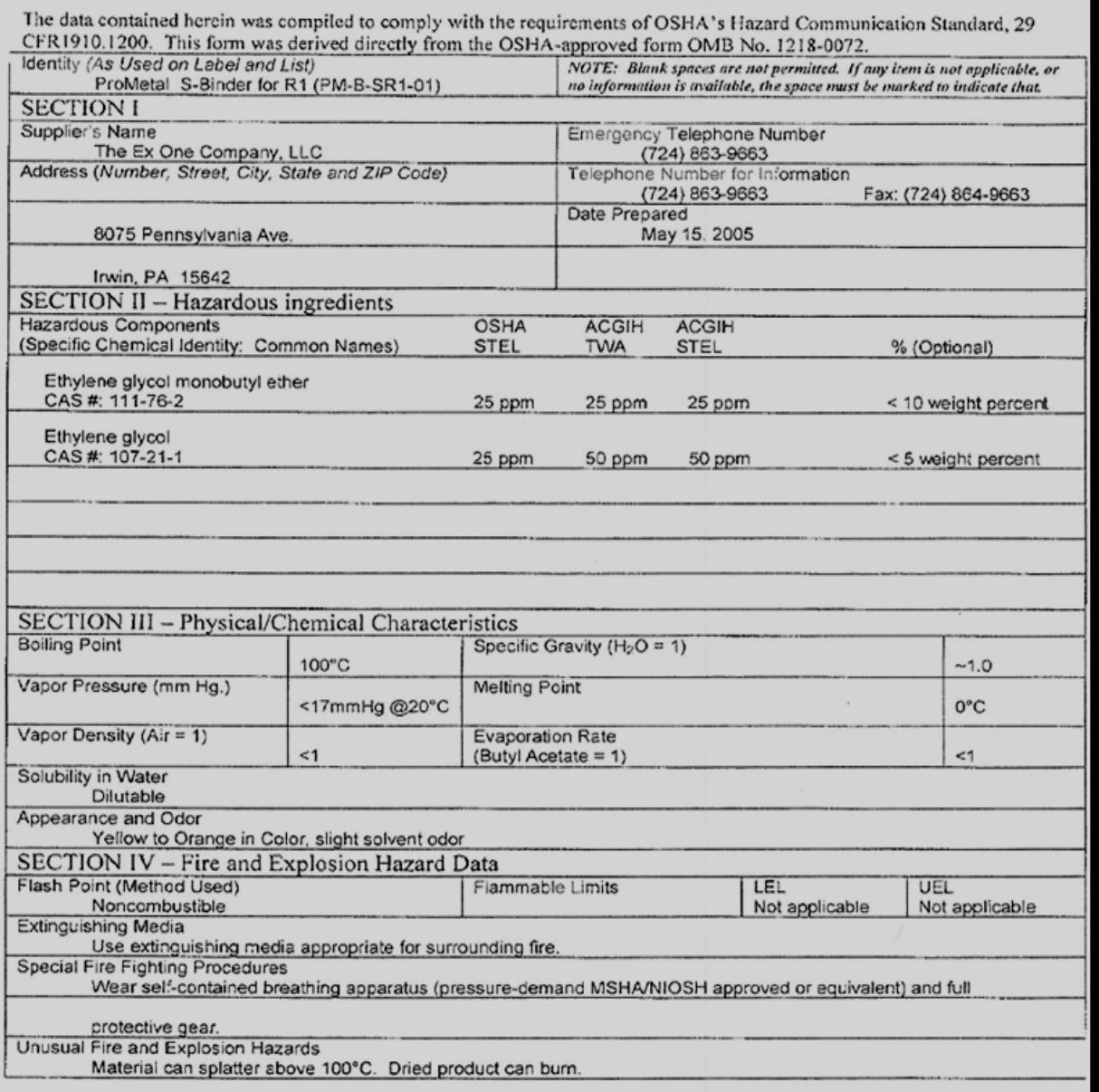


IPROMETAL

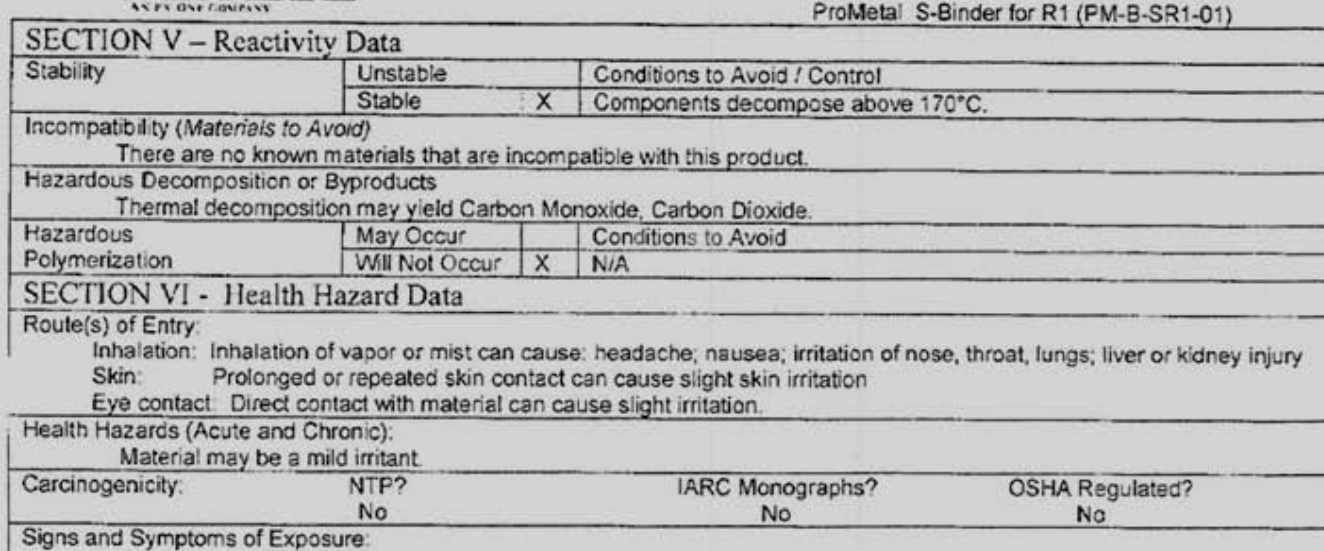

May cause headache, nausea, irritation of the nose, throat and respiratory tract. Prolonged or repeated skin contact can cause slight skin irritation. Direct eye contact with material can cause slight irritation.

Medical Conditions Generally Aggravated by Exposure:

Pre-existing respiratory, skin or eye conditions may be irritated

Emergency and First Aid Procedures

If inhaled, move subject to fresh air. Wash clothing and affected skin areas thoroughly with soap and water; consult

a physician if irritation persists. Flush eyes with water for at least 15 minules: consult a physician if irritation persists. If ingested give two glasses of water to drink; consult a physician. Never give anything by mouth to an unconscious person.

SECTION VII - Precautions for Safe Handling and Usc

Steps to Be Taken in Case Material is Released or Spilled

Wear apprcpriate protective equipment when handling a spill of this material. See Section VIII for recommendations. If exposed to material during clean-up cperations see Section VI for actions to follow.

Keep spectators away. Floor may be slippery: use care to avoid falling. Contain spills immediately with inert materials

(e.g., sand, earth). Transfer liquids and solid diking material to separate suitable containers for recovery cr disposal

CAUTION: Keep soills and cleaning runoff out of municipal sewers and open bocies of water.

Waste Disposal Method:

Do not flush to sewer. Incinerate in an approved facility

Precautions to Be Taken in Handling and Storing:

Monomer vapors can be evolved when material is heated curing processing operations. See Section VIII for types of ventilation required. The minimum recommended storage temperature for the material is $1 \mathrm{C}$. The maximum recommended storage temperature for this material is $60 \mathrm{C}$

Other Precautions

US DOT Hazard class: Nonregulated

SECTION VIII - Control Measures

Respiratory Frotection (Specify Type)

A respiratory protection program meeting OSHA 1910.134 and ANSI Z88.2 requirements must be fol lowed whenever workplace conditions warrant a respirator's use. None required if airborne concentrations are maintained below the following exposure limit (Ethylene Glycol Monobutyl Ether: $450 \mathrm{ppm}$ )

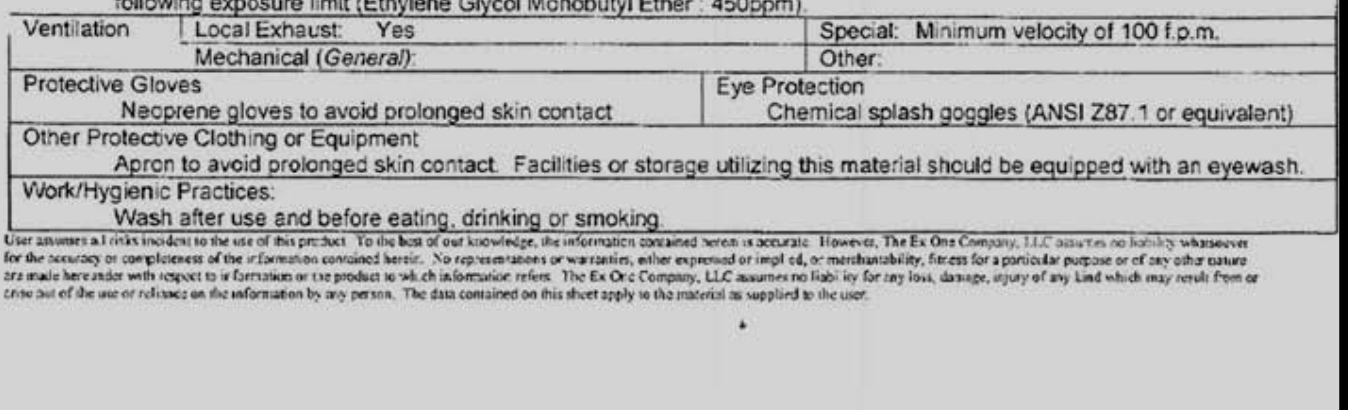




\section{APPENDIX D: MATERIAL SAFETY DATA SHEET FOR CLEANER}

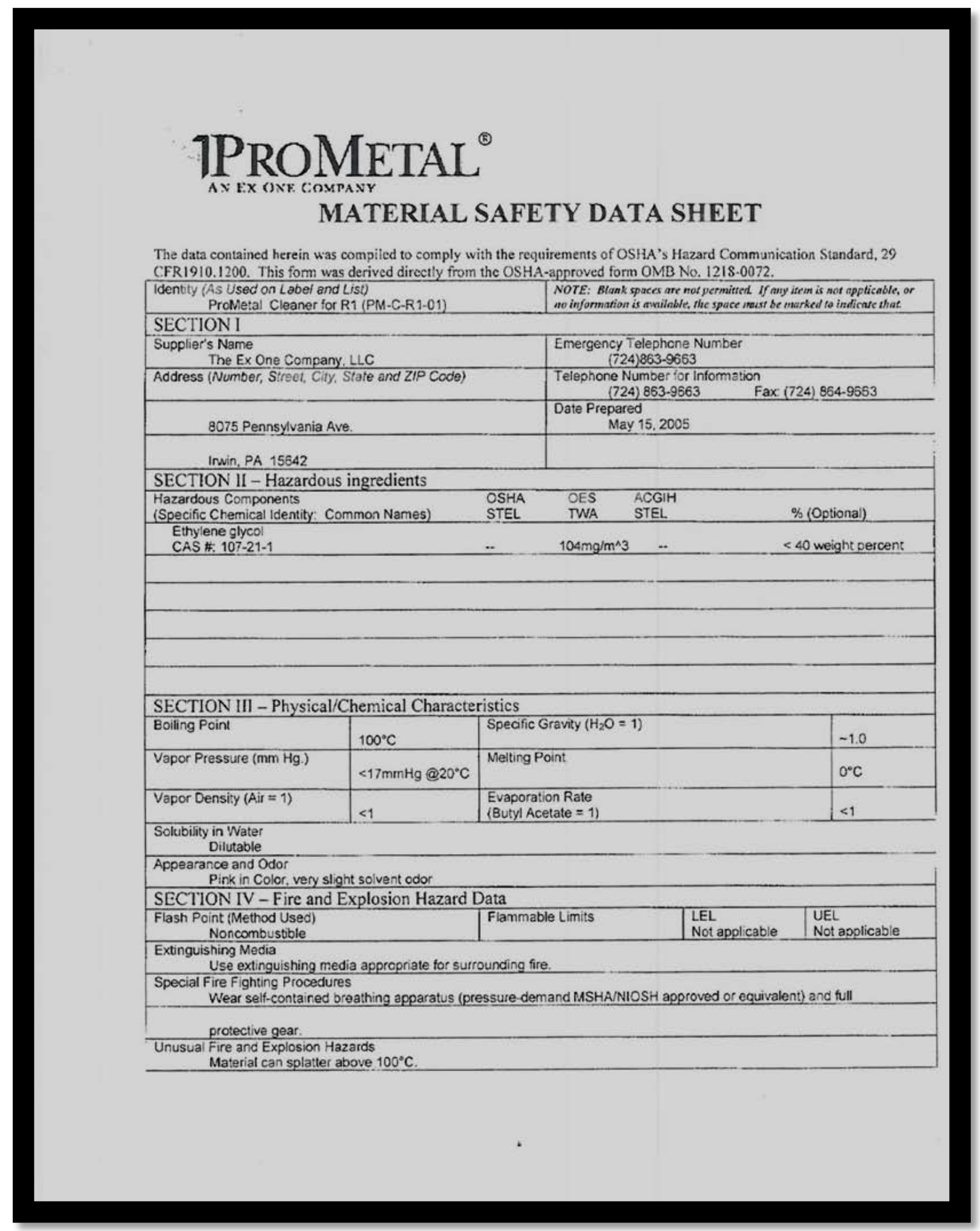


IPROMETAL

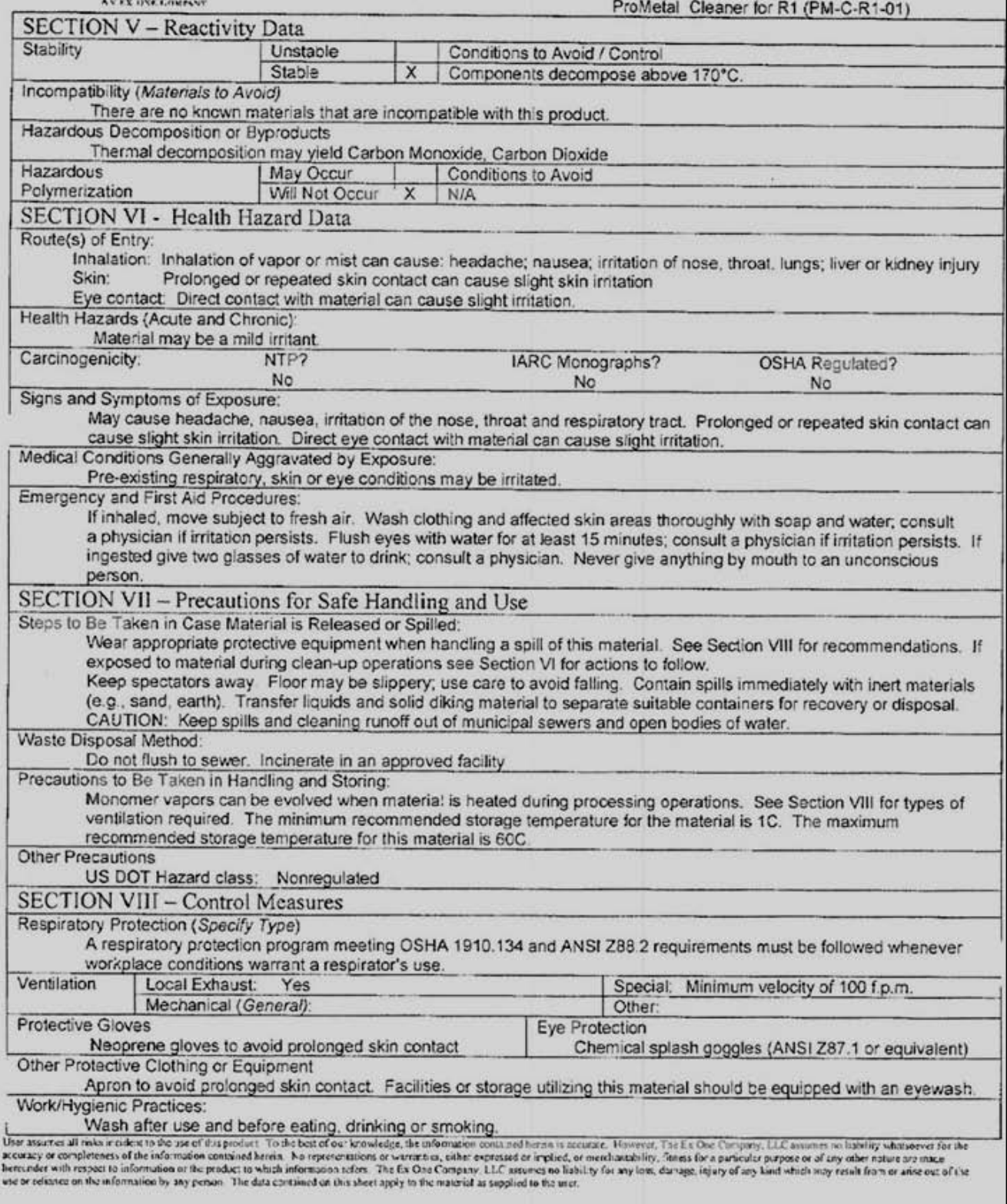

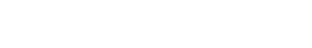

John H. Hagen Hagen@mail.wvu.edu, $c=U S$
Date: $2009.12 .1409: 30: 31$ 